Claremont Colleges

Scholarship@ Claremont

CGU Theses \& Dissertations

CGU Student Scholarship

2012

\title{
Accelerated Culture: Exploring Time and Space in Cinema, Television and New Media in the Digital Age
}

Thomas J. Connelly

Claremont Graduate University

\section{Recommended Citation}

Connelly, Thomas J.. (2012). Accelerated Culture: Exploring Time and Space in Cinema, Television and New Media in the Digital Age. CGU Theses \& Dissertations, 50. http://scholarship.claremont.edu/cgu_etd/50. doi: 10.5642/cguetd/50

This Open Access Dissertation is brought to you for free and open access by the CGU Student Scholarship at Scholarship @ Claremont. It has been accepted for inclusion in CGU Theses \& Dissertations by an authorized administrator of Scholarship @ Claremont. For more information, please contact scholarship@cuc.claremont.edu. 
Accelerated Culture: Exploring Time and Space in Cinema, Television and New Media in the Digital Age

by

Thomas J. Connelly

\section{Claremont Graduate University \\ 2012}

(C) Copyright Thomas J. Connelly, 2012

All Rights Reserved 


\title{
APPROVAL OF THE DISSERTATION COMMITTEE
}

We, the undersigned, certify that we have read, reviewed, and critiqued the dissertation of Thomas J. Connelly and do hereby approve it as adequate in scope and quality for meriting the degree of Cultural Studies.

\author{
Dr. Henry Krips \\ Professor of Cultural Studies \\ Department of Cultural Studies \\ Claremont Graduate University
}

\author{
Dr. Eve Oishi \\ Associate Professor of Cultural Studies \\ Department of Cultural Studies \\ Claremont Graduate University
}

Dr. James Morrison

Professor of Film and Literature

Department of Literature

Claremont Mckenna College

Dr. Dana Polan

Professor of Cinema Studies

Tisch School of the Arts

New York University 


\begin{abstract}
Accelerated Culture: Exploring Time and Space in Cinema, Television and New Media in the Digital Age

by

Thomas J. Connelly
\end{abstract}

This dissertation seeks to understand the impact of speed on the interrelation and the overlapping of the production and consumption of cinematic and televisual texts. It explores the immediacy of digital media and new economic processes, and how they are informing structures of perception, as well as lending themselves to new and different ways of seeing the moving image in the digital age. These visual expressions are evident in the changing perception of the long take; the increasing use of video gaming aesthetics and database narratives; new and variant forms of narrative and visual styles in television; and the speed of new media technology on new voices and avant-garde expressions in independent and DIY cinema (such as the Internet, personal camcorder, mobile screens, and desktop editing). Conversely, VCR, DVD, DVR devices (as well as online streaming and DVD and Blu-Ray rental sites) have transformed the consumption of the moving image. Time-shifting devices allow for halting and controlling the flow of passing time, permitting for greater textual analysis. And, reciprocally, these new perceptions of the moving image inform expressions of filmic time and space. The speed of digital media and new economic formations raise concerns about lived reality and the attenuation of time, place, and community. It brings forth questions of the waning of pastness and memory, the diminishing of critical distance, and the vanishing of slow time. I argue, however, these shifts that are occurring in cinema and television illustrate 
that processes of speed are not the prime determinant in the production and consumption of moving images. Rather, they are based on a contingent and open-ended model of articulation—sites where disparate elements are temporary combined, unified, and thus, practiced and lived under the ever-changing conditions of existence. 


\section{Acknowledgments}

There are a number of people I would like to thank for their support during this milestone achievement. Firstly, I would like to thank my committee members, Henry Krips, Eve Oishi, James Morrison, and Dana Polan for their support and guidance in completing this project.

I thank my advisor Henry Krips who played a significant role in my academic journey as a teacher, mentor and friend. As chair of my dissertation, his careful reading and comments in the final stages of the project were tremendously valuable. I thank Henry for suggesting me to read Antonio Gramsci and Michael Warner, both important figures in my dissertation. As a teacher and writer, he inspired me to explore the complexity and conjunctural nature of politics and culture. And I thank him for introducing me to his family and for his support in my move from the east coast.

I thank Eve Oishi for helping me plan my academic trajectory at CGU. Her guidance and encouragement helped me to navigate the qualifying exams. Eve helped me to development my voice as a writer. Her "Introduction to Cultural Studies" course made me think deeply about categories of time and space. And I thank her for recommending David Harvey's work on postmodernity and Mary Ann Doane’s work on cinematic time.

Enrolling in James Morrison’s film courses confirmed why I love cinema. As a teacher, he provided me with the language to put my ideas into words. His film theory course was extremely important in the development of my ideas for my dissertation. I was deeply honored to be part of his long take panel at the SCMS conference in 2011. I thank him for introducing me to many great novelists and film scholars, especially Dana Polan's work.

I want to thank Dana Polan for being my outside reader. Dana's writings on cinema and television greatly contributed to my project. His book on The Sopranos inspired me to re-watch all seven seasons this past summer, which became a central object of study for this project. It is a tremendous honor to have Dana as a part of my dissertation committee.

I want to thank my friends and family for their support these past four years. I especially want to thank Paul Biagiotti for all of our great conversations about cinema and for introducing me to mumblecore. I want to give gratitude to the faculty at the department of English at the University of Vermont. I especially thank Todd McGowan for encouraging me to pursue my Ph.D., and for connecting me with Henry Krips.

I want to thank the staff members at the Arts \& Humanities office at CGU for their assistance.

Writing a dissertation can be a lonely process. I thank my dog Beatrice for being a presence and not barking too much!

Lastly, I want to thank my wonderful and beautiful wife and best friend, Katie. Without her support, I would not have been able to pursue my Ph.D. I thank her for listening as I attempted to problem-solve the many obstacles encountered during the writing and researching of this project. I thank her for her editing expertise. Most of all, I thank her for always being there for me. 


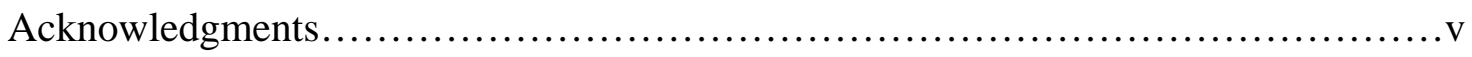

Introduction:

Accelerated Culture........................................................

Chapter 1:

The Velocity of the Long Take...............................................37

Chapter 2:

The Politics of the Long Take: Gus Van Sant's Elephant................................72

Chapter 3:

"Made in America:” The Television of Delay in Twin Peaks and

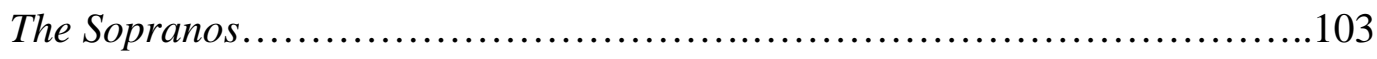

Chapter 4:

“An Uncertain Future:” The Instant, Narrative Closure, and the Pensive and

Possessive Spectator in Twin Peaks and The Sopranos..........................132

Chapter 5:

Exploring Mumblecore: Speed, Digital Cinema, Media Convergence,

Publics and Counterpublics................................................................164

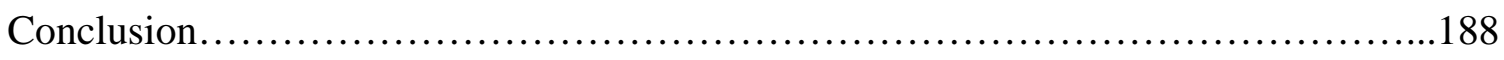

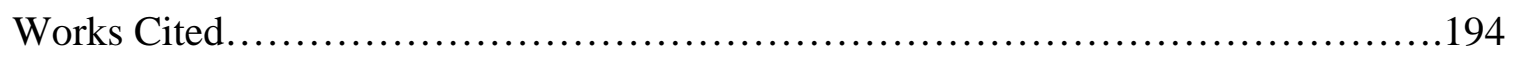




\section{Introduction: Accelerated Culture}

The end of the 1950s witnessed two major inventions in the world of science and technology that would significantly reshape experiences of time and space. The first was the FAA’s certification of Pan American World Airways’ new Boeing 707, ushering in what became known as the jet age. The Boeing 707 would not only alter the entire infrastructure of airline transportation, but also reconfigure the way goods and services were trafficked and circulated around the globe. The second invention was a device created by Jack Kilby called the microchip, which would dramatically influence the future of computer technologies, spawning what is termed "miniaturization." The advent of the microchip, for example, led to the creation of IBM's 1401—-the first modern computer. Fred Kaplan notes that the IBM 1401 took up 34 square feet, whereas IBM's previous computer (the UNIVAC), without the microchip, had taken up 220 square feet (76-83). Decades later, the fusion of the microchip with computer technology would inspire the creation of the Internet and media devices, such as iPods, laptops, and smart phones.

The jet airliner and microchip are clear examples of new technologies that have augmented perceptions of time and space in everyday life. There is no denying that taking a jumbo airliner from Los Angeles to New York City, within roughly five to six hours, is a significant advancement for the travel industry. The same goes for the invention of the microchip and the process of miniaturization for the computer and electronic industries. The New York Times recently reported that 70 million iPhones and 30 million iPads were sold last year alone (Duhigg and Bradsher, "iPhone”). But determining the narratives and practices that are generated out of the uses of technology is a far more complex task, not only because they can be unpredictable, but because 
consumption can potentially inform production and vice versa, creating a complex circuit of meaning in the articulation of a cultural object.

This study seeks to understand the impact of speed on the interrelation and overlapping of the production and consumption of televisual and cinematic texts. It explores the immediacy of digital media and new economic processes, and how they are informing structures of perception, as well as lending themselves to new and different ways of seeing the moving image in the digital age. These visual expressions are evident in the changing perception of the long take; the increasing use of video gaming aesthetics and database narrative; new and variant forms of narrative and visual styles in television; and the impact of the speed of new media technology (such as the Internet, personal camcorder, mobile screens, and desktop editing) on new voices and avant-garde expressions in independent and DIY cinema. Conversely, VCR, DVD, DVR devices (as well as online streaming and DVD and Blu-Ray rental sites) have transformed the perception of the moving image. Time-shifting devices allow for halting and controlling the flow of passing time, permitting for greater textual analysis. And, reciprocally, these new perceptions of the moving image inform expressions of filmic time and space.

The speed of digital media and new economic formations raise concerns about lived reality and the attenuation of time, place, and community. It brings forth questions of the waning of pastness and memory, the diminishing of critical distance, and the vanishing of slow time. I argue, however, that these shifts that are occurring in cinema and television illustrate that the processes of speed are not the prime determinant in the production and consumption of moving images. Rather, it is determined by a contingent 
and open-ended processes of articulation—sites where disparate elements are combined, unified, and, thus, practiced and lived under the ever-changing conditions of existence.

This project consists of three components that are interrelated with each other in regards to time and space, culture, and new media technology. The first is the postmodern condition of time and space and the shrinking perception of the world. The second is the notion of convergence culture and digital cinema. The third are the political concepts of hegemony and articulation. Drawing upon these three theoretical components, I explore questions of speed and delay, as well as time and memory pertaining to culture and technology in the fields of cinema and television. For instance, how are conditions of new media creating new opportunities for cinematic and televisual expressions? What is the relationship between time-shifting technologies and human memory? How is digital cinema influencing shot duration as in the long take? Are there connections between shot duration and the politics of a film or televisual text? Are there correlations to the Internet and the formation of alternative artistic publics pertaining to visual texts? I will be investigating these questions throughout this dissertation.

The term speed is used in four senses interchangeably throughout this study; how it is aesthetically represented in the moving image; its role in advancing new technologies as in new media; its role in changing processes of capitalism; and as a tool of communication, for example, social networking, emailing, and texting. The term duration is used to note an object's continuance in time as in the length of a film shot. The term new media describes new forms of digital communication, such as the Internet, smart phones, CDs, and DVDs. 


\section{Flexible Accumulation and the Postmodern Condition of Time and Space}

The jet airliner and microchip developed during a post WWII American society that saw significant economic and production growth. The development of suburban neighborhoods, new infrastructure projects (such as the building of the Interstate highway system) and new technologies (like the television, the VCR, and computers) were some of the advances spawned during the post WWII production and consumption boom in American society. Whereas the social formation of modernity is typically linked to notions of industrialism, urban growth, and mechanical power; postmodernity is marked by de-centralization, intensified production of images and signs, accelerated consumption, and a burgeoning information age. Of course, changes in experiences of time and space and the speeding up of culture is a phenomenon characteristic of both modernity and postmodernity. Marita Sturken notes that the industrial and post-industrial world is not "defined by the replacement of modernity and postmodernity. Rather, it is a time defined by the tension between the two" (72). Here, we must stress that modernity and postmodernity are not strictly polar opposite formations; but overlap and share similar concerns in regards to technological change and the acceleration of social life.

According to David Harvey, the condition of postmodernity is the compression of time and space where the world perceptually appears smaller. Harvey links this transition from modernity to postmodernity through the concept of "flexible accumulation," an economic development that "confront[s]...the rigidities of Fordism” (147). For Harvey, a characteristic of flexible accumulation is a "new round" of time-space compression. Tracing the beginning of the annihilation of space through time in the era of the Enlightenment, Harvey notes it "had in common a relatively unified common-sense of 
what space and time were about and why their rational ordering was important” (258). The "totalizing vision" of time and space during the Enlightenment was to dominate nature and to "liberate man" for social progress. The systematic and homogenous ordering of time and space, Harvey writes, "formed limiting containers to thought and action” (252). The idea of universal time and space led to regimentation and management of mass populations. The Enlightenment thinkers' desire to control and conquer time and space was to transform and emancipate society from nature.

But even as European space was becoming more unified due to "the internationalism of money power," it pushed towards an economic crisis, culminating in the 1848 political uprisings throughout the continent (262). According to Harvey, in response to the financial collapse of 1848 , new capitalistic practices and projects were developed to produce capital growth and expand markets "on the path of globalism" (264). Large projects such as the Suez Canal, the expansion of the railway system due to the telegraph, the invention of the automobile, and the growth in large communication systems (particularly radio and cinema) would be an "investment" into the conquering of space.

These new forms of capitalism in America, for example, resulted in new forms of the division of labor and measurement of time, a development that would come to define Fordism. Fordism emerged out of Henry Ford's motto of an eight hour and five dollar work day, an economic development based on Taylorization—-the division and standardization of labor for mass production of goods. Fordism was tremendously beneficial during the American postwar boom. But, as Harvey points out, there were "serious signs" in the mid 1960s that Fordism was in crisis. Some of these signs were a 
decline in corporate productivity and profitability, leading to "acceleration in inflation." New industrialized countries, such as Japan and Germany challenged the United States "hegemony within Fordism” (141). Significant increases in fuel and energy prices due to the oil crisis in the early 1970s, alongside the increasing cost of the Vietnam War, led to an economic recession, "undermining” the processes of Fordism.

According to Harvey, the economic stagnation of the early 1970s resulted in new labor and economic practices used to ward off inflation and to generate financial growth and stability. These new changes in capitalism are what Harvey terms "flexible accumulation... [which] is characterized by the emergence of entirely new sectors of production, new ways of providing financial services, new markets, and, above all, greatly intensified rates of commercial, technological, and organizational innovation” (147). The development of flexible accumulation enables employers to place more stress on labor forces, reconstruct work structures, increase outsourcing and sub-contracting, and de-regulate in order to get out of the "rigidities" of Fordism and to generate financial growth through vertical integration.

The impact of flexible accumulation and the compression of time and space were felt in the film and television industry in the areas of technology, production, and consumption. The film industry in the Post WWII period saw significant changes in how audiences spent their income and leisure time, resulting in a drastic reduction in box office attendance. Some of these new changes were due to an increase in birthrates, veterans entering into educational institutions, and families moving to the suburbs. As Tino Balio notes, "Because the country was at peace, goods and services were diverted to 
civilian purposes. Houses, automobiles, appliances, and other commodities were purchased in abundance, cutting in on disposable income” (401).

There were two notable factors, in particular, which led to the decline in box office revenues. The first was the Paramount Case in 1948, which required that five major studios divest from their first run theatres. Before the court decrees, the major studios utilized a practice of block booking which forced theatres to accept a studio's films in large groups or "blocks" (Cook, 46). The blocks contained desirable or attractive films tied to a star along with B-quality films. The courts had found this practice to be monopolistic because the major studios had control of production, distribution, and exhibition. The courts demanded the studios divest from their "lucrative exhibition circuits.” The Paramount Case dramatically cut into film's studio’s profits. Michael Conant notes, "Estimated attendance of indoor theatres dropped from 3,352 million in 1948 to 1,011 million in 1958 and to 553 million in $1967 \ldots$. Domestic theatre admission revenue dropped from \$1,245 million in 1948 to about \$900 million in 1958 and recovered to $\$ 1,082$ million in 1967” (539). The second factor was the coming of television in the 1950s. By the end of the 1950s, more than 90 percent of American homes owned a television set. And as the number of television stations increased (as well as the variety of programming), television would come to replace movies as the dominant form of leisure activity in post WWII society.

These technological, economic, and cultural factors resulted in the major film studios being absorbed into conglomerates. Specifically, the de-centralization of Hollywood and the rise of media synergy through mergers-and-acquisitions in the 1980s signaled a major transition in the corporate structure from a film industry into a 
communications industry. According to Stephen Prince, the 1980s had the steadiest stream of mergers-and-acquisitions because buyers saw potential growth in the information age. Prince points out that the communication conglomerates were interested in the Hollywood industry because a blockbuster film could not only generate large profits from the box office, but were also "giant revenue machines that could drive ancillary markets to produce additional returns” (42). For example, markets such as cable, satellite, video, soundtracks, and amusement park rides could all be tied to a film, and thus, potentially generate large revenue streams by synergies in leisure entertainment. Prince adds, "to facilitate this strategy and drive merger-and-acquisitions activity, a new market infrastructure emerged, consisting of investment bankers, law firms, valuation companies, accountants, and strategic planners whose time and resources were devoted to m\&a [merger-and-acquisitions] analysis and forecasting” (45). Coca-Cola, NewsCorp, and Sony were some of the enterprises looking to the media industry to put into practices long-term future business plans and strategies which required new methods into the production and marketing of leisure entertainment. These horizontal and vertical integrations in the film industry resemble Harvey’s description of flexible accumulation and the acceleration of capitalism in an emerging globalized world. Whereas raw goods and infrastructures defined the period of industrialization, the de-centralization of Hollywood and the rise of synergy in home entertainment in the 1980s illustrate the potential wealth and financial growth in the speed and instantaneous as well as the global communication commodities linked to the burgeoning information and computer age.

It is also important to stress that these new economics practices in Hollywood were felt not only locally, but also globally. As an example of Hollywood's power and 
economic “dominance,” Miller et al. note, "In 1985, 41 per cent of film tickets bought in Western Europe were for Hollywood fare. In 1995, the proportion was 75 per cent. And 70 per cent of films on European television come from the US” (17). In this regard, cinema and television represent a major export for the US in the service sector. Miller et al. note, "Annual expansion in the trade [for the US] between 1970 and 2000 averaged 11.4 per cent compared to 7.8 per cent yearly growth in GDP [Gross Domestic Product]" (58). These statistics and the palpable increase in forces of globalization raise concerns about locality. More so, these numbers indicate that the de-centralization of the major studios in the post-Fordist era did not lead to disorganization, but actually intensified their organization, in the forms of "new regimes of accumulation" (Harvey 145)

The transformation of Hollywood into a communication industry coincides with changes in the social sphere in regards to flexible accumulation and the compression of time and space. Fredrick Wasser point out that changing leisure time and work schedules, for instance, had a direct connection to the consumer's need for a VCR. He notes that this change in audience viewership occurred primarily because of a significant increase in women entering the labor force. Here, the "time-shifting" technology in media device of the VCR allows audiences to record and watch programs that match the home lifestyle of the nuclear family, giving viewers more choice, ownership, and control in the consumption of television programming and movie rentals.

The cultural practice of time-shifting and video renting also augmented the blurring of the private and public spheres in relation to postmodern time and space. In the early 1990s, Anne Friedberg described audiences’ relationship to postmodern spatially and temporality as an intensification of what she termed the "mobile and virtual 
gaze.” For Friedberg, the mobile gaze is linked to movement; whereas the virtual has connection to the representations of visual texts. She notes that in modernity, "The Cinema developed as an apparatus that combined the 'mobile' with the 'virtual'” (3). For Friedberg, postmodern social spaces, such as shopping malls and multiplexes, are a continuation of modernity's arcades, panoramas and dioramas. But she adds that a new relationship to time and space in cinema spectatorship has emerged in postmodernity, because boundaries between public and private spheres "have now been more fully eroded” (4). For example, to rent or purchase a movie on DVD transfers the cultural artifact made for public sphere entertainment to the domestic space of the home where one can watch the movie on one's own time. In addition, home-viewing movies can be watched in parts and repetitively. It is possible for scenes and images to be isolated and analyzed. Friedberg points out that the renting of the videocassette marks a temporal and spatial "loss." As she puts it, "The market of commodified video-movies available to the home viewer has meant that the 'aura' of the original moment of cinema exhibition... disappears.... One can literally 'rent' another space and time when one borrows a videotape to watch on the VCR” (139-141). From this standpoint, the notion of timeshifting marks a significant blurring of the private and public spheres in relation to home and public entertainment. ${ }^{1}$

The changing perspective of the private and public sphere in the consumption of media texts as well as the immediacy of electronic and digital communication raises concerns about postmodernity and the fragmentation of society. Writers have reflected

\footnotetext{
${ }^{1}$ The major film studios, at first, viewed the VCR's ability to time-shift as a threat because they believed audiences would stop attending theatres. But they eventually saw the "viability" of the video market, and the revenue it could potentially generate, especially for blockbuster films. Top Gun, which was the number one box office film of 1986, sold over 3 million units on video cassette in 1987 (Prince, Gold 105).
} 
upon the potential symptoms and dangers of an accelerated society in relation to the mass media and the manufacturing of signs. Commenting on the speed of information in mass media, Jean Baudrillard contends that the proliferation of signs is an "implosion" of meaning. As he puts it, "Information devours its own content. It devours communication and the social" (80). Drawing upon Marshall McLuhan's concept of "the medium is the message,” Baudrillard argues that it is the medium itself that has been imploded through the process of simulation. In other words, the proliferation of simulation (copy of a copy with no original) has usurped the referential (the medium). It is what Baudrillard famously phrased as the "desert of the real.” For Baudrillard, reality in postmodernity becomes disconnected and devoid of origins and referents—-thus, an emptying of the ground for the production of meaning-making caused by the acceleration of information. Without the grounding or base to generate meaning, reality is no longer reality. Reality becomes what Baudrillard phrase as "hyper reality.” For Baudrillard, social reality is depleted of meaning through the mass media's blurring of signs and referents, thus resulting in "entropy" and the liquidation of the medium.

Like Baudrillard, Paul Virilio is concerned with the shrinking perception of the world due to the speeding up of life. Virilio's writings have been the most engaged with the topic of speed in relation to technology, art, and politics. Coining the term "dromology" as the logic of speed, Virilio has sought to understand speed and its relationship to subjects of the military, ideology, cinema and the mass media. For instance, Virilio's The Vision Machine focuses on the drawbacks for mass society in relation to new vision technologies of speed. A "vision machine" is a technical prosthesis of our vision. For Virilio, natural vision undergoes a significant 
transformation from geometrical optics to wave optics. For example, the glass of a telescope lens acts as a vision machine which alters our sense of perception because it brings reality closer to the subject. That is, the capacities of the human eye are extended through the machine's glass lens. With wave optics, glass becomes an electronic window. In this sense, the transmissions of radio and television signals now provide us with instant "real time" messages. Light is converted into a new energy that bypasses the eye. For example, a video camera captures an event which is then transmitted into televisions in homes and public places. Virilio argues that the vision machine (due to its immediate transmission) augments our experience of time and place in what he describes as the aesthetic of disappearance. As he puts it: "an aesthetic of disappearance....arisen from the unprecedented limits imposed on subjective vision by the instrumental splitting of modes of perception and representation” (49). Here, the annihilation of space through time through "vision machines," suggests a depletion of reality and loss of connection in the social order. In this regard, both Baudrillard and Virilio’s writings are concerned with the diminution of the referent for generating meaning in sped-up societies. What is at stake in the acceleration of culture is the loss of the gap and distance needed for both critical reflection and social communication.

Both Baudrillard's and Virilio’s work on speed and postmodernity are provocative. Their claims suggest a one to one relation between technology and culture. They also suggest that technology is separate from practices of culture. Technology certainly has an impact on the speeding up of culture. The Internet, mobile phones, and computer tablets, for example, are cultural artifacts that allow for instantaneous communication. But, technological or economic processes alone do not shape culture. 
We must also consider the practices of meaning-making generated in the combination and "linkage" of these technological and economic conditions.

The central premise of this dissertation is that the practices of meaning-making enabled by the acceleration of culture often lead to unpredictable and contingent outcomes. For example, it has been well documented that the VCR and the phenomenon of video renting benefited artists working outside the Hollywood system. According to Stephen Prince, “From 1983 to 1987 independent production distributed by the majors remained relatively constant, fluctuating between 49 and 64 pictures per year. By contrast, pictures distributed independently of the majors rose from 125 in 1983 to 242 in 1986 and 203 in 1987” (117). These numbers indicate that (in the midst of mergers and acquisitions and the de-centralization of the majors film studios) flexible accumulation created new conditions and opportunities for filmmakers working outside of Hollywood to seize upon in the 1980 s.

We will also consider the social practices and publics that emerged out of the video revolution and how access to archives of movies helped inspire filmmakers to shape their knowledge of film and cinematic expression. Consider film directors Quentin Tarantino and Roger Avary as employees of the infamous rental store, Video Archives, located in Manhattan Beach, California. Video Archives was owned and managed by a thirty-something film enthusiast, Lance Larson. When he opened Video Archives in 1979, Lawson did not cater specifically to the Hollywood blockbuster crowd, stocking his store shelves instead with a diverse selection of foreign, classic and documentary titles. Lawson's archive of movies drew cinephiles and cineastes to his place of business, eventually leading to the store's cult status. Employees Tarantino and Avary were part of 
a group of friends and other video store employees who were trying to break into the film industry in the 1980s and early 1990s. The "Video Archives gang" was a small group sharing their passion and knowledge of film and desire to make movies that reflected their love of Hollywood and foreign cinema. ${ }^{2}$ At night, they would hang out and watch movies at the store, and constantly challenge each other's knowledge of cinema. On occasion, their debates on cinema would seep into the store and result in arguments with store patrons! In addition, they created their own employee video selection as a way to display their favorite films to the public. Avary even built an inventory software program designed to catalogue the archive. In a 1994 interview, Avary stated, “There’s a fresh generation of filmmakers, and they're coming out of the video store. All of us have the advantage of a data base of thousands of movies” (qtd. in Peary 131). Tarantino and Avary became close friends and would help each other with their stories and screenplays and would eventually write Pulp Fiction (1994). Both directors were labeled as video generation filmmakers, what Variety termed "rebels with a pause" (qtd. in Polan, Pulp Fiction 36-37).

In this instance, we can see postmodern technologies of speed (the VCR, video renting, and the computer) positively impacting time and space, as well as creating a sense of community and place: Video as a "time-shifting" artifact can be accessed instantaneously and be watched based on one's lifestyle. The video recorder enables viewers to pick and chose when, for example, to watch a television program that matches one’s schedule. As Paul McDonald notes, "With the VCR, time-shifting fractured the temporal organization of the [programming and broadcast] schedules by allowing

\footnotetext{
${ }^{2}$ For more information about the Video Archives gang see Jami Bernard's Quentin Tarantin: The Man and His Movies. 1st U.S. ed. New York: Harper Perennial, 1995, and Jeff Dawson's. Quentin Tarantino: The Cinema of Cool. New York: Applause, 1995.
} 
television viewers the freedom to uncouple the time of viewing from time of scheduling” (38). Video Archive also carves out a space that, I will argue, becomes a public, in Michael Warner's sense. For Warner, publics are formed not only by their selfawareness, but also an "orientation to strangers" (75). In other words, for Warner, a public without openness to the stranger can not be a public. The public formation based on Video Archives' exhibits not only the feature of “stranger relationality,” but also another feature that Warner deems necessary to a public, namely the creation of a "social imaginary": a sense of place and community materialized out of cineastes, cinephiles, and inspiring artists who shared a love of cinema. In short, the formation that arose out of the Video Archives gang illustrates a social practice based upon a technology of speed that created a sense of community and stranger relationality as oppose to alienation and disconnection in the acceleration of culture.

\section{Convergence Culture and Digital Cinema}

Today, when we consider the power and speed of the Internet and how it has opened new avenues for not only information seekers of film, but also new exhibition of movies via online streaming and video-on-demand sites, it becomes clear that subjects are even more "mobile and virtual" than Anne Friedberg had envisioned in the early 1990s. For instance, in a recent Hollywood Reporter interview with HBO executives, according to co-president, Richard Plepler: “About half of HBO’s audience comes from on-demand platforms and mobile-broadband” (Guthrie, “Games”). A recent Los Angels Times article on Netflix reported that, "More than $60 \%$ of the 2 billion-plus hours of video streamed by Netflix subscribers during the fourth quarter of 2011 originated on the 
small screen [television]” (Fritz and Flint, "Netflix”). Theses numbers indicate significant changes in ways in which audiences are now watching television.

In addition, the availability of filmmaking tools, such as desktop editing and more affordable portable high definition video cameras, now offer independent and DIY artist more opportunities to showcase their work. If we combine these new media apparatuses with web platforms, such as social networking, tweeting and blogging, we find a unique concoction of cultural practices occurring at the beginning of the twenty-first century with new opportunities for cinematic expression. It is what Henry Jenkins refers to as “convergence culture"-a concept that describes "technological, industrial, and cultural and social changes in the ways media circulates within our culture” (282).

In Convergence Culture, Jenkins explores how meaning is produced through the convergence of old and new media technologies, and how "consumer active participation" creates new forms and expression of practices such as fandom and online communities. For example, the Video Archives gang demonstrates a social practice that developed around the technology of the VCR and the business of video renting. Here, it must be stressed that old media are not replaced by new media in convergence culture, instead they shape and mould social reality in new and unforeseeable ways. Convergence media, in this respect, is another development of accelerated culture in the digital age.

Media convergence and digital cinema are creating new conditions for independent and DIY filmmakers, enabling the uses of web platforms and digital tools to promote their work beyond the private sphere. Media tools (such as desktop editing and high quality and portable digital video camcorders) alongside web platforms (such as online streaming and social networking sites) have generated new spaces for artists to 
present their work in a public forum. The Blair Witch Project (1999) has often been cited as an early example of convergence culture in relation to digital cinema and the Internet. Shot on digital video and $16 \mathrm{~mm}$ for a supposed budget of $\$ 40,000$, The Blair Witch Project is a "mockumentary" horror film about three filmmakers who disappeared in the Black Hills Forest of Maryland while investigating the legend of the "Blair Witch.” The film is presented to viewers as recovered footage of the documentary. The Blair Witch Project is widely recognized as the first film to use the Internet as a vehicle for promoting and marketing the film's release in the summer of 1999. Chuck Tryon notes, "While blogs have been widely used to promote studio films...their more interesting use has been in the promotion of documentary, independent, and DIY filmmaking” (145). For example, The Blair Witch Project's co-directors Daniel Myrick and Eduardo Sanchez came up with an innovative way to promote their film. They created a website that gave the illusion that the murders in the film were actually real. The Blair Witch Project made over \$248 million dollars in world wide box office sales, clearly marking itself as the first blockbuster/self-made film in the digital age.

The phenomenon of The Blair Witch Project and its experimentation with the digital video format and social networking raises the question of the amateur filmmaker in relation to the public and private spheres. Consider the scene when the filmmakers stumble upon a group of humanoid stick figures hung within the trees. Heather, the director of the project, is carrying a portable high $8 \mathrm{~mm}$ video camera to document their journey in the making of the documentary. The stick figures are first presented to viewers through the lens of video (Heather's perspective). Excited about her discovery as possible evidence for the Blair Witch, Heather calls out to her crew to grab the CP 16mm 
camera to document their findings. In this respect, the found evidence must be legitimized through the medium of film versus video. What is at stake here is a tension between "amateur” video and the film as a "professional” medium. Heather's need to photograph the stick figures in celluloid implies video’s relegation to the amateur's home movies, (or in this case, Heather's personal and private video of her experience making the Blair Witch documentary). Here, we see the film playing with the notion of video as assigned to the private and domestic spheres. ${ }^{3}$

But, as Jenkins points out, digital cinema and "grassroots convergence” has transformed the private sphere of the amateur "home movie" into work for public exhibition. Jenkins notes, "Many of the other classic markers of amateur film production have disappeared...these films are public movies-public in that, from the start, they are intended beyond the filmmaker's immediate circle of friends and acquaintances” (142143). This transformation of the private home movie into the public forum is the phenomenon of parody video, where fans repurpose their favorite television shows or movies into short digital videos. Of course, it is also true that many of these videos become calling cards as a way to break into Hollywood. Nevertheless, YouTube, Vimeo and other video sharing sites offer amateur filmmakers a platform to showcase their work outside the realm of the home, friends and/or family. From this standpoint, The Blair Witch Project as a practice of convergence culture through its utilization of digital platforms to promote the film, and, at the same time, sets up a productive dialogue with the medium of celluloid film.

\footnotetext{
${ }^{3}$ It is also interesting to note how the film plays with the postmodern notion of simulation and "vision machines” when Josh (Joshua Leonard) becomes upset with Heather, who continues to videotape, regardless of being lost in the woods without a map, suggesting that she is not fully aware of the urgency of their situation. He says to her at one point "I see why you like this video camera so much.... It's not quite reality.” I thank Katie Connelly for this point.
} 
The frantic aesthetic of The Blair Witch Project as well as its employment of both digital video and film addresses technological and stylistic changes within the Hollywood mode of production. David Bordwell and Janet Staiger describe three benefits in regards to new technologies and their impact economic practices of the studio system. First, production efficiency saves the studio costs and solves production problems. Secondly, new technology can potentially distinguish one studio’s product from other competing studio's project. And, thirdly, advances in new products continue Hollywood's tradition of striving towards standards of quality (243-246). They importantly add that new technologies must not de-stabilize the standardized mode of classical narrative. Most often when new special effects are employed in Hollywood, they are used to "complement" the film's story world. In this sense, the system has to be able to incorporate technological changes with little or no disruption of the system. New technologies, for example, synch sound or 3-D, must be worked into the realist classical narrative form that prevents viewers from becoming conscious of the apparatus that creates the film's virtual setting. It can certainly be argued that new effects may be so stunning that they call attention to themselves, for instance, the creation of bullet time photography in The Matrix. But it is important to stress that Hollywood's incorporation of such new technologies follows not only an economic model, but also the studio's history of utilizing classical realism to create transparent story worlds.

Thus, The Blair Witch Project's employment of $16 \mathrm{~mm}$ film for authenticating evidence and its use of digital video as the behind the scenes footage for making the documentary realizes a tension between cinema’s professional standards of quality and the amateur quality of videography. Yet at the same time, as in The Blair Witch Project, 
the video quality and its grainy look may be stylistically motivated, because it establishes its credentials as "authentic."

\section{Hegemony and Articulation}

But what are the political implications when technologies are not used within the boundaries of Hollywood's standardized and hegemonic mode of production? Consider the Dogme 95 movement and its attack on pristine and precise cinema. Dogme 95 was created by Danish filmmakers Lars von Trier and Thomas Vinterberg. The year 1995 marked the 100th anniversary of cinema and these directors wanted to capture the grassroots spirit of the early silent filmmakers in order to create a more personalized and rawer style of cinema. They created "The Vows of Chastity” which contains ten rules that define a Dogme film. For example: films must be photographed in handheld style; the story cannot be shot of out order; there can be no artificial lighting and no extradiegetic music. Dogme 95's embracing of digital video cameras not only broke with the traditional methods of filmmaking, but was also a direct response to the narrative precision of Hollywood.

The manifesto of Dogme 95 demonstrates that technologies of speed can be political and resist the hegemonic mode of filmmaking. Antonio Gramsci reminds us that hegemony is a process where the dominant party retains and reproduces its power through winning consent. For Gramsci, in order to win consent, the majority or dominant powers have to appeal to the subaltern or subordinate group in order sustain its rule. But consent is not fixed, and can always be contested. Hegemony, therefore, is a process without end: a subordinate group can always resist the dominant group. As Marcia Landy puts it: “Gramsci’s dialectical analysis proceeds from the assumption that 
everything in life is in constant motion, that everything is interrelated rather than rigidly schematic and systemic” (53).

Popular forms of culture prove to be an important site for the analysis of hegemony because popular cultural texts can trace tensions between both dominant and subordinate groups. Drawing upon the work of Gramsci, Ernesto Laclau and Chantel Mouffe, Stuart Hall describes how the production and consumption of popular cultural objects take place within the lived practices of every day life through a process that he refers to as "articulation." For Hall, articulation is an operation of meaning-making that does not have any necessary correspondence with overarching economic or technological causes. Articulation is the linkage or bridging of disparate elements under certain “conditions of existence.” In other words, articulation is not reduced solely to the economic or technological modes of production, but instead depends upon how they are expressed, practiced and communicated within social reality. Articulation unifies various elements to forge meaning in the consumption of cultural artifacts. Hall argues further that the linking of these disparate elements is shaped by communal "maps of meaning” and frames of knowledge such as family, race, religion, and work.

Both Hall's model of articulation and Gramsci's notion of hegemony and censusmaking are founded on the argument that the base (force of labor and economics) and superstructure (civil society) do not have any "necessary correspondence” in relation to practices of meaning-making. Thus, Hall and Gramsci's work on culture and politics move away from economic reductionism linked to classic Marxism (and its notion of ideology as false consciousness). Rather, they use an open-ended model that looks for struggles at sites of specific conjunctures, without reducing them to economic processes 
(“Articulation” 53). The concepts of articulation and hegemony do have some similarities to the postmodern notion of "living in contingency means living without a guarantee” (Bauman, "Postmodernity” 15). But, I want to stress the acceleration of culture in postmodernity is not a matter of "anything goes," or a celebration of living with uncertainty. Again, Hall's notion of articulation proves fruitful in this regard; we need to understand both the workings of form and content and how they are contingently articulated in order to unpack how a cultural object is produced and received in social life.

Gramsci and Hall's work on the interaction of hegemony, culture, media and politics offers a mapping between alternative and dominant modes of filmmaking. More specifically, their concepts enable a reading of text within its historical and social conditions. For example, classical cinema has historically thrived on creating transparent and self-governing realist narratives built on linear and successive ordering of time and space. Such realism is what Roland Barthes refers to as the exnominated process in the mythmaking of the cinematic sign. Barthes notes, "Myth hides nothing and flaunts nothing: it distorts; myth is neither a lie nor a confession.... [The] very principle of myth [is] to transform history into nature" (129). The process of evacuating the connotative code (the associate meaning) is what turns the sign from its cultural status into a naturalistic illusion. Exnomination guarantees the sign's truth—suppressing contradictions and differences, located at the connotative level. Exnomination grants the sign illusion of objectivity, so that it cannot be challenged. Of course, the text is never closed, because contingencies and contradictions are always present. ${ }^{4}$ But in classical

\footnotetext{
${ }^{4}$ Nicholas Rombes makes this observation in what he calls "The Adorno Paradox.” He writes, "Without film's closed system, there would be no need for Adorno's assaultive writing. Hollywood cinema helped to
} 
Hollywood cinema realism suppresses such flaws (both in terms of content and form) and naturalizes the film's content by concealing the film's constructed and mediated reality. By way of contrast, any deviation from the standard mode of production reveals the sign and reduces it to what Gramsci calls “common sense.” From this perspective, The Blair Witch Project's playing with medium of film, and Dogme 95's declaration of avant-garde styles may be seen as a form of resistance directed against Hollywood's realist narratives.

In this context, it is important to note that the dominant group does not restrict to its hegemonic practices. On the contrary, subcultural styles can be incorporated or "nominated" into the status quo. Dick Hebdige describes this phenomenon as the cycling of subculture resistance. He notes, "Each subculture moves through a cycle of resistance and defusion and...this cycle is situated within the large cultural and commercial matrices” (130). Consider, for example how science fiction television and cinema has incorporated shaky handheld camera shots and fragmented and jagged patterns of editing as a way to aesthetically represent the real. In particular, shows such as Firefly (20022003) and Battlestar Galactica (2004-2009) and films such as District 9 (2009), and Terminator Salvation (2009) have utilized a documentary-like style as a way to create a sense of alarm and immediacy. Even though subcultural style can be appropriated by the status quo, the process of hegemony is without end. As Hebdige points out, hegemony is not "universal," but has to "be won, produced, sustained" (16). In Hall’s terms, the cultural texts of cinema or television are always open to negotiated and oppositional reading practices; meanings will vary from person to person based on an individual's experiences and frames of knowledge (“encoding/decoding” 133-134). What is not to

make possible the very form of critique Adorno claimed was impossible. His writing proves the lie to very claim it makes" (13). 
deny, of course, that heterodox styles can be incorporated into the status quo, thus illustrating the dialectal nature of hegemony.

\section{Speed and Delay, Project Outline and Methodology}

The raw and spontaneous style of The Blair Witch Project and Dogme 95 cinema raises the question of digital cinema’s privileged relationship to speed and immediacy. In Jean Rouch’s 1973 essay “The Camera and Man,” he reflects on the future of filmmaking by stating, "Tomorrow will be the day the self-regulating color videotape, of automatic video editing, of ‘instant reply’ of the recorded picture (immediate feedback)” (98). Here, Rouch’s envisions advances in technologies of speed impacting processes of filmmaking. The portability of digital cameras, for instance, now allows the camera operator to be mobile within the filmic space, creating for viewers a point and shoot perspective that elicits a sense of urgency and spontaneity. Digital film permits instant turnover time in screening footage; whereas celluloid film requires time for development and processing. The emergence of random-access or non-linear computer-based digital video systems enables filmmakers to quickly access any point within the shot footage, whereas traditional film/tape editing consoles requires the editor to search and scroll through footage in a sequential manner.

Digital technologies and mobile screens have spawned new styles that have reconfigured and articulated the expressions of space and time in Independent and DIY cinema. Holly Willis notes, "While the Hollywood film industry strives to meld film stock and digital video, the tools used in digital film and sound work have created an undeniable sense of creative convergence...”(45). The hybrid of media aesthetics such as music videos, graphic design and video gaming are impacting avant-garde and alternative 
expressions of filmmaking outside of the traditional mode of production. For example, more filmmakers are experimenting with non-linear forms of storytelling, such as database narrative, where information is presented to viewers in an installation art-like perspective that invites spectators to render and organize the disparate information as they travel through the film's catalogue of data. ${ }^{5}$ Filmmakers are employing the aesthetics of multi-screens within a single screen as well as superimpositions and more mosaic and fragmented patterns of editing. ${ }^{6}$ Digitalization also permits more experimentation in the long take. The digital film Russian Ark (2002) was filmed in one 96 minute long take that traverses the Russian State Hermitage Museum. In order to record this amount of footage, the output from the high definition camera was sent directly to the computer's hard disk. Of course, it is true that these techniques have been used throughout cinema. For instance, Alfred Hitchcock’s Rope (1948) experimented with the long take, by shooting the entire film with the illusion of no edits within one setting. ${ }^{7}$ But digital media offers more tools and easier access for artists to play with cinematic time and space, resulting in new forms of filmmaking outside the confines of Hollywood cinema and television.

But what happens when the speed of digital technology comes in contact with the delaying and the halting of the moving image? How does slowness interact with speed

\footnotetext{
${ }^{5}$ See Janet H. Murray's Hamlet on the Holodeck: The Future of Narrative in Cyberspace. Cambridge, MA: The MIT Press, 1997; Lev Manovich's The Language of New Media. Cambridge, MA: MIT Press, 2001; Marsha Kinder's “Narrative Equivocations between Movies and Games.” The New Media Book. Ed. Dan Harries. London: British Film Institute, 2002; and Alexander R. Galloway's Gaming: Essays on Algorithmic Culture, Volume 18. Minneapolis: University of Minnesota Press, 2006.

${ }^{6}$ See Anne Friedberg’s The Virtual Window: From Alberti to Microsoft. Cambridge, MA: MIT Press, 2006.

${ }^{7}$ It is also worthy noting Hitchcock's follow up film, Under Capricorn (1949), where he continued to experiment with the long take.
} 
and delay? What is the relationship between accelerated culture and mobility and stasis, and time and memory?

Earlier, I introduced Pan Am’s Beoing 707 and Kilby’s invention of the microchip as significant technological advances in the acceleration of culture. Two important cinematic developments in perceptions of time and space occurred around this same time. The first was the freeze frame of Antoine Doinel's (Jean-Pierre Leaud) face at the lip of the ocean: a haunting look that gazes back at the audience in François Truffaut's The 400 Blows (1959). The second is the unprompted use of the flashback and non-linear structure in Alain Renais' Hiroshima mon amour (1959). Both films importantly highlight the acceleration of culture, not only because they gesture towards modern styles of filmic narration, but because their formal aesthetics complexly engage with questions of time and memory. The freeze frame non-closure ending of The 400 Blows demonstrates that when the flow of the film is deliberately slowed down, time and space can rise to the surface, and come into dialogue with each other. Laura Mulvey refers to the presence of mediation and pause in the cinematic narrative as the "cinema of delay.” Mulvey notes, "This cinema of record, observation and delay tends to work with elongated shots, enabling the presence of time to appear on the screen” (129). The films of Michelangelo Antonioni, Stanley Kubrick, and Abbas Kiarostami, for example, deliberately employ a slow aesthetic using long takes and static framing in order to emphasize empty and ambivalently motivated spaces. Slowness and freezing the frame, in this sense, reveal the relationship between movement and the unfolding of time (its linear and mechanical progression). Whereas realism and linear forms of storytelling 
attempt to make the text appear natural and transparent, the slowing down of the film and its successive flow of images places emphasis on its registration of time and space.

In many ways, the complex structure and editing of Hiroshima mon amour demonstrates cinema's intimate relationship to memory. The film’s fragmented and disjointed re-counting of Elle’s (Emmanuelle Riva) affair with a German solider during WWII, for example, captures the fleeting nature and elusiveness of human recollection. DVD and VCR devices now permit viewers to delay and repeat the temporal progression of the visual text, significantly changing viewers' relationship to time and memory of the moving image. Mulvey notes, “The new technologies work on the body of film as mechanisms of delay, delaying the forward movement of narrative and taking the spectator into the past” (181). For Mulvey, restoring a movie onto DVD, for instance, brings to life the indexical nature of the film where "the aesthetic of the past meets the aesthetics of the present” (21). Again, one only has to think of cinema before the advent of the VCR, where film, in this sense, had its own temporal existence, unfolding in the darkened movie theatre. But new digital technologies ("the aesthetics of the present”), and their ability to halt the flow of the moving image, transform and bring cinema's history (the "aesthetic of the past”) to a "new life.” As Mulvey states, “Once the consumption of movies is detached from the absolute isolation of absorbed viewing (in the dark, at 24 frames per second, in narrative order and without exterior intrusions), the cohesion of narrative comes under pressure from external discourses, that is, production context, anecdote, history” (27). For Mulvey, “unexpected” and “deferred meanings” of a film can be uncovered through new digital technologies (144). This slowing down and 
"freezing” of the temporal image not only allows for greater emphasis on textual analysis, but also, as I indicated in the example of the Video Archives gang, generates new publics.

But there is a paradox in the relationship to speed and delaying cinematic time. We have to become faster in order to slow down the moving image. Before the advent of time-shifting technologies, cinema had a privileged connection to memory, because we could not halt the flow of the film. The speed of digital media, whether it is the Internet or a DVD player, now allows for instant repetition and replay, possibly capturing meanings missed in its initial viewing. This transformation in the process of consumption of the moving image, I argue, is due to the acceleration of culture.

In this context, chapters one and two focus on the changing perception of the long take in the digital age. The long take has often been associated with slower paced and art-house cinema, which is evident, for instance, in the films of Jean-Luc Godard, Michelangelo Antonioni, and Abbas Kiarostami. These filmmakers often emphasize slowness through elongated pacing in order to evoke contemplation and "pensiveness" from its spectator. David Bordwell points out that under the classical Hollywood mode of production the long take was often avoided because it can potentially disclose the apparatuses that create a film's narrative world. The importance of the linear ordering of time and the invisible editing style is that they create the illusion of seeing through the text.

Drawing upon the films Children of Men (2006), Cloverfield (2008), and War of the Worlds (2005), chapter one argues that the velocity of the long take can sustain the illusion of transparency of the moving image without destabilizing narrative time and space. Using Stuart Hall's model of articulation, I argue that technology can change the 
vision of filmmakers, and, in particular enables the long take to be used as an expression of speed, but also inversely, that the visions of filmmakers can impact technological advances such as new camera supports and digital technologies. To explore this phenomenon, I draw upon Mary Ann Doane's work on the contingent and the emergence of cinematic time. Doane argues that the force of the contingent is what resists meaning and destabilizes an ordered sense of time. I argue that the long take as a form of speed illustrates the contingent as both "lure” and "threat.” Today's digital media and advances in camera supports have made it easier for filmmakers to move the camera through space. More specifically, digital technologies can remove unwanted objects within the frame, which, in turn, raises questions of indexicality and its relationship to capturing physical reality. D.N. Rodowick claims there is a waning of indexicality in digital video, because it does not directly capture physical reality but instead quantifies the physical reality through binary code of digitalization. I argue, on the contrary, that digital video sustains a direct connection to the index. This is because the desire for the instantaneous is also connected to the contingent, and therefore "wedded" to the index.

Recently, critics have raised concerns about the status of slow cinema in alternative cinema. For example, Sight \& Sound editor Nick James' editorial "Passive Aggressive” criticizes the use of the long take as a way to attract "an easy life for critics and [film festival] programmers.” James asserts, "Slow Cinema has been the clear alternative to Hollywood for some time, but from now on.... I'll be looking out for more active forms of rebellion.” James' criticism is directed at the increasing occurrences of slow cinema in recent art-house films. It is, as he calls it, "passive-aggressive," suggesting that slow aesthetics "demand great swathes of our precious time to achieve 
quite fleeting and slender aesthetic and political effects: sometimes it's worth it, sometimes not.” For James, the art-house culture has lost something of its essence with the emergence of bloggers and online criticism, a development which he negatively describes as “dominated by an inward-looking, worshipful fan-boy contingent more interested in finding more obscure directors to deify than in engaging with cinema out of desire” ("Passive”).

IFC (Independent Film Channel) blogger and Sight \& Sound contributor Vadim Rizov echoes James' criticism of the trend in slow cinema in recent art-house cinema, noting that it features "movies that show up expecting to be hailed for their high seriousness without earning it first.” Rizov states, "In the modern slow cinema, boundaries aren't getting pushed: people are operating within a recognized, default artistic idiom. That suggests people are missing out on the chance to push the medium forward (wherever 'forward' might be located)” (“Slow”). For Rizov, by contrast with traditional films, slow cinema requires more pensive and "cunning” viewers in order to catch the narrative's subtle nuances, which new art-house films lack in their use of the long take.

James and Rizov's argument about the long take and the political has similarities to former Cahiers du cinema editors, Jean-Luc Comolli and Jean Narboni’s essay, “Cinema / Ideology / Criticism,” which critiques ideology and realism, and its relationship to film spectatorship. They note, "Cinema is one of the languages through which the world communicates itself to itself. They constitute its ideology for they reproduce the world as it is experienced when filtered through ideology” (689). Realism, for Narboni and Comolli, is reactionary because it reproduces and values the dominant 
ideology by disguising the components that build a film's virtual world. Narboni and Comolli's posit that the elements that create the illusionary world of cinema have to be denaturalized for viewers in order to "sever the connection between cinema and its ideological function” (689). Realism, from this perspective, is linked to a comfortable and passive spectatorship thus, suppressing the possibilities of resistance to the status quo. They add, "They [films imbued through the dominant ideology] are very reassuring for audiences for there is no difference between the ideology they meet every day and the ideology on the screen” (690).

From this perspective, the speed and pacing of a film has a similar ideological function in the dominant mode of filmmaking. Immediacy helps to create transparency as well as immersing viewers into the story's world. Hollywood's narratives are traditionally built on linear, successive ordering of fictional time and space as a way for viewers to anticipate future events of the story without drawing significant attention to its artifice. In other words, the calculated speed of a film through the invisible style of editing “erases” the film's "brush strokes," allowing viewers to see through, rather than at, its surface (Bolter and Grusin, Remediation 24-25). The question, then, is whether (as James and Rizov seem to argue) by becoming the new standard device for alternative cinema, the resistive or political impact of the long take is diminished.

Chapter two explores the question of a film's political content in connection with the long take in Gus Van Sant's Elephant (2003), an independent film based loosely on the events of the Columbine high school massacre that occurred in April 1999. I argue that deliberate use of slow long takes does not necessarily mean temporal and structural disruption solely for the sake of "progressive" political effects upon its spectators. Nor 
should it suggest that the long takes cannot produce narrative tension and character consciousness. The intentionally slow duration of the long takes in Elephant both supports a political dialogue and creates an interactive and exploratory spectatorship. I make this claim in the context of pointing out that the non-linear presentation of the long takes in Elephant is characteristic of a database narrative and video gaming perspective. Given that video gaming and the Internet were highlighted as possible causes into the Columbine shootings, the long take calls upon viewers' memories of the event, and subsequent debates on the marketing of violent entertainment to the youth. The challenge of watching Elephant is its refusal to offer solutions or closure on those very issues, such as bullying, video gaming, and gun violence. I then argue that the political resides in the film's invitation to viewers to make sense of the story's narrative blanks generated by the ambiguity of the long take. At the same time, the film fulfills functions of traditional realism in its uses of speed ramping and video-gaming aesthetic to generate dramatic tension and character consciousness. From this standpoint, ideology does not have to be exposed in order for a film to generate political effects. Rather, the political is located in Elephant's invitation to viewers to map and build their own "narrative paths" out of its disparate pieces.

Turning to the medium of television, chapters three and four examines the role of speed is offering new ways of seeing the televisual text in the digital age. Specifically, these chapters consider David Lynch and Mark Frost’s television series Twin Peaks (1990-1991) and David Chases' The Sopranos (1999-2007) as representative of Laura Mulvey's concept of the "cinema of delay.” I suggest that we refer to them as examples of the "television of delay" in order to distinguish them from the cinema of delay, which 
is a self-enclosed narrative constructed for a single sitting. These seminal series illustrate changes in television's style and modes of narration, as well as the new economic and technological conditions of postmodernity.

The 1980s was a transitional decade for television. To compete with the increasing popularity of cable and satellite television, the major networks began to reconstruct their mode of production. In his book Televisuality, John Caldwell points out that one of these structural changes was to transform television as a self-conscious and highly visual medium in order to market and distinguish its products. I argue that these new processes are a result of the impact of flexible accumulation and the compression of time and space upon the television industry.

David Lynch, Mark Frost, and David Chase seized upon these new opportunities by introducing art-house and European styles of cinema into primetime television. Here, I provide a formal analysis of both shows in order to show how delay and movement are aesthetically represented in the television medium. I argue that narrative digressions and the intrusions of delay halt the narrative flow in order to evoke the uncanny, the absurd, the surreal, and the transcendental. I also argue that in certain instance these digressions advance the narrative action through the character's magical-like or supernatural deduction. This is most notable in both shows use of the dreamscape. As Chase states, "We've used...dreams to further the narrative” (qtd. in Sepinwall, "Dreams”).

Here, I examine two key dream sequences in both shows. The first is the infamous red room sequence in episode three, season one of Twin Peaks. The other is the 23 minute dream sequence in the episode "The Test Dream" in season five of The Sopranos. I argue that the dreams provide a conduit or gateway for characters to 
overcome obstacles within the everyday world. For Dale Cooper (Kyle MacLahan) of Twin Peaks, the red room dream sequence provides clues to solving the crime of who killed Laura Palmer (Sheryl Lee). For Tony Soprano (James Gandolfini), it is not so much about decoding the objects within the dream for meaning. Rather, the experience of the dream itself helps him to overcome his reluctance to kill his cousin, Tony Blundetto (Steve Buscemi) for taking part in the unauthorized murder of a New York gang member. From this perspective, digressions in both shows oscillate between decelerating the unfolding of time and space, as well as manifesting into unspoken or magical-like deductions that progresses narrative action.

Chapter four continues to explore these two shows by looking at their reception. More specifically, I spotlight the notion of narrative closure in connection with Mulvey's concept of the pensive and possessive spectator, and its relationship to time and memory. These modes of viewership, I argue, provide insights into the controversial ending of the last episode of The Sopranos, and the pressure that ABC and eager viewers put on Lynch and Frost to reveal Laura Palmer's murderer sooner than later in Twin Peaks. The abrupt cut to black that completes The Sopranos' saga left the narrative in a state of disequilibrium, providing no answers into Tony's fate. Narrative deferral, I argue, elicits a pensive spectator to contemplate and reflect upon the text's ambiguity. However, many viewers who were looking for closure were dissatisfied with the ending, and, subsequently, crashed HBO's website in search of answers. Closure and visual pleasure, in this sense, has an intimate relationship to speed, because it offers immediate gratification in the resolving of cause and effect. The controversial ending of The Sopranos denies viewers the possibility to repeat or "possess" the image, revealing a 
tension in the encoding and decoding of the text. Furthermore, the pensive and possessive modes of spectatorship raise questions of ownership of the text. This was the case when ABC and eager fans put pressure on Lynch and Frost to reveal Laura’s murderer sooner than later. The time between Twin Peaks and The Sopranos provides insights into changes in the production and reception of the televisual text. More so, they offer insights into technological advances and speed in which culture communicates and circulates information.

Since the release of the Dogme 95 films The Celebration (1998) and The Idiots (1998), and the box office success of The Blair Witch Project, there has been a tremendous increase in independent digital features at the turn of the millennium. Films such as Julien Donkey-Boy (1999), Bamboozled (2000), Chuck \& Buck (2000), Time Code (2000), Tape (2001), Waking Life (2001), The Chateau (2002), Tadpole (2002), 24 Hour Party People (2002), Pieces of April (2003), and 28 Days Later (2003) all were shot and edited using digital technology. Chapter five will explore the role of digital technologies of speed as a form of communication and its impact on the formation of publics and communities. Specifically, I will focus on a small underground film development called "mumblecore” that emerged in 2005 at the SXSW Film Festival.

Since the coinage of the term, there has been debate amongst critics and writers on how to categorize these films, and whether mumblecore constitutes a new cinematic movement. Rather than trying to resolve these questions, I will look at the conditions that have led to the formation of this movement, and examine some of features of mumblecore that differentiate from past formations of independent and DIY cinema. To answer these questions, I consider new media technologies and online social media, and 
how they benefit independent and DIY filmmakers. I argue that the highly personal aspect of mumblecore and the shared sensibilities and "structure of feeling” of its filmmakers collectively exhibit, constitute what Michael Warner describes as the social imaginary and "world making" function of a counterpublic_- "a public...understood to contravene the rules obtaining in the world at large, being structured by the alternative dispositions or protocols, making different assumptions about what can be said or what goes without saying” (56). Thus, like the Video Archives gang in the 1980s, mumblecore can be seen as providing a basis for this formation of a new (albeit small) public in independent cinema, developed out of social networking and web-related film distribution and production technologies. But an important difference in the emergence of mumblecore is the role of the Internet and its relationship to traditional publics. To understand this process, it is important to distinguish traditional publics organized by “texts through time," such as newspapers and magazines, from virtual publics that are also formed around texts, but are de-centralized and available instantaneously, such as video content on YouTube, or 24/7 access to online websites. The former I shall refer to as material publics and the latter as online publics. The key to understanding these two publics is to not see them as mutually exclusive realms. Rather, the two formations of material and online publics interface and feed off of each other. For example, the social networking of fans of a cult film can materialize in the public screening of the film. I argue that mumblecore as a counterpublic is located at the interface of these two spheres. In this respect, mumblecore represents demonstrates how a sense of place and community can be sustained in the context of the acceleration of culture. 


\section{Chapter One}

\section{The Velocity of the Long Take}

We had to take a lot of things that were really well-rehearsed and find a way to make them seem accidental... (qtd. in Levy, "Cloverfield”).

---Matt Reeves, director of Cloverfield (2008)

The Hampton robbery scene in Joseph H. Lewis’ crime drama Gun Crazy (1950) has become one of the most celebrated examples of the long take. The sequence involves a bank heist—which takes place from a point of view of the outlaws Bart and Annie, played by John Dall and Peggy Cummins. The scene begins with Bart and Annie driving through a small town, pulling up alongside a bank, Bart exiting the car and entering inside the bank. While Annie waits for Bart, she distracts a nearby police officer by talking to him, and then knocks him out when Bart exits the bank with the stolen money. Both get back into the car and quickly drive out of a town—all in one continuous shot. According to Lewis, the scene was four pages long and scheduled for eleven camera shots, but he decided to film the scene in one long take. To create the sequence, Lewis used a stretch Cadillac and removed all of the seats to fit the camera operator and a bare bones production crew. Instead of following the script, Lewis had both actors Dall and Cummins improvise their dialogue to enhance the suspense and realism of the scene. Lewis stated that the scene was so real that, "Off-screen there were people that yelled, 'They held up the bank, they held up the bank'...none of the bystanders [of the town] knew what we were doing. We had no extras except the people the policeman directed. Everything — cars, people-was there on the street” (qtd. in Kitses 47). At the time, there 
were no camera supports for a travelling car shot for on-location photography. ${ }^{8}$ This required Lewis and his crew to rig the Cadillac in order to achieve a long take that was not only both fast and fluid, but also intense enough that viewers root for Bart and Annie’s success getaway.

The twelve minute long take ambush car sequence in Alfonso Cuarón’s sci-fi political thriller, Children of Men (2006) has also become a landmark continuous shot. The long take involves Theo (Clive Owen) and the underground immigrant rights group called “The Fishes” transporting Kee (Claire-Hope Ashitey), a “miracle” pregnant refugee, to a group of scientists called the "Human Project" who are trying to find the cause of the worldwide plague of infertility. Unexpectedly their car is ambushed by an armed gang. As in Gun Crazy, almost the entire scene unfolds inside the car as if viewers are following alongside the characters. Using a furnished car made specifically for this complex “claustrophobic” long take, Cuarón’s cinematographer and his crew laid "PowerSlides," tracks on the roof of the car in order for the camera to fluidly slide back and forth. Attached to the camera was a newly developed technology called the "Sparrow head." Controlled by a joystick, the Sparrow head allowed for precise camera movements, offering a full range of vision occurring both inside and outside the car. Similar to the improvisation by Dahl and Cummins in Gun Crazy, the actors during the scene did not know when the camera would be filming them, which gave their performances spontaneity, as well as enhancing the suspense and speed of the long take. But unlike Gun Crazy, this long take took eight days to shoot. And, strikingly, the long

\footnotetext{
${ }^{8}$ Travelling car shots often use the special effect of "travelling mattes," which combine or "composite" separate pieces of film footage. For example, a character driving a staged car in the studio is combined with the background footage of an actual travelling car.
} 
take was shot in six sections, joined through digital compositing and invisible transitions, giving the illusion of continuous time and space (Fordham, “Human” 39).

I have chosen to use these examples of the long take for a number of reasons. For one, both examples clearly provide insights into technological advancements of camera supports and digital effects over the past fifty years. Secondly, they show that the long take can be immersive, as well as a form of shock and spectacle. Thirdly, and most importantly, they are examples of how consumption can impact the production of the moving image.

To clarify this last point, let's take a closer look at the epigraph in the making of Cloverfield, a film that tells the story of a group of five New Yorkers during one night when a gigantic monster descends upon the city, shown through the "found footage" from a digital camcorder. The long takes in Cloverfield are a unique example of a frantic style of filmmaking, where the moving image is presented to viewers entirely from the perspective of a personal camcorder. Certainly handheld photography is not a new technique in the history of filmmaking, and is often seen in documentaries or fictional cinema that formally attempts to create a "reality effect," either in an entire film or in a specific scene. Of course, I am not suggesting that the handheld technique does not play a similar role in creating the intensity and franticness of Cloverfield. Rather, Matt Reeve’s comment about the “well-rehearsed” scenes made to "seem accidental” in Cloverfield is informed by the impact of viral videos and social networking, or what J.J. Abrams, the film’s producer, referred to as "YouTube-ification.”

The amateur quality of the long take in Cloverfield that attempts to digitally create an illusion of a "homemade catastrophe," demonstrates the interrelatedness of the 
production and consumption of a cultural object. It is a process that Stuart Hall describes as articulation, the linking and unifying of disparate elements into practices of meaningmaking. Hall notes, "An articulation is thus the form of the connection that can make a unity of two different elements, under certain conditions. It is a linkage which is not necessary, determined, absolute and essential for all time” (“Articulation” 53). For Hall, articulation is open, indeterminate, and contingent; it is a process of negotiation, not fixed across various discourses, but instead occurring at sites where disparate elements "that form a temporary unity" under certain circumstances. As Paul du Gay et al. note, "Rather than privileging one single phenomenon—such as the process of production—in explaining the meaning that an artefact comes to possess...it is the combination of processes [e.g. representation and consumption]—in their articulation—-that the beginnings of an explanation can be found" (3).

Drawing upon Cloverfield, Children of Men, and War of the Worlds (2005), this chapter argues that the velocity of the long take is able to sustain the illusion of transparency of the moving image without destabilizing narrative time and space. It suggests that technology can inform the long take as an expression of speed. Inversely, visions of filmmakers can impact technological advances. To explore this phenomenon, I draw upon Mary Ann Doane’s work on contingency and time in early cinema. Doane points out that contingency and the film's mechanical moving image are both intimately connected to the irreversibility of the arrow of time. ${ }^{9}$ She adds that, "contingency

\footnotetext{
${ }^{9}$ The film's narrative, of course, can jump back and forth through time, which is achieved by the cut. This certainly does not mean that flashbacks and flash forwards cannot destabilize linear narrative order. Allan Cameron's reading of the a-temporal and a-chronological structure in Memento (2001) and 21 Grams (2003), for instance, makes note of flashbacks and flash forwards in the "breakdown in narrative hierarchy" in both films ("Contingency" 66). In this regard, linear narrative order and contingency are not mutually exclusive, but can negotiate between "temporal drift" and "temporal anchoring."
} 
emerges as a site of awe and fear, constituted as both lure and threat” (13). For Doane, "The lure of contingency...lies precisely in its resistance to systematicity, in its promise of unpredictability and idiosyncrasy” (225). She also argues that contingency can overwhelm and "threaten the crucial representation of totality, wholeness" (12). For Doane, the "double valence [of the lure and threat of contingency] is played out in the rapid representational transformations of the cinema" (144). In short, the significance of cinema lies in its capacity to both contain and exhibit the contingency of time as "lureand-threat.”

In this context, the "lure" of the long take in these three films is to register and contain, as well as frame and display the contingent. I argue that, in certain cases, the desire to contain the contingent can lead to new camera support technologies. In terms of reception, the "lure" of watching "real time" in the long take, lies not only in introducing the "threat" of the unexpected, but the desire for the instantaneous and pure presence of time. ${ }^{10}$ For example, the "real time" effect in the bank robbery scene in Gun Crazy situates viewers with a high level of suspense and anticipation as a "lure-and-threat.” Will Annie and Bart get away in time? And in Children of Men: will Theo and Kee escape the rebels' attack and make it to the "Human Project?"

Lastly, today's post production digital technology has the capability of removing undesirable elements that occurred during production; it can slow down and manipulate the speed of the moving image as well as creating movement in the shot itself. It can even digitally disguise transitions in the long take as noted in Children of Men. The last section of this chapter considers D.N. Rodowick’s critique of digital video and analogue,

\footnotetext{
${ }^{10}$ It is important to stress that "real time" is isomorphic with profilmic time. The long take is not truly representing real time, but simulating it.
} 
and their relationship to time, the index, and the ontology of film. Rodowick argues that there is a diminishing of indexicality associated with digital video, because computerized binary code "quantifies” rather than, as Bazin puts it, "embalms time.” Digitalization, according to Rodowick, may have potential repercussions for how viewers perceive the moving image. Drawing upon Doane’s work on the emergence of cinematic time, I argue that the element of contingency and the "ephemeral chance" is bonded to the production and consumption of the moving image. Indexicality certainly has a different technological relationship to the computerization of physical reality. I argue, contrary to Rodowick, that digitalization does not diminish the importance of the index, because indexicality also has a privileged connection to contingency and the indeterminacy of the instant and pure presence of time. In this respect, the model of articulation, and the forces of the contingent and the instantaneous provide a pathway for exploring the long take as a form of speed and narrative immersion.

\section{Contingency and the Emergence and Standardization of Filmic Time and Space}

The camera’s ability to frame and make "legible” the contingent offers insights into unpacking the velocity of the long take as a form of speed and immersion. Contingency, as Mary Ann Doane points out, was a central attraction in the emergence of cinema at the turn of the twentieth century, because it "proffers the subject the appearance of absolute freedom, immediacy, directness” (11). For Doane, contingency is "irreducible" to the structuring and systematic ordering of time; it is what resists interpretation. Drawing upon Charles S. Peirce, Doane argues that the contingent is linked to the instant, "a point" that is ungraspable because the subject is "riven by delay." The present and the past cannot be detached from each other, because they are bound 
together in "the continuum of time," making impossible the "pure experience of the present” (101). Drawing upon Henri Bergson and Peirce, Doane adds that the present is always “contaminated" by both memory work and temporality and thought. The moving image, however, allows for the documentation of the past, arresting and framing the contingency of time. Doane notes, "The significance of the cinema...lies in its apparent capacity to perfectly represent the contingent, to provide the pure record of time” (22). The camera's ability to render the raw materials of daily life transfers and structures the contingency of time into an event and durable record.

According to Doane, modernity had tendencies of both the "rationalizing" and the “abstraction” of time. On one hand, modernity's large institutions, division of labor, newly created world time-zones, and the disciplines of science attempt to manage and control the contingent. But modernity also "valorizes" the contingent, for example, in photography, impressionism, and, of course, cinema (10). The appeal of cinema at the turn of the twentieth century was that it countered modernity's systematic ordering of time by putting the contingent on display and making it "legible.” Doane specifically cites "actualities film" as the most dominant genre of early cinema. These early films captured "that which happens," thus allowing audiences to experience the contingent on display: for example, the demolition of a building, the arrival of a train, or the death of an elephant.

But as filmic discourse developed into a narrative system linked to the emerging Hollywood studio, it standardized filmic time and space. For the classical narrative to create the illusion of a seamless and transparent story world, shots must be organized in a manner that does not aesthetically reveal gaps in the construction of time and space. This 
is typically achieved through a process that David Bordwell describes as "decoupage," which he notes is "the mapping of the narrative action onto cinematic material" (60). Bordwell argues that Hollywood's handling of narrative temporal and spatial order has to be clearly motivated. As an example, he cites the frequent uses of the deadline or appointment narrative as a mode of storytelling. The deadline narrative fits nicely with goal orientated stories, and thus, suppresses their artifices of cinematic production (more to come on this in chapter four).

Speed has a privileged relationship to the invisible editing model because it immediately removes the presence of mediation for the purposes of narrative immersion. Narrative time and space are constructed through the mode of practices created by the classical narrator system, and these modes, according to Bordwell, must be compressed or remain absent within the story in order to create the illusion of a unified and transparent system of storytelling. Therefore, shot duration must be directed towards the resolution of suspense. The management of cinematic speed creates a narrative rhythm and increases excitement. Shot length becomes crucial in terms of compressing gaps and avoiding lingering dead time. Bordwell notes, "When this does not happen, when the narration dwells upon 'dramatically meaningless intervals,' duration comes forward as a system in the film and vies with causality for prominence" (47).

Jay David Bolter and Richard Grusin describes this process in terms of their concept of hypermediacy, which they identify as foregrounding mediation, thus offering "a heterogenous space....in which representation is conceived of not as a window on to the world, but rather as 'windowed' itself” (34). By emphasizing dead time within a film's narrative or dwelling longer on images that are ambivalently motivated, the system 
of mediation reveals itself to viewers. Instead of punctuating narrative causality, the film begins to question or comes into dialogue with the construction of time and space itself. For this reason, once the story is broken down and divided into shots, long takes are usually or almost always discouraged, because they draw attention to the film's mediation of time and space.

Bordwell goes on to argue that the majority of Hollywood films (during the classical period) did not exploit long takes as a means of narration in order to subordinate the film's construction of time and space. The emergence of the continuity editing model structured and orchestrated the contingent for the purposes of narrative and psychological causation. But, as we shall see later in the chapter, the long take as a form of speed can be just as immersive as the continuity editing system, and allow for the presence of mediation without destabilizing the film's system of time and space.

Although the emergence of the studio system began to systemize filmic time and space, the element of contingency and "chance” remained prevalent in the production and consumption of the moving image. ${ }^{11}$ This is because, as Doane notes, "Only chance can explain the new; only chance can account for the overwhelming diversity and variety in the universe” (100). In short, contingency and chance set up the conditions and possibility for the new. The long take provides an exemplary site for contingency and the emergence of the new. ${ }^{12}$ This is notable, for example, in the early 1920s when the

\footnotetext{
${ }^{11}$ Of course, this is not to suggest that editing and other elements of filmmaking are not susceptible to the force of the contingent. Despite classical cinema's systemization of the representation of time, Doane points out, they "continued to exploit the idea of the filmablity of the contingent without limit" within the mise en scene (230). Consider set designs and costumes and story worlds that appear as "uncontaminated" by modernity's systematic ordering and rationalization of time in everyday life.

12 For this reason, the production of elaborate long takes often requires a different mode of preproduction in order to prevent mistakes during filming. It can even require the development of new technologies, as well shall see later in the chapter. Consider the digital film Time Code (2000) which is made up of four 90
} 
expressionistic style of European cinema began to challenge the standard method of editing and shot construction. German filmmaker, F.W. Murnau's use of the "unchained" and mobile camera in The Last Laugh (1924) provides an early example of the long take. Murnau's flowering use of filmic time and space evokes both the "lure-and-threat" of the contingent, as well enabling new possibilities for cinematic expression.

Murnau's employment of the mobile long take both physicalizes character psychology and embodies narrative tension. For instance, in the second shot of the film, the image travels towards the hotel's revolving doors. The image holds as the doors spin in the foreground, while in the background pedestrians exit a cab. Within the same image, the door man (Emil Jannings) emerges out of the bustling city street and approaches the spinning doors. The long take in this scene shows how information within the frame can elicit a sense of urgency and quickness within the cinematic space. Once the image is fixed, we see multiple planes of temporality existing in one frame.

The Last Laugh is one of the first films to track the camera backwards and forwards, up and down and side to side as a mean to express character interiority. Murnau’s cinematographer, Karl Freund, termed this technique as the "unchained camera," which allowed for elaborate mobile shots such as the opening image that descends within the hotel's elevator (Cook 127). The Last Laugh is part of a group of films Carl Mayer termed the "Instinct Theatre." David Cook notes that the "instinct" film generally avoided intertitles, contained few characters, and "dealt realistically with oppressiveness of contemporary lower-middle-class life, and by extension, with

minute long takes, running simultaneously with the screen divided into four quarters. Even though the film was improvised, director Mike Figgis needed an outline of the story in order to prepare for the shoot. Since the screenplay format cannot show four simultaneous events, he used sheet music where each character represented a color-coded musical bar-line in order to match the unfolding of events in a horizontal and parallel pattern. 
irresistibility of fate in a disintegrating society” (126). In its treatment of narrative materials and formal experiments, Murnau fused social realism of the instinct film with expressionism, for example, in the portrayal of the aging doorman and the lower-middle class tenement he lives in. At the same, he utilized the unchained camera as a way to capture his psychological state within the doorman's circumstances. In their dealing with the collapsing and uncertain world of the doorman after he loses his job, contingency and its resistance of systematic time both become a part of the narrative. At the same time, contingency sets the condition for new visual experiments outside of the classical model of narration, as illustrated in Murnau's mobile camera work and expressionistic long takes.

\section{Technological Advances and their Influence on Speed and Shot Duration}

Murnau's complex camera movements created a new level of cinematic narration that had never been captured in cinema before. His process of visualization not only revealed the possibilities of the film camera, but also created new representations of filmic time and space through the marrying of artistic vision and new technologies. But the process of moving the camera was very difficult for filmmakers during the early classical period. This was primarily due to the lack of camera support technologies. However, filmmakers were still able to find ways around these technological limits and, in certain cases, created new camera supports in the moment of production. In this regard, the desire for speed and movement in the long take had real effects in new technologies. Here, I would like to highlight some of the early advances in camera supports and explore their impact upon the speed of the long take and Hollywood's mode of production. Tracing these early technological advances will provide a context for 
understanding how today's digital technologies are offering new ways of seeing the long take. $^{13}$

Although most films of the early classical period did not employ camera mobility, Murnau's camera style made a strong impression on the world of Hollywood and camera technology of the 1920s. In Lutz Bacher's detailed research on the mobile long take, he notes that "The development of camera technology during the last years of the silent film was the direct result of this [Murnau's] influence” (16). Murnau's set designer Robert Herlth adds that after seeing The Last Laugh, Hollywood contacted UFA, Murnau's studio, asking what camera they had used. Herlth states that "It [the letter] added that in the USA there was no such camera, and no town to compare with the one in our film” (qtd. in Eisner 67). Almost all film cameras at the time were hand cranked by the camera operator. However, Murnau's cinematographer, Karl Freund used a Stachow camera which was much lighter and had a spring-motor cranking mechanism. ${ }^{14}$ These small but effective new advances in camera technology helped Murnau and Freund to focus specifically on sophisticated camera movements.

Furthermore, elaborate technological developments in the late 1920s and 1930s enabled the moving camera to shoot more expressive forms of cinema. In 1929, Universal Studios, under the direction of Paul Fejos, designed a camera crane for their musical Broadway. Barry Salt notes that this crane was used "to carry out long takes that

\footnotetext{
${ }^{13}$ It should be noted that other technological advances (alongside camera supports) also shaped the velocity of the long take such as better lighting apparatuses, improvements in film stock and automatic dialogue replacement (ADR). For a detailed account of these advancements, see Bordwell et al. The Classical Hollywood Cinema: Film Style \& Mode of Production to 1960. New York: Columbia University Press, 198 and Barry Salt’s Film Style \& Technology: History and Analysis. Third Edition. London: Starword, 2009.

${ }^{14}$ Freund used two cameras during the production of The Last Laugh for the purposes of creating three negatives for the export of the film. The other camera was a pathe-industrial camera. The Stachow was specifically used for camera movements.
} 
traversed the many levels of the vast night club set during the musical numbers, but not for the dialogue scenes” (203). This was because the early development of film sound imposed limits on camera mobility. Cameras had to be placed in a glassed booth (called "blimped cameras") to prevent the microphone from recording camera noise during the filming of a take. In musicals, however, because the sound was laid down during post production, the camera was allowed to move more freely through cinematic space. In general, the majority of expressive mobile camera movements and/or long takes during the 1930s were found in the musical genre.

During the 1940s, however, there was an increase in the use of the crane for mobile long takes outside of the musical genre: the ball sequence in Orson Welles' The Magnificent Ambersons (1942), and the crane movements in the Penn Station scenes in Vincent Minnelli’s The Clock (1945) are two early examples. But probably the most significant invention of the 1940s was the crab dolly, a camera support which allowed for more flexibility of movement. During the filming of Alfred Hitchcock’s The Paradine Case (1947), cinematographer Lee Garmes and his camera crew had to solve the problem of filming a complex travelling long take. They came up with a four-wheeled dolly which permited the camera operator to move forward and turn sideways at a 90 degree angle—a method of steering termed "crabbing." According to Garmes, the crab dolly "offered for the first time the means of shooting a continuous take and at the same time afforded all the variety of viewpoints that ordinarily would be achieved in a succession of takes made with the camera in different set ups at different angles” (qtd. in Bacher 7475). The crab dolly proved to be fruitful in Hitchcock's experiment with extreme long takes in Rope (1948) because the camera operator could follow the characters through 
space without jerky or obtrusive movements. The technology of dollying also helped Hitchcock solve the set problem of moving the camera from room to room. He placed the walls and furniture on wheels, so they could be easily and quietly pushed aside as the camera and characters moved in tandem. The invention of the crab dolly laid the groundwork for further employment of the long take in the cinema of the 1950s, as seen in the works of directors Vincent Minnelli, Otto Preminger, and Max Ophuls. ${ }^{15}$

In Lotte H. Eisner's book on Murnau, she refers to notes typed by Murnau in which he expresses a wish for "Father Christmas [to create] a camera that can move freely in space.... What I mean is one [a camera] that at any moment can go anywhere, at any speed. A camera that outstrips present film technique and fulfills the cinema's ultimate artistic goal” (84). Murnau's wish practically came true in the 1970s with Garrett Brown's invention of the steadicam. The steadicam is a camera support that physically attaches to the camera operator's body as he or she tracked its subject. Handheld photography had already established itself as a style employed by narrative filmmakers and documentarians, but the steadicam could not only track its subject with fluidity, but could also run in the pro-filmic space without the camera obtrusively bouncing up and down. Early examples of steadicam movements can be seen in Hal Ashby’s Bound for Glory (1976), John Avildsen’s Rocky (1976), and Stanley Kubrick’s The Shining (1980).

The Louma crane was another camera support developed in the 1970s that helped to shape the mobile camera. Designed by Jean-Marie Lavalou and Alain Masseron, the

\footnotetext{
${ }^{15}$ It is interesting to note that the emergence of CinemaScope in the 1950s also had an effect on average shot length. This was primarily due to a technological factor of distorted "close views." David Bordwell notes, "In the late 1950s Panavision lenses eliminated the peculiar distortions of close views yielded by CinemaScope's anamorphic process. American filmmakers could now return to over-the-shoulder framings and strong singles decoupage” (Traces 150).
} 
Louma crane allowed filming in difficult or unaccommodating spaces by using precise camera movements that would be impossible for a human camera operator to achieve. The crane had a tubular arm that extended 23 feet with the camera mounted at the end. The Louma crane was the first camera mount that use remote control technology to film complex camera movements. The crane was operated by a "stepping motor," which Salt notes is "a small electronic motor in which the drive shaft could be controlled electronically to turn through an exact fraction of a revolution in either direction, rather that just rotating continuously in one direction” (315). The Louma crane was brought from Paris to Hollywood in 1978, and first used on Steven Spielberg's 1941 (1979).

Unique to both the Louma crane and the steadicam was the use of a video monitor known as the video assist. ${ }^{16}$ The video assist diverted light from the camera's viewfinder into a video monitor for the camera operator and director to view and track the subject's movements in space. The video assist could also be used for instant playback. ${ }^{17}$ But more importantly, the interfacing of the video monitor allowed for more sets of eyes to work in tandem with the perspective of the camera operator, allowing better precision in the filming of complex takes, as in the intricate steadicam movements through the corridors of the hotel in The Shining.

The interfacing of the video monitor in The Shining returns us to the "lure-andthreat" of the contingent in the speed of the long take. Kubrick is an exemplary filmmaker who embraced new technology in order to create a calculated cinema.

\footnotetext{
${ }^{16}$ It should be noted that the video assist was not made specifically for the steadicam or Louma crane. It was first used on Jerry Lewis’ The Bellboy (1960).

${ }^{17}$ For a full analysis of video assists, see Stephen Prince's A New Pot of Gold: Hollywood Under The Electronic Rainbow, 1980-1989. New York: Charles Scriber’s Sons, 2000. pp. 111-115.
} 
Kubrick's precise filmmaking reflects the regimented and systematized worlds (past, present, and future) depicted in his films. ${ }^{18}$ This is often noted in Kubrick's symmetrical framing of objects. At the same time, there is the "lure" of displaying the contingent as a "threat" for viewers within these stringent environments. For instance, the speed of the long take of Danny traversing through the corridors on his big wheel bike has a videogaming perspective (more to come on this in chapter two), immersing viewers into a selfcontained world of the Overlook hotel. The movement through the labyrinth spaces against the film's haunting soundtrack builds anticipation and suspense towards what lies ahead and lurks around the corner, as in Danny's terrifying encounter with the ghost of the Grady twins.

Tracing Murnau’s motor-cranked “unchained camera” to Kubrick’s lucid and ethereal steadicam movements demonstrate the significant advances in camera support technologies and camera movement. The Louma crane and steadicam are examples not only of the camera helping to capture new and dynamic expressions of filmic time and space, but also of how video wave optics begins to interface with the production and aesthetics of filmmaking, gesturing towards the emerging world of digital technologies and computer-generated images (CGI).

\section{Digitalization, Postmodernity and Competing Narratives}

Today, digital technologies allow for even more precision and movement through space in the filming of the velocity of the long take. The combination of film and new digital media offer filmmakers a variety of new forms of temporal and spatial framing. In The Language of New Media, Lev Manovich points to the use of digital compositing and

\footnotetext{
${ }^{18}$ See James Morrison’s “The Old Masters: Kubrick, Polanski, and the Late Style in Modern Cinema.” Raritan 21 no2 Fall 2001.
} 
its ability to render various images into a fluid, seamless and continuous shot. This is not to suggest that early filmmakers did not experiment with techniques as in the process of matting to create transparent images. For example, the famous deep focus shot of young Charles Foster Kane in Citizen Kane (1941) playing with his sled in the background while his parents prepare for his departure, was created through the process of matting and keying. But, with the state of the art simulation technologies, films are able to incorporate many layers blended together within the frame, such as virtual actors, crowd sequences and matted paintings with live action recording. Furthermore, Manovich states, "Digital compositing does represent a new step in the history of visual simulation because it allows the creation of moving images of non-existent worlds" (153 Author's emphasis). New digital technologies not only allow the creation of new and imaginative virtual worlds, but also allow mobility within those specific dimensions. The uses of CGI effects become so life-like that the filming of a scene not only gives a sense of urgency and speed, but also shows how the long take (through the help of digitalization) enhances narrative immersion.

Steven Spielberg's adaptation of H.G Wells' War of the Worlds, for example, combined both live action and CGI effects to create a realistic and documentary-like effect. Spielberg uses blended long and sweeping takes in order to film Ray Ferrier's (Tom Cruise) escape out of New Jersey with his family in a speeding van while the “tripod-like” Martians are attacking the city with their heat-ray weapon. Spielberg had originally conceived of shooting the three minute scene in many cuts, but then decided to film the escape in one long take sequence shot. Manovich refers to this combination of live action and CGI 3-D as "synthetic realism.” For Manovich, "achieving synthetic 
realism means attaining two goals - the simulation of the code of traditional cinematography and the simulation of the perceptual properties of real life objects and environments” (191-192). For the first goal, like traditional photography, computer codes simulate a virtual camera that has lenses, depth of field, and lighting. For the second goal, however, the simulation of 'real scenes' become more complex, because the images are constructed from scratch, making the illusion of photo-realism harder to obtain. Although Manovich notes that the goal of computer-generated graphics is the achievement of photorealism, he also argues that synthetic photographs are more 'realistic' than traditional photographs because "the synthetic image is free of the limitation of both human and camera vision. It can have unlimited resolution and an unlimited level of detail" (202). In this sense, the synthetic image becomes "too real” or hyperreal. To make the synethic image appear more like traditional film photography, the resolution of the computer-generated images have to "diminish their perfection" as a way to match the details of the film's images by adding grain or diluting the color of the image.

The use of CGI in the long take in War of the Worlds renders a "real time" effect through shaky camera movement in order to create a sense of immediacy and suspense. But the documentary style of the long take in War of the Worlds is also part of the new landscape of science fiction cinema that stresses the imperfection of the image rather than the precision of it. This is notable in the degraded images and handheld camerawork in films, such as District 9 (2009), Star Trek (2009), and Terminator Salvation (2009). Nicholas Rombes argues, “There is a tendency in digital media —and cinema especially - to reassert the imperfections, flaws, an aura of human mistakes to 
counterbalance the logic of perfection that pervades the digital” (2). The promise of digital technologies and synthetic photography is the perfection of images and sounds without decomposing and deteriorating of its materiality. For Rombes, the emphasis on mistakes and "degraded representation of reality" is connected to death and the "human signature," as a means of counteracting the perfection of digital media.

The presence of mistakes is not only an allusion to human finiteness and death, but is also intimately aligned with the instant, the contingent, and the indeterminacy of time itself (Doane 145). From this perspective, the long take in War of the Worlds has a double logic in regards to narrative immersion and the emphasis on the imperfect. On the one hand, simulation technology renders life-like images of Ray Ferrier's escape from the Martians, which was not filmed on a real Interstate, but staged using green screen technology. Bolter and Grusin describe this process as "interfaceless interface” where 'the user will move through the space interacting with the objects 'naturally,' as she does in the physical world.... In this sense, a transparent interface would be one that erases itself, so that the user is no longer aware of confronting a medium, but instead stands in an immediate relationship to contents of the medium” (23-24). But there is also the handheld camerawork that aesthetically places emphasis on the artist or human presence behind the image. In this respect, the path to transparency in the long take oscillates between building artificial images through synthetic 3-D images in order to achieve synthetic realism, and regulating the presence of "mistakes" that works against the perfection of digital technologies.

But how does the emphasis on mistakes and accidents sustain transparency in the long take? And how do we account for the human presence that does stand between the 
“contents of the medium” and viewers' spectatorship? This returns us to the phenomena of "YouTube-ification." Films that employ degraded and shaky camera movement are connected to the emergence of digital media. Smart phones, mobile screens, wireless Internet, and small digital cameras allow for the instantaneous recording of events, which can be quickly uploaded to the Internet and shared with friends and family members through email and social networking sites. Many of these images have a homemade or amateur quality. In this respect, the presence of mediation is part of everyday life, transforming structures of perception, offering new ways of seeing the moving image. This is not to deny that the presence of mediation can also be distracting (more to come on this below). Rather, it is how the presence of mediation is articulated into the story world. This is exemplified in the point-and-shoot perspective, by creating a spontaneous and unpredictable style of photography, which positions viewers as a sort of witness to the event. This perspective is evident in the frantic long takes employed in the disaster/monster thriller film Cloverfield.

Cloverfield, as noted earlier, is the story of five New Yorkers who experience a night of attacks of a monster who descends upon the city. The film is experience entirely through the point of view a personal video camera, operated mainly by Hud (T.J. Miller). The camera documents the group's attempt to survive the monster's fury as the group moves through the city in efforts to rescue Rob’s (Michael Stahl-David) ex-girlfriend, Beth (Odette Yustman) who is trapped in a collapsed building. Similar to War of the Worlds, the film's depiction of billowing smoke from collapsed buildings and throngs of people crossing the Brooklyn Bridge evokes anxieties of terrorism of post 9/11 (Sanders 96-97). But the film also considers a new culture of the personal camcorder and mobile 
devices, where anyone can randomly and instantaneously capture and circulate public incidents. This is evident in the film's long takes and its emphasis on the point-and-shoot perspective, where zooms and fast pans elicit a sense of urgency and immediacy. Here, the film's illusion of amateur cinematography points to a new culture of digitalized media and instant communication. For example, shortly after the monster attacks the city, everyone at Rob's apartment huddles around the television to watch the news, which offers an instant feed of images. Suddenly, the building begins to quake, and Hud and his friends flee Rob’s apartment and join others on a crowded and distressed street. Filmed in one long and frantic take, the camera turns upon the avenue and suddenly, in the distance, the Statue of Liberty's head bounces off a building and crashes nearby as a group of people descend upon the statue's head, instantly documenting it with their smart phones. Shortly after the decapitation of the Statue of Liberty's head, smoke surges down the avenue from a collapsed building. As a crowd of people runs for cover, the point of view of the camera bounces up and down as Hud and his friends run across the street and hide in a store where a blast of smoke and debris rocks the building. Again, the images of dust and smoke allude to the traumas associated with the collapse of the Twin Towers during 9/11. Furthermore, the long take, presented as the documentation of an event, illustrates the "lure-and-threat" of contingency, the instant, and catastrophe that Doane identifies as an "intimacy between witness and event" (207). Here, the instant is connected to the desire for the pure presence of time, which Doane argues is impossible to obtain because we are always "riven" by the past and memory work. Whereas capitalism and the rise of industrialism sought to structure and order time, cinema framed and put the contingent on "display," making it "legible." In this sense, the shaky camera 
and immediacy of the long take in recent science-fiction cinema not only negotiates with the perfection of digital media, but also reflects upon conditions of postmodernity.

Jean-Francois Lyotard's The Postmodern Condition: A Report on Knowledge is often cited in noting the distinction between the social formations of modernity and postmodernity in terms of how knowledge is used and valued. Lyotard argues that totalizing and top-down systems of modernity are problematic, because they leave little or no room for differences and do not consider smaller narratives at a local level. In other words, one grand system cannot account for how knowledge is produced and legitimized in a given culture. Lyotard draws upon the field of science to explain this phenomenon. Scientific discourse uses its own models or paradigms in order to deduce or falsify claims and findings within their respective fields. But in order to explain "scientific statements" to the public at large, scientists must convey their knowledge using language outside of their discourse. Lyotard notes, "scientific knowledge does not represent the totality of knowledge; it has always existed in addition to, and in competition and conflict, with another kind of knowledge, which I call narrative...” (7). Scientific knowledge and narrative knowledge are two different types of discourses. Scientists have to explain their statements through narrative knowledge in order to convey information to a larger public. Narrative is how we communicate knowledge and understand who we are. But one system cannot speak to all the different types and processes of knowledge at work in society. Since different cultures will have different rules and processes of legitimizing and categorizing knowledge, they can compete with one another in what Lyotard refers to as "language games." 
Cloverfield, in its evoking of post 9/11 anxieties, addresses the problem of how to represent and document a traumatic event. Rather than seeking one narrative to explain the film's catastrophe, Cloverfield uses Lyotard's notion of postmodern competing narratives. The film's point-and-shoot long takes elicits a sense of urgency, constantly undercutting viewers' gaze. The "unprofessional” long take lacks fixity, presenting spectators with parts and fragments instead of the whole. The film's panicked camera style within the long take provides only glimpses or quick sightings of the monster, suggesting the impossibility of representing this large scale disaster through one point of view or one grand narrative. Yet, this persistent disruption of the gaze sustains viewer engagement, by piquing their desire to know why and what led to the invasion on the city, as well as calling upon the imagination to fill in what is not shown.

At the same time, throughout the documentation of the attack on the city, footage of Rob and Beth's prior trip to Coney Island intermittently intrudes into the film’s narrative. This is because Hud, who is operating the camcorder, is recording over Rob's original recording of the trip to Coney Island. For this reason, edits in Cloverfield are abrupt and spontaneous in order to mirror the turning on and off of the camera. Since Hud is unsure of how to properly use the camcorder, he occasionally causes the footage of Rob and Beth's original recording to surface as a sort of technical glitch. Rob and Beth's relationship serves as the film's subplot, which is manifested by a technical glitch, rather than through practices of traditional editing. But more importantly, the documentation of the disaster and the unprompted jump cuts between Rob and Beth’s trip to Coney Island act as two competing worlds: the attack on the city recorded by Hud, and Rob and Beth's personal recording. In this sense, two planes of time unfold for viewers: 
one of documentation of an event and the other of personal and home use. These two worlds of time interrupt and compete with each other throughout the film.

Children of Men similarly employs a method of competing narratives in its apocalyptic depiction of a future world in its use of the long take. But unlike Cloverfield, the long take allows viewers to fix their gaze within the shot, because the film wants to evoke a tension between the action unfolding in both the foreground and background. Slavoj Žižek argues that the true focus of Children of Men is the background. ${ }^{19}$ The dynamic of foreground and background plays an important function in the positioning of objects and their potential meaning. Žižek notes, for instance, the scene where Theo meets his cousin, Nigel (Danny Houston), who runs the ministry of the arts. As Theo enters Nigel's home, a large sculpture of Michelangelo’s David is seen the background. The statue of David, as Žižek states, is bereft of meaning, because it is "deprived of a world.” The same holds true for the re-creation of Storm Thorgeson's iconic image of Pink Floyds’ pig (taking from the album Animals) that floats in the sky seen through Nigel's window in the distance. The film's futuristic world sees immigrants and refugees as similarly deprived of a world. This is indicated in the action unfolding in the background rather than the foreground.

The film's use of background and foreground exhibits similarities to Andre Bazin's realist account of deep focus composition. Bazin argues that depth of field photography "is both a more active mental attitude on the part of the spectator and a more positive contribution on his part to the action in progress” (35-36). For Bazin, depth of field "preserves" the ambiguity of reality and evokes spectators to explore and map the shot in depth. By contrast, Brian Henderson notes Jean-Luc Godard "repudiates the

\footnotetext{
${ }^{19}$ See Children of Men's DVD and Blu-Ray supplement for Žižek's entire reading of the film.
} 
realist aesthetic.” Godard uses the flattening of space in the plane of perception of the long take (which Henderson identifies in the traffic shot in Weekend [1967]) in order to create critical viewers of the text. Henderson notes, “The viewer is not drawn into the image, neither does he makes choices within it; he stands outside the image and judges it as a whole" (65, Author's emphasis). He goes on to argue that the flattening of the background space in Godard’s long take in Weekend, “is a demystification, an assault on the bourgeois world-view and self image” (80). Children of Men utilizes aspects of both Bazin's and Godard's accounts of the long take, creating an immersive and political environment (more to come on this in chapter two). Cuarón’s visual effects supervisor Franz Churchill echoes this, stating, "Alfonso wanted to catch what he called 'moments of truthfulness' where the camera panned past characters to wander off exploring the environment.... It was a visual motif that used wide-angle lenses, which made every frame say something about the protagonists in their world” (qtd. in Fordham, "Human” 34). From this perspective, Children of Men has simultaneous and competing narratives (Theo's trajectory and events occurring in the background) which evoke viewers' curiosity and a desire to look within the mise en scene. Children of Men envisions a futuristic world where the fear of the other escapades into a world of dystopia and instability. The power of the deep focus and wide-angle lenses in combination with synthetic imagery in the film’s long takes invites viewers' to explore and navigate these worlds, thus creating a plurality of meanings.

As we have seen, the moving frame and speed of the long take in Children of Men, Cloverfield, and War of the Worlds heightens viewers' investment in the narrative, as well as giving these films a "reality effect," which I have argued is, in part, a reflection 
of the emerging culture of digitalization. Furthermore, it brings forth the speed of digital devices that are able to record instantly and transmit moving images that can be halted and replayed (more on this in chapters 3 and 4). But this certainly does not suggest that films that emphasize human presence through mistakes and accidents cannot also distract viewers from the text itself. The final long following take in "the uprising sequence” in Children of Men, where Theo navigates through the gun battle between the refugees and the British, offers an example of this conundrum of mediation and distraction. The scene was shot in six sequences using digital compositing and "invisible transitions" in order to give the illusion of one continuous shot. During one of the sequences, an explosion occurs as fake human blood splatters onto the camera lens. But within moments, the blood on the lens gradually disappears. According to Frazer Churchill, the film's visual special effects supervisor, the blood squib was detonated prematurely, and Cuarón was unable to stop the take because so many elements were happening at once. Here, the squib incident clearly illustrates the challenge of containing contingencies in the production of the long take. Cuarón decided to keep the mistake. But this required two tasks for Churchill and his special effects team: they had to digitally add more blood to mask the transition in order to enjoin the next sequence, and then digitally remove the blood from the entire image before it became a distraction (Fordham, "Human” 43). This brings me to the last section of the chapter, which addresses the question of digitalization versus analogue film in relation to temporality, indexicality, and film’s ontology. If digital media can remove unwanted objects within space or disguise a transition, does it alter the experience of passing time as well? What is at stake in the opposition between 
the binary code of digitalization and the analogue film's one to one relationship in its capturing and “embalming” of light and space?

\section{Digital, Analogue, Indexicality, and Time}

The removal of the blood on the lens in the long take in Children of Men raises philosophical questions in regards to the time, indexicality, and the past. These concerns, are not new, and can be traced back to the formalist accounts of Sergei Eisenstein's montage theory and Andre Bazin’s writings on deep focus and the long take. Eisenstein and Bazin’s accounts of shot length and viewers' relationship to the world make up a major component of classical film theory. These concerns pertaining to ontology and cinema’s essence continue to be addressed today. Lev Manovich argues that simulation technologies invert Sergei Eisenstein's dialectical montage. Instead of bringing forth the film's mediation through the collision of shots, the immediacy of simulation technology creates a transparent text. Manovich considers Eisenstein's techniques of montage in relation to simulation and new media technologies. Eisenstein’s dialectical montage posits that montage should operate as shots in conflict. Thus, conflict of shots, for Eisenstein, generates energy and creates an impression of movement. The relation between images is based on a formal conception of editing created by Lev Kuleshov called the "Kuleshov effect.” For instance, if you present a shot of a man with a blank expression, cut to shot of a bowl of soup and then back to the man with the same blank expression, spectators will fill in a third element: the man is hungry. In short, for Eisenstein, form determines the meaning of the shot-not the content. Manovich notes that the virtual image is there for viewers on the screen, but the mode of production that renders the reality (that is, the processes behind the scenes) is synthesized via the 
interface of the computer to offer the illusion of a seamless reality. He refers to this as "the aesthetic of continuity" (142). Manovich points out that, "Compositing in the 1990s supports a different aesthetic characterized by smoothness and continuity. Elements are now blended together, and boundaries erased rather than emphasized” (142). In other words, simulation technology arranges the components within a shot and renders them in montage like fashion to create a seamless film image.

Manovich addresses the question of what happens to film's indexical nature when we can modify and mold new images through digital technology. He argues that "this logic [of a digital moving image] subordinates the photographic and the cinematic to the painterly and graphic, destroying cinema's identity as a media art” (295). The ability to construct a computer generated image returns back to nineteenth century art which was created by hand. A new kind of cinematic realism emerges with computerization of the image, according to Manvoich: "the computerization of culture not only leads to the emergence of new cultural forms such as computer games and virtual worlds; it redefines existing ones such as photography and cinema” (9). For Manovich, the interfacing of computer generated images and in the production of the moving image has changed cinema's relationship to the index in the digital age. He argues that cinema is no longer an "indexical media technology but, rather, a subgenre of painting” (295).

In a similar vein, D. N. Rodowick's critique of simulation technologies investigates whether digital cinema can express duration. Specifically, he draws upon Russian Ark (2002), a 96 minute long take filmed in the Russian State Hermitage Museum using high definition video and composite imaging. Rodowick notes, “The key to resolving the discrepancy between Russian Ark's self-presentation and its ontological 
expression as digital cinema is to understand that it is a montage work, no less complex in this respect than Sergei Eisenstein’s 1927 film October” (165, Author’s emphasis). Rodowick identifies a contradiction in Russian Ark's experiment with the long take because it does not directly capture physical reality. Rather, it relies primarily on many “digital events” which involve digital capturing, synthesis and compositing. In this sense, the long take does not "embalm time" as Bazin argues. Rodowick concludes that analogue film has a different relationship to duration than digital cinema because of the mechanical and chemical processes that it uses in capturing the passing of time.

The long take in Russian Ark is a unique experiment in that its images are rendered mathematically via the binary code of computer language; whereas traditional photography captures light as it comes through the lens and penetrates the emulsion of the film, thus leaving a physical trace of reality. Film theory has drawn upon Charles S. Peirce's classification of the icon, symbolic, and index in describing film's physical molding of time and space onto celluloid. For Peirce, the icon is the thing represented through similarity, such as a stop sign. The symbolic is how we decode the object, as in coming to a halt when we see the stop sign. The index has a direct connection to its object, but is empty of content. Peter Wollen notes that the index is "a sign by virtue of an existential bond between itself and its object” (122). For example, a footprint in the sand or tire marks at the stop sign points to the existence of an object, even though the object is no longer physically present. In this sense, the index is what directs us to the trace of the object. Or, as Mary Ann Doane puts it: "indices have no resemblance to their objects, which, nevertheless, directly cause them” (92). 
Film has an intimate relationship to the index because of its chemical process, which "embalms" the time and space of a physical reality. Traditional camera capture light and space as it comes through a lens and penetrates the emulsion of the celluloid, chemically leaving a physical trace or footprint. Digital media, by contrast, record a series of 1 s and 0 s, and are quantified and transcoded through the algorithm of binary logic. In short, computer generated images lack a material tracing of reality, because, as Rodowick notes, the rendering of the image must pass through an interface (to decode the binary codes) in order to perceive the image. As he puts it, “all digital recording or synthesis requires digital-to-analogue conversion to become humanly perceptible” (112). But does this mean the advent of digital images radicalizes the material nature of cinema? Is there a "waning of the index" with the emergence of digital cinema as Rodowick claims?

According to Rodowick, "In digital capture, the indexical link to physical reality is weakened, because light must be converted into an abstract symbolic structure independent of and discontinuous with physical time and space” (117). For Rodowick, digital privileges space over duration; whereas analog film "transcribe[s] rather than represent [events]” in its direct contact and rendering of light and space (116). Digital computation, by contrast, abstracts and transcribes physical reality into a perceptual image, or what Rodowick describes as “symbolic expression.” What is at stake in the emergence of digital cinema in its supposedly weakened indexical state, is that it has "no qualitative relationship with either space or time...” (125). For Rodowick, the instant transmission of digitalization suggests a new relationship to speed, duration, and history. The past, in this sense, stays within "our historical present” (146). The computer is not 
representing physical reality, but simulating it through its decoding of binary numbers; whereas film captures the unfolding of time in a direct one to one relationship.

Rodowick describes analogue film's continuous one to one process of “input and output” as "automatic analogical causation" (49). It is an operation of transcription in "continuous" time, where the recorded and projected event "preserves the isomorphism of its source" (113). Rodowick argues, however, that "the power of the computer-the enormous variety of the functions they serve and the transformation they effect—results from the fundamental separation of inputs and outputs” (127). Just as Paul Virilio’s "vision machines" alter structures of perception through the glass lens and the transmission of wave optics, the medium of the computer "implodes" perception by the digital capturing of physical reality. This is primarily why, Rodowick claims, digital cinema is not a new media, because digital capturing is based on interfacing and prepping the information, which must then be passed through the older media forms such as analog's input and output processes in order for us to perceive the image. His example is from The Matrix (1999) where Cypher (Joe Pantoliano), watching two screens of symbolic codes, does not need an interface to decode its language. He says to Neo (Keanu Reeves), "You get use to it.... I don’t even see the code. All I see is blonde, brunette, redhead" (qtd. in Rodowick 112). In this respect, digital capturing has a different relationship to time, because it has no physical and causal contact with reality through its “symbolic notion.” For this reason, Rodowick claims, digitalization does not represent, but simulates. Analogue film, on the contrary, has a direct connection to reality and does not require an interface to transcribe the meaning for human perception. 
This returns us to Rodowick's critique of Russian Ark, which he identifies as a "montage work" and "digital events," rather than continuous unfolding of time and space. ${ }^{20}$ For Rodowick, the long take in Russian Ark severs the film’s causal connection to physical reality through its utilization of digital video. What is at stake in Russian Ark's use of the long take is digitalization's interruption of the input and output processes and the connection to and certainty of the past. Rodowick's concern with indexicality, time, and digital technology raises a number of points which cannot be fully examined here. But there are some points I would like to address specifically in connection with the waning of indexicality. ${ }^{21}$

The digital removal of the blood on the lens and invisible transitions in the long take in Children of Men, and the sweeping long take in Russian Ark are both assured of their indexicality. Although digital and film have a different process of capturing physical reality, they are still bonded to the index, because, as Doane notes, it direct viewers to "See this!” (208). That is, the index leads viewers to decode its tracing of something past. The index is always inscribed with the contingent, the instant, and the

\footnotetext{
${ }^{20}$ Rodowick is not suggesting that images cannot be manipulated as noted earlier in the example of the famous deep focus shot in Citizen Kane, when a young Kane is seen playing with his sled through the window in the background. Importantly, for Rodowick, matte photography is an "automatic analogical causation," not binary code of digitalization, which has a different relationship to capturing physical reality.

${ }^{21}$ It is important to note that centrally at stake for Rodowick in the decline of analogue film is skepticism and the divided subject of modernity. Drawing upon Stanley Cavell's notion of automatism, Rodowick posits that film engages the split subject of modernity by putting us back in touch with the world, paradoxically, through moving images of skepticism. In order to reconnect with the world, cinema offers a pathway to perceive "the whole of the world" (67). That is, cinema shows us the everyday safely at a distance. This distance between absence and presence opens the possibility of diminishing skepticism by showing us "a world past," because mechanical reproduction of cinema relieves viewers the burden of perception. For Rodowick, this is an epistemological situation; it is not a psychological, but an ethical and moral concern. It is not a disavowal, but a "reconnection" with the world under a "common duration." Here, Rodowick proposes "an ethics of cinema" because film confronts us with our "own metaphysical conditions" (72). Watching a film confronts us with time's passing and how we value our own experience of time. An ethics of time raises the question of self-examination and our relationship to the everyday in terms of "time, memory, and history" (75).
} 
indeterminacy of time. These are forces that counter the systematic ordering of time and resists meaning. What is at stake in the long take is not only the possibility of revealing the film's artifice, but also the potentiality of the unexpected or unplanned event during the filming of the event. Even though these instances of the long take tried to prevent accidents from occurring during filming, the very fact they have chosen to employ one continuous shot demonstrates the "lure-and-threat" of the contingent in their commitment to the irreversibility of time's arrow. At the same time, the fascination and excitement of the long take is tied to its invitation to watch "real time" unfold as a witness to the event as it traverses cinematic space. Russian Ark's long take, for example, is one of the central attractions of the film. This demonstrates that the contingent is "wedded" to both the production and the consumption of the moving image.

Rodowick sees certainty in the one to one connection in analogue film's capturing of light and space which, in turn, sustains its indexicalty. He argues that digital cinema's indexicalty is "weakened" because it simulates physical reality rather than transcribing it. What Rodowick does not consider is that the index is always bonded to the contingent and indeterminacy of time. Indexicality and the contingent are intimately tied to each other because they are both devoid of content. Doane notes, "Indexicality is inevitably linked with the singular, the unique, with the imprint of time and all its differentiating forces" (208). For Doane, the commonality of these forces is their "obsession with instantaneity and contingency” (208). In other words, the inaccessibility of the instantaneous ties it to the contingent and indeterminacy of time. Digital media is assured of its indexicality not through a direct contact to light and space but through the desire to capture the instant and pure presence of time. At the same time, the contingent 
and desire for the instant sets the condition for new cinematic expressions, which can result, as we have seen, in the creation of new technologies during the production of the long take.

Furthermore, digital technologies can remove and add objects to the frame in post production, as noted in the removal of the blood on the lens in Children of Men. This certainly offers filmmakers some flexibility in production. But this phenomenon does not diminish indexicality. This is because digital tools are also representative of the desire for the instant, which, again, is connected to the contingent. The ability to use software for better precision of the moving image enables the fascination with the instantaneous. Here, we are reminded of Kubrick's use of the video assist in the production of The Shining to aid in the calculation of the steadicam shot. But, as Doane points out, the instant (a point of zero degree threshold) is impossible to obtain because we are "riven by delay” and memory-work. Here, a paradox emerges in terms of movement and the instant in regards to the velocity of the long take as form of immersion. We seek faster technologies for better precision in the frame; but we also desire to reduce the possibility of disturbing the image. The blood on the frame in Children of Men, in this respect, literally brings the presence of death to the frame as a "threat," which has to be reduced in order to sustain viewers' interest in the action unfolding in the narrative. The blood, in a certain sense, is what Roland Barthes characterizes as the punctum, something that “pricks” and “disturbs” the moving image (27). Paradoxically, through technologies of speed, the click of the mouse is able to remove this "wound" from the mise en scene.

This brings me to my final point which is the phenomenon of adding mistakes and degrading the moving image that Rombes describes as countering the perfection of digital 
media. Here, human presence enters into to the velocity of the long take as noted in the point-and-shoot perspective of Cloverfield, or Ray Ferrier's escape from the Martians and their heat-ray weapons in War of the Worlds. I suggest that this process of adding mistakes does not indicate we are "haunted by the spectre of digital" as Rombes argues. Nor does it support Rodowick’s claim that “'reality’ is still recognized only its photographic appearance, and we are barely prepared for the new ontological situation emerging within composited images” (177). I argue that we see the practices of digitalization giving way to what Laura Mulvey notes as a "technological curiosity" (27), which is creating new modes of perception that can be adapted for new expressions of cinema. DVD bonus materials, mobile screens, websites and blogs on cinema, portable camcorders, desktop editing software: all of these digital media are not only becoming more a part of our everyday world, but are also offering new ways of consuming and circulating the moving image, and new acts of seeing. Conversely, these conditions of digitalization are informing styles of filmmaking, with more filmmakers using handheld photography and shaky camera movements. As I have argued, the regulated presence of mediation does not disturb the moving image, because they are becoming more integrated into everyday life, which is evident in the phenomena of video content platforms such as YouTube. 


\section{Chapter Two}

\section{The Politics of the Long Take: Gus Van Sant's Elephant}

In the previous chapter, I described how the long take is not directly linked to a particular mode of production, but instead emerges contingently from several conditions of existence. I also traced the marrying of artistic vision and new film technologies in order to illustrate how the long take as a form of speed can be immersive without destabilizing cinematic time and space. Furthermore, these new styles of the long take reflect the new conditions of a digital culture where the presence of mediation is becoming more a part of everyday life. This was specifically noted in the phenomenon of YouTube and its impact on the long take in Cloverfield. In this chapter, I would like to further explore how digital media technology is informing the long take, but as a form of slowness and its connection to a film's political content.

The struggle for hegemony, as Antonio Gramsci points out, involves a constant tension between dominant and subordinate groups. In its simplest terms, hegemony describes how a dominant party retains and reproduces its power through winning consent. But hegemony is not fixed to the leading group; it is always contingent, open to negotiation, and can change in response to new conditions of existence. From this point of view, the speed and pacing of film may indeed have ideological and political implications. In particular, a change from Hollywood realism, the transparency of the text and chronological narration to the slow unfolding of events through slow shot duration and non-linear narrative may have a direct effect upon the hegemonic mode of production. 
But here I would like to make a different argument: namely that in Gus Van Sant's Elephant, (2003), a film based on the events of the Columbine high school massacre that occurred in April 1999, the uses of slow long takes exist in creative tension with the film's political content, as well as creates an interactive and exploratory spectatorship associated with database narrative and video gaming aesthetics. ${ }^{22}$

Elephant captures the everyday routine of several high school students as they move throughout the inner and outer spaces of the school shortly before the shooting occurs. Within this brief time frame, viewers experience the crisscrossing of characters John (John McFarland), a troubled teen who manages an alcoholic father; Elias (Elias McConnell), a photography student and friend of John's; Nathan (Nathan Tyson), a popular jock and lifeguard; Carrie (Carrie Finkle), Nathan’s girlfriend; Michelle (Kristen Hicks), a teen who is highly self-conscious of her body; Brittany (Brittany Mountain), Jordan (Jordan Taylor), and Nicole (Nicole George), three bulimic teens; and the two students who plan and execute the attack on the school, Alex (Alex Frost), a pianist and sketch artist, and Eric (Eric Deulen), his slacker friend.

Elephant's tragic ending evokes memories of the Columbine shootings, and the national debates on youth marketing of violent entertainment that circulated in the media after the event. But the film's refusal to make judgments on topics such as Goth music, video gaming, the Internet, and gun control—key issues publicly debated into the causes of Columbine—-makes Elephant unique in terms of its political discourse. I will argue

\footnotetext{
${ }^{22}$ Though Elephant is based on the Columbine massacre, the film was also influenced by a short film also called Elephant (1989) directed by British filmmaker Alan Clarke. Clarke's Elephant dealt with the issues in Northern Ireland and were based on actual accounts of killings that had occurred in Belfast. The film is comprised of long shots were a character enters into a specific setting, randomly kill a person and then exits the surroundings. There is minimal dialogue and the killings are not clearly motivated. Like Van Sant's Elephant, Clarke's narrative approach assumes viewers will have previous knowledge of the events already brought to the film.
} 
that, paradoxically, the political power of Elephant lies in this refusal, which allows viewers to bring to the film their own memories and knowledge of the Columbine event as well as the surrounding debates on violent entertainment, in order to make sense of the story's ambiguous text. As Van Sant states, "It's handing over a lot to the viewer because of there being a lot [of prior knowledge of the event] inside the viewer, I think, that can contribute to the activity of watching the film” (qtd. in Canavese, "Last Days").

But we must also consider Elephant's structural presentation of long takes and non-linear sequence of events in relation to the Columbine shootings and the subsequent debates over youth marketing of violent entertainment. Here, I suggest we see the film's installation-like presentation of the event as reflecting what Marsha Kinder describes as database narrative, which "refers to narratives whose structures exposes or thematizes the dual processes of selection and combination that lie at the heart of all stories and that are crucial to language...” (6). Whereas traditional narratives synthesize and subordinate time into a linear and chronological order, database narrative brings forth its structure or "paradigm" to underscore the processes of selection and combination. Kinder notes, "Such narratives reveal their arbitrariness of the particular choice made, and the possibility of making other combination which would create alternative stories” (6). Database narrative elicits a heightened interactive spectatorship, inviting viewers to organize, compare, explore, and navigate its disparate pieces, which can lead to various and contingent outcomes of meaning.

Certainly database narrative is not a new phenomenon but can be traced throughout the history of cinema. The non-linear and achronological order of events in films, such as Man with a Movie Camera (1929), Meshes of the Afternoon (1943), 
Hiroshima mon amour (1959), Last Year at Marienbad (1961), The Phantom of the Liberty (1974), and Koyaanisqatsi (1982) bring the film's database to its surface. There are also films that embed a database aesthetic within a chronological ordering of time, as in the uses of split and multi-screen projection of simultaneous information, such as Pillow Talk (1959), The Boston Strangler (1968), Woodstock (1970), and Sisters (1973). ${ }^{23}$ Over the past twenty years, there has been an increasing trend towards database narrative, evident in such films as Groundhog's Day (1993), Pulp Fiction (1994), Run Lola Run (1998), Time Code (2000), Code Unknown (2000), Memento (2001), Thirteen Conversations About One Thing (2001), Eternal Sunshine on the Spotless Mind (2004), The Science of Sleep (2006), Inception (2010), and Source Code (2011), to name but a few. Allan Cameron points out that although chronological narrative is still the dominant mode of narration, the popularity of these films "signal[s] the point at which these [database] aesthetics have been accepted by popular culture at large" (16). ${ }^{24}$

I argued in the previous chapter that this trend toward database narrative is, in part, a result of the impact of digital media on the production of the moving image. And similar, tendencies towards database narrative can be found in other mediums linked to digital media. Consider news programs that use live news “crawlers" and stock tickers that are positioned simultaneously below multi-screens of "talking heads"—all within one frame. We can also see database aesthetics in recent television commercial that

\footnotetext{
${ }^{23}$ For more about framing, windows and multi-screen perspective, see Anne Friedberg's The Virtual Window: From Alberti to Microsoft. Cambridge, MA: MIT Press, 2006.

${ }^{24}$ Allan Cameron's recent work has attempted to index database aesthetics into what he terms "modular narratives." In this study, he offers four groups of modular narratives: anachronic narratives, forking paths narratives, episodic narratives, and split screen narratives. For more details, see Cameron's Modular Narrative in Contemporary Cinema. New York: Palgrave macmillan, 2008.
} 
utilized split and multi-screen images. Even smart-phones predicate users managing and organizing their media content. This increasing trend towards database narrative request viewers and users to interface, explore and combine layers of information in order to build a "trajectory" and narrative threads out of the database. In this regard, database narrative not only engages in a political discourse through foregrounding its process of selection and combination, but also demonstrates how computing practices and video gaming aesthetics inform new forms of cinematic expression at the turn of the millennium.

If we take into consideration that Internet and violent video games were cited as central causes of Columbine, the database and puzzle-like structure of Elephant becomes even more politically significant. Following the Columbine tragedy, Congress held hearings on youth marketing of violent entertainment, putting political pressure on the entertainment industry to regulate media content. In this respect, Elephant's database aesthetics evoke a tension between the notion of manufactured consent by Congress, and debates pertaining to violent entertainment and youth violence. But I add that the politics of the film does not lie in the attempt to make viewers aware of "hidden truth" as a means of mobilizing them for radical social change. Instead, I suggest that we view the mapping of Elephant's non-sequential narrative and slow pacing as engaging audiences on the terrain of what Gramsci terms the conjunctural—an "occasional” and "spontaneous" site where political, economic, and ideological forces converge in the struggle over meaning (177).

\section{Realism and Spectatorship}


To understand how Elephant's use of long takes and slow duration evokes an interactive spectatorship without relying on the styles of traditional Hollywood, it is important that we, first, briefly define realism and its relationship to spectatorship. Tracing these concepts will provide a better understanding not only of how Elephant breaks with traditional representations of reenactments, but also how the film's deviation from the standard mode of Hollywood production connects to its political content without overtly alienating viewers from engaging with the text.

As we saw in the previous chapter, the dominant mode of classical Hollywood mode of production is "realist" in the sense of producing stories that appear to be objective and unmediated. Linear narratives, clear character identification, motivated editing, a precise sense of time and space, a centered viewer vantage point, and narrative closure all connect to this dominant mode of production. From this standpoint, realism has a close connection to speed, because the immediacy of the image is what helps to create the illusion of transparency. Speed and motivated editing, in this sense, "erase" the mediation of the apparatus in order to further immerse viewers into the story. In other words, duration in narrative cinema has to be paced and edited so that spectators are not made aware of the mediating process in constructing a film's story world. By contrast, as I argued in the previous chapter, regulated mediation and human presences (e.g. pointand-shoot perspective, handheld camerawork, and purposely degraded image) are characteristic of a digital mediated culture.

Elephant's experimentation with the long take and strategic framing plays with the centered perspective and motivated pacing associated with realism thus, bringing the mediation of time and space to the surface of the film and thereby creating a sense of 
uncertainty. Take, for instance, the scene early in the film where the long take, from a perspective that hovers above the action in a centered frame, shows a wide angle shot of John's drunken father's Mercedes Benz as he carelessly drives his son (who happens to be late) to school (Figure 1). John’s father strikingly side-swipes a parked car and then almost runs over a teenager riding his bike. After almost driving off the road again, John decides to take over at the wheel. A Mercedes-Benz is clearly a status of upper class and wealth. Affluence in cinema is often a point of tension portrayed in teen dramas. Films like Sixteen Candles (1984), Pretty in Pink (1986), Heathers (1989), and Clueless (1995) center their narrative conflict and drama on class status and material goods. So right from the beginning of the film, Elephant quickly distinguishes itself from the traditional Hollywood teenage drama in its depiction of the affluent father as the figure of drunkenness and uncertainty, features which are echoed in the ambivalence of the long take. ${ }^{25}$ Specifically, the long take in the opening sequence attaches a sense of unreliability and unknowingness to the father portraying him as the reckless adult. But more so, through its lurking perspective and centered framing (more to come on this later) the long take evokes a feeling of foreboding and sense of unforeseen danger, alluding to the film's horrific ending.

\footnotetext{
${ }^{25}$ One here is even reminded of the opening of Rebel without a Cause (1955) where viewers are introduced to an intoxicated teenager, Jim Stark (James Dean) who is arrested for public drunkenness.
} 


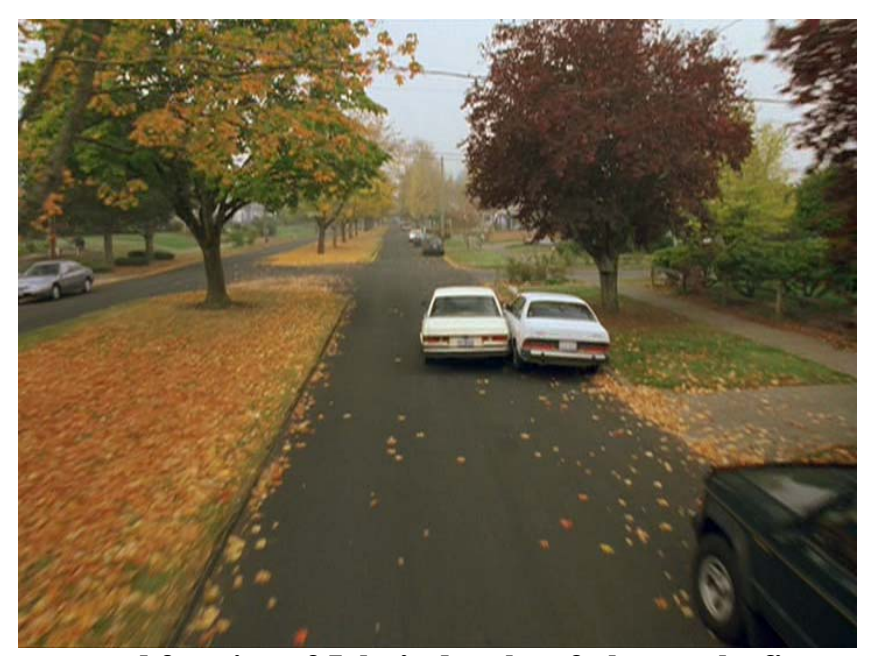

(Figure 1. The centered framing of John's drunken father as the figure of uncertainty)

Hollywood has historically relied upon narrative closure and linear temporality with narrative gaps and ambiguities tied-up and resolved into satisfactory endings (more to come on this in chapter four). Elephant's non-linear structure, emphasis on slow pacing, and unexplained narrative occurrences, by contrast, draws attention to contradictions and unknowable causes that remain unexplained, such as Alex and Eric's attack on the high school. Part of the challenge of watching Elephant is going through the trauma of the event without narrative closure. Yet, at the same time, the non-closure of the event also helps to generate the politics of Elephant.

In this regard, the two scenes that have caused the most public dialogue are Alex and Eric watching the Nazi documentary and their taking a shower together before their attack on the school. For instance, Todd McCarthy's review in Variety notes, "Certainly any material is fair game for dramatization given the proper approach.... And while it is clearly not Van Sant's intent to offer a facile explanation for why two teenage boys marched into their high school with assault weapons with the aim of picking off as many of their fellow students as possible he reveals the killers to be gay-inclined Nazis!” 
(“Elephant,” Author emphasis). ${ }^{26}$ The controversy in Van Sant’s choice to keep the shower and Nazi scene illustrates that when narrative ambiguities are not subordinated to character psychology or not given narrative closure, they can draw attention to themselves as well as engaging public debates.

On this basis, we may argue that Elephant's experimentation in constructing nonchronological story lines, and its deliberate slow unfolding of time and space function as a site of political struggle with the traditional and dominant styles of Hollywood. But this does not mean that Elephant's viewers are expected to draw a particular message from the text. Certainly Elephant seeks critical readers of the film, but it also recognizes, indeed, by its openness to encourage variations of meaning made in decoding its text. In particular, Elephant does not try to alienate spectators formalistically by making them overtly aware of its political discourse in order to emphasize “a message.” Instead, Elephant invites viewers into the everyday life of teenagers as they navigate through the high school setting, but without a clear cut or linear narrative that explains what leads to its tragic ending. As Van Sant states:

It's not that I don't want you involved in the characters, but I want you involved by watching them.... We could have invented a more traditional psychological narrative. I have my ideas why Columbine happened, but that's not this film. I wanted a poetic impression rather than dictating an

\footnotetext{
${ }^{26}$ It is interesting to note that Van Sant debated whether or not to remove the shower scene. In an interview with Film Comment, Van Sant states, "I asked almost everyone I could think of about removing the kiss scene.... [F]or me, the scene was my projection of the way that boys are when they are locked up in a basement for a year. That they may not be having sex, but they are communicating with each other in a sexual way, all the time. Because boys do that...I didn't want to take it [the kiss scene] out for the wrong reasons, and the reason people gave were all wrong ones" (qtd. in Taubin, "Problem” 33).
} 
answer. I wanted to include the audience's thoughts (qtd. in Peary, “Elephant”).

The film's representation of the Columbine event negotiates with the traditional aesthetics of docudrama or historical narration by experimenting with multi-perspective character view points, improvisational dialogue, and intentionally slow long takes. Thus, the film creates narrative conflict without using the traditional shot construction and motivated editing associated with the dominant mode of filmmaking. This then raises the question: how does the long take in Elephant achieve both a political and interactive narrative as well as create narrative tension while at the same time drawing attention to its mediation?

\section{Database Cinema}

To begin, let's look at Elephant's representation of Columbine in order to understand how the film creates a heightened interactive spectatorship through its database narrative and slow unfolding of events. As noted earlier, Van Sant's use of a multi-form narrative in Elephant demonstrates how new media technologies and computing practices are challenging the boundaries of traditional representations of narrative time and space at the turn of the millennium. More specifically, the 1990s and beginning of the twenty-first century saw significant changes in forms or representing with the advent of new media technologies and the re-imaging of cinematic time and space. Films such as Reservoir Dogs (1992), Pulp Fiction (1994), Lost Highway (1997), Memento (2001), The Rules of Attraction (2002), 11:14 (2003), and I'm Not There (2007), to name but a few, play with temporality by creating narrative structures counter to linear storytelling. These new narrative environments can be seen as taking on the 
characteristics of what Janet H. Murray describes as "the transformative power of the computer” (154). Murray notes that one of the ways in which to understand the new narrative settings spawned by digital media is "the ability to present simultaneous action in multiple ways” (157). For instance, in movies and television, simultaneous action is rendered through the management of parallel and cross-cutting techniques that compress action and anticipate future events to come. But the computer, Murray observes, presents "all the simultaneous action in one grid and then allows the interactor to navigate among them” (157). Navigating a web page, for example, permits the user to organize the disparate data laid out by the computer through search engines or hyper links. Elephant's shifting narrative and non-linear presentation of events, in this sense, can be seen as sharing characteristics of a computer's concurrent presentation of multi-information.

The computer is a way of exploring and navigating a database. According to Lev Manovich, the logic of the database is distinct from the logic of the narrative. Manovich notes, "Many new media objects do not tell stories; they do not have a beginning or end; in fact, they do not have any deployment thematically, formally, or otherwise that would organize their elements into a sequence. Instead, they are collections of individual items, with every item possessing the same significance as any other” (218). The database represents the world as a list of items; whereas narratives create cause and effect in the rendering of the database.

Manovich draws upon the semiotic concepts of syntagm and paradigm to describe the relationship between narrative and database practices. The syntagm combines and strings words into sentences; whereas the paradigm is a set of words to draw from in order to form sentences. The syntagm is manifested by its presence in speech; whereas 
the paradigm is a structuring absence. Manovich argues that new media technologies reverse the functions of syntagm and paradigm. He notes, "On the material level, a narrative is just a set of links; the elements themselves remain stored in the database. Thus the narrative is virtual while the database exists materially” (231). The database, in this sense, is not materialized through a linear, self-imposed temporality as in realist narratives, but must be registered and organized by viewers. This is not to suggest, however, that there is a strict “dialectal opposition” between database and narrative. Marsha Kinder argues that “All narratives are constructed by selecting items from a database and combining them to create a particular story, while each retrieval of information from a database has a narrative dimension, but only in the broad cognitive definition of narrative...”("Equivocations” 126). In this sense, the paradigm and syntagm are not mutually exclusive, but “always function together.” But in database narrative, the paradigm, which is usually invisible, is surfaced by revealing its combination and selection of specific formal components of the story.

Both Kinder and Manovich point out that cinema already exists at the crossroads of database and narrative. The process of shooting and editing footage constructs a narrative out of the film's database. The motivated and invisible Hollywood style of editing, for example, is a way of naturalizing and concealing the process of building a trajectory out of the film's database of footage. But, as noted earlier, today we are seeing more filmmakers consciously exploring and engaging with the database/narrative dynamic. This is, in part, due to newer and faster digital technologies that allow for more tools and options that permit the artist immediate access to play with a film's database. But it also suggest audiences’ new relationship to the proliferation of mobile screens and 
computing practices in everyday life, where viewers are becoming more accustomed to multiple data within one screen. As Murray states, "The kaleidoscopic power of the computer allows us to tell stories that more truly reflect our turn-of-the-century sensibility” (161). Database cinema thus expands the confines of paradigmatic and syntagmatic relationships, not only offering audiences a new way of experiencing cinematic time and space, but also reflecting a new landscape of digital media technology. In this regard, database narrative is another phenomenon of accelerated culture, offering new ways of seeing the moving image in the digital age.

The simultaneous occurrence of events in Elephant is characteristic of database cinema: viewers must map the non-linear sequences and surplus information in order to make meaning of the film's non-chronological structure. But more so, the database orchestration of long takes and character timelines suggests the impossibility of representing a traumatic event through one grand narrative. In the previous chapter, I argued that Cloverfield and Children of Men employed competing narratives as a way of eliciting a plurality of meanings. In a similar way, database narrative offers a unique way of organizing the film's data by de-centralizing the master narrative, and allowing the possibility of multiple readings, drawing upon competing narratives.

The Boston Strangler's use of split-screen projection is worthy of note in this respect. Like Elephant, The Boston Strangler is based on real events. It tells the story of Alberto DeSalvo who killed thirteen women in the early 1960s in Boston. In order to capture the city in panic, director Richard Fleischer employed a new technique of multiimage projection, a technique he discovered at the Montreal Expo in 1967. Here, the multi-images suggest the impossibility of representing a traumatic event through one 
perspective. Instead, excess information is siphoned through various view points concurring on one screen, for example, in the public precaution sequence where people are simultaneously shown locking doors, shutting shades, buying guns, and scrutinizing strangers. Similarly, Gus Van Sant's experiment with narrative structure and multicharacter perspective in Elephant lets viewers construct alternate ways of understanding what led to this national tragedy. The film's narrative gaps and a-chronological ordering of events suggests that we may never know all the causes that led to the event.

At the same time, the long take is able to elicit viewer curiosity through delayed exposition and strategic positioning of character timelines. For example, when popular student and life guard Nathan is first introduced into the film, the camera tracks behind him as he exits the playing field and walks towards the school. Shortly before reaching the school entrance, the camera stops moving with him as he continues walking towards the door. Typically, films will chop away this excess coverage or "waiting time" of the sequence as a way to ration the story and to keep the narrative moving forward in time. But Van Sant retains the image as a way to slow down the narrative and to show the entire action sequence, thus allowing audience to enter and exit with characters as they move through space. Van Sant notes that this type of long take sequence "adds contrast to the parts of the story where something is happening; it resonates, and those lulls add a reality” (qtd. in Macaulay, “Sands of Time”). Because viewers have already been introduced to other characters before Nathan's entry into the story, this particular scene, although ambiguous in terms of narrative exposition, generates dramatic tension through delayed action and without using traditional means of editing and shot structure linked to the invisible editing model. Rather than offering one perspective of the event, the 
installation art style of presentation of the character timelines offer viewers multiple vantage points that compete with each other.

As the story unfolds and characters begin to cross each other's paths, it requires viewers to retrieve and organize previously viewed knowledge in order to make sense of the film's collection of character data. Consider the scene when Nathan enters the administrative office with his girlfriend Carrie to get a pass to leave early. As the image tracks Nathan and Carrie, we suddenly see John, who was introduced at the beginning of the film, sitting with the principal who is talking to him about his repetitive tardiness. Although John and Nathan do not know each other, a narrative tension is created by the crossing of their paths. This is because Nathan's movement through the playing field and corridors of the school converges with spectators' previous experience of John's temporal and spatial narrative trajectory at the start of the film. During John's introduction into the story, Nathan, at the same time, is moving through the school setting towards the administrative office, to which we are not yet privy. ${ }^{27}$ The crossing of these two simultaneous events take on the logic of the database, inviting viewers to compare and contrast John and Nathan's scenes and how they fit into the film's larger timeline. John and Nathan's timelines are not experienced through traditional parallel or crossing cutting action linked to linear storytelling, but through viewers' recollection of a past event, in accordance with a database mode of operation.

The film's reliance upon viewer's knowledge of the Columbine event also takes on the features of database cinema and competing narratives. As the film progresses and more characters cross paths with each other, the story becomes more dramatic because

\footnotetext{
${ }^{27}$ Mike Figgis' Time Code is interesting to note in this context, because viewers are visually privy to four simultaneous events rendered through four separate screens within one screen.
} 
viewers anticipate the final event, which is Alex and Eric's attack on the school. When Alex and Eric are first introduced into the story, there is a sense of uncertainty, because the film expects spectators to know that their plan is to attack the school. In this sense, the effect of the film's repeating, re-shuffling, and delaying of other character timelines, leading up to the final event is similar to the dramatic effect felt in traditional parallel and cross cutting: namely a disruption in the flow of the story towards its final resolution.

But instead of experiencing the passing of time in a linear fashion, viewers are presented with the opportunity of exploring and navigating through the film's temporal anomalies and out-of-order sequencing of events. Though it can be argued that Elephant's nonnarrative approach distances spectators or makes them aware of their viewership, I suggest that the film's temporal rifts and crisscrossing of character trajectories helps to further immerse viewers into the story, by inviting them to map and link the interwoven planes of character timelines in relationship to the final event. (And we shall see later, the combination of database aesthetics and viewers' knowledge of the Columbine event is where we find the film's political dimension). Elephant's database logic is both constructed from spectator's knowledge of the event and frames of perception, as well as through the positioning of the scenes themselves, inviting viewers to draw upon memory of previous scenes within the film to complete the film's narrative puzzle.

\section{Speed Ramping and the Body}

I argued that Elephant's long takes and non chronological positioning of character timelines creates an interactive form of spectatorship similar to the database narrative. Another database aesthetic employed in Elephant is the device of speed ramping, where the frame rate of the film is increased in order to slow down the image within the shot. 
One of the first films to popularize speed ramping is Martin Scorsese's Raging Bull (1980). During the film's fight sequences, the camera is "over cranked” in order to elongate the duration of the moving image, therefore interiorizing Jake Lamotta's (Robert De Niro) distorted sense of time and space. Today, desktop editing programs such as After Effects can remap and change the duration of the image without under or overcranking frames within the camera during production. A shot can be filmed at the normal filming rate and later altered in postproduction, thus manipulating time itself. For example, cutting to close shot can give the viewer a sense of character psychology as well as dramatizing the unfolding of events. Speed ramping can achieve this same effect by slowing down the speed of the image and drawing viewers to a specific action for dramatic and narrative purposes.

In Elephant, speed ramping not only punctuates specific moments in the story for dramatic effect, but also, without the use of motivated editing, signals where characters trajectories cross each other. In this regard, Elephant's utilization of the aesthetic of slowness within the slow long take emphasizes narrative conflict and character consciousness. For example, when viewers first meet Michelle on the playing field, Nathan and his friends are seen in the background playing football. As Michelle enters the frame, she glances up at the sky with a look of amazement as the students playing in the background suddenly move in slow motion. The image then returns to normal speed as she exits the frame. The image continues to hold onto the same shot as we see Michelle re-enter the frame in the far background, now out of focus, joining the rest of the gym class. Within the same shot, Nathan enters the frame as he puts on his lifeguard sweatshirt. The image then tracks behind him as he walks to the school's entrance to 
meet his girlfriend, Carrie. The zigzagging effect of Nathan and Michelle’s movements on the playing field, (as they shift from foreground to background), combined with the technique of speed ramping, captures character consciousness while at the same time generating narrative tension and viewer curiosity.

The combination of audio and speed ramping also produces conflict and character interiority. Shortly after Nathan enters the school, the image tracks him from behind as he moves through a corridor and up a stairway to the second level. Exiting the building, he crosses an overpass that connects to another section of the school. As Nathan enters the second level section, he passes Brittany, Jordan and Nicole, catching their gaze. Brittany watches Nathan intensely as he passes by. But instead of staying on Nathan’s back, the camera focuses on the three teens and suddenly the image slows down, as Brittany says to the camera: "so cute." The speed ramping of the image draws attention to the three teens. And later in the film, the image will return back in time to this same moment in order to show their point of view, following them through the school corridors and into the cafeteria just before the shootings occurs. As Nathan continues walking (still in slow motion) loud sounds of a baby are now strangely heard as the corridor noises are lowered in the film's sound mix. As the sound of the baby fades out, the image returns to normal speed as the ambient sounds of the hallway increase. Nathan meets his girlfriend Carrie. They both walk to the administrative office to get a pass to sign out of school, where their path crosses with John who just finished speaking with the principal for his consistent tardiness. Here, viewers find out that Nathan may have gotten Carrie pregnant. Rather than using the traditional techniques of editing to capture a character's feelings, the devices of speed ramping and audio cross-fading of baby noise and ambient sounds of 
the hallway manifest Nathan's inner conflict. Again, narrative drama is punctuated within the long take through sound and speed ramping without the use of traditional editing techniques.

But probably one of most dramatic instances of speed ramping occurs when John leaves the school and encounters Alex and Eric who are about to unleash their maniacal plan. As noted earlier, Elephant's minimalist presentation of the narrative assumes that viewers will bring knowledge and memories of the Columbine event to decipher the film's incomplete text. When Alex and Eric are introduced into the story, there is a sense of anxiety and uncertainty, which is registered by the use of speed ramping. Just before John crosses their path, he is greeted by a dog, Boomer, on the school's entry walkway. John calls the dog, while in the background Alex and Eric approach with their bags full of guns and explosives. Boomer runs up to John and jumps up as the image slows down. The image returns to normal speed as John asks Alex and Eric what they are up to (Figures 2 and 3). Alex warningly tells him, “Just get the fuck out of here and don’t come back.”

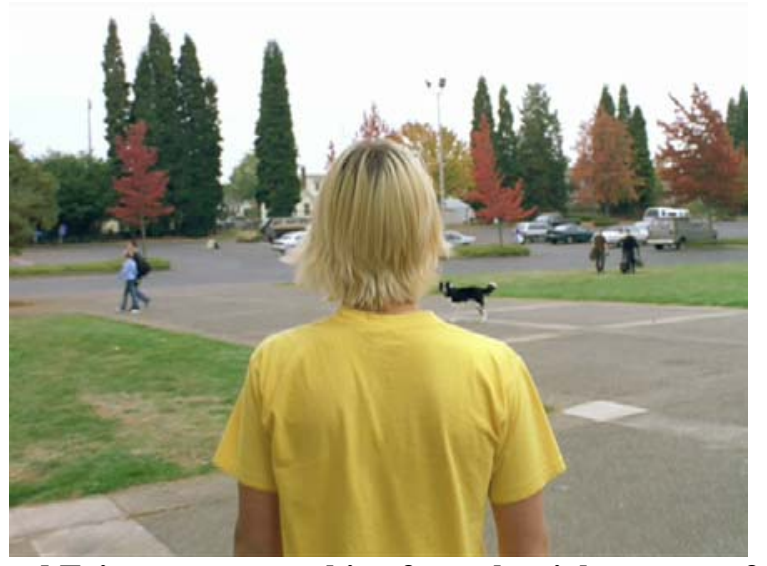

(Figure 2. Alex and Eric seen approaching from the right corner of the frame in the background with firearms) 


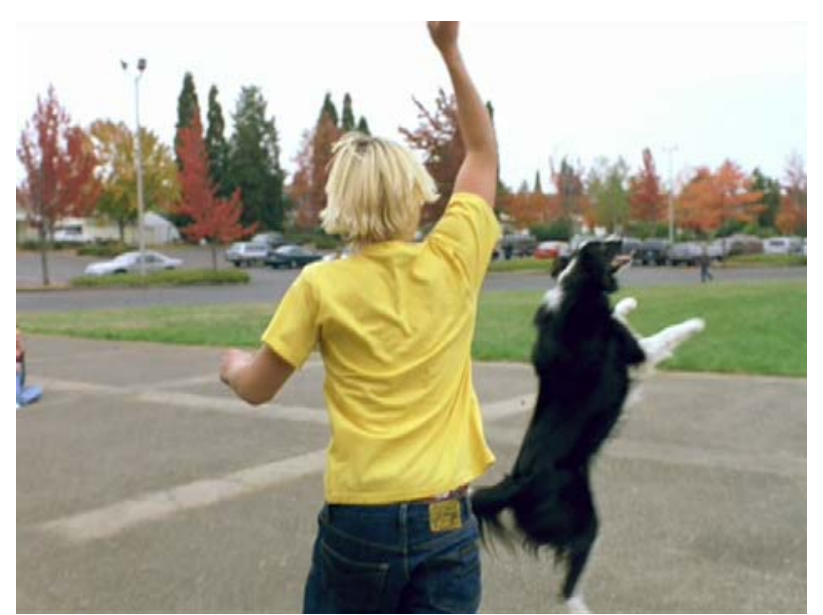

(Figure 3. Boomer and John in slow motion, an aesthetic of speed ramping)

It is important to stress how speed ramping in these three sequences places emphasis on the body's movement through the protraction of the moving image. Here, we are reminded of the Futurists' work on the infinitesimal representation of an object in motion. Drawing upon Anton Giulio Bragaglia’s “Futurist Photodynamism,” Mary Ann Doane points out that the Futurists sought to "trace” a "distorted state" of a moving object to counteract the “cold and mechanical arbitrariness” of cinematography that simply captured “the instantaneous.” As she puts it: “[Bragaglia’s photodynamism] pursed his concerns with the trajectories of moving objects through photography” (86). The desire of the Futurists was to register an emotion, "the sensation of movement" in its infinitesimal expression of the object in motion. ${ }^{28}$

In this respect, a film that has some similarities to Elephant (and the death trilogy in general $)^{29}$ in terms of affect and motion, is Godfrey Reggio’s Koyaanisqati and its use of time-lapse and slow motion photography. Koyaanisqati ("life out of balance”) is a

\footnotetext{
${ }^{28}$ It is interesting to note the increasing use of extreme slow motion reply in sporting events and the affective quality for television spectators. Giving the speed of sports, especially football and hockey, speed ramping replays, in certain ways, follows the Futurist's desire to induce a "psychic emotion" in its tracing of a moving object.

${ }^{29}$ Van Sant's unofficial death trilogy consists of the films Gerry (2002), Elephant, and Last Days (2005).
} 
film essay that explores the relationship between nature, people, and machines through juxtaposing images and music. Important for our discussion of Elephant is the emphasis on images of nature in relation to speed and slowness: for example, Elephant's opening credit sequence involves time-lapsed photography of the sky as it quickly changes from day to night, filmed against a telephone pole, while teenagers are heard playing off screen. Similar to the time-lapse photography in Koyaanisqati, the opening image in Elephant evokes a disjunction between the forces of time and life that unfolds off-screen. In the context of the memories of Columbine that the film assumes its viewers bring to the decoding of the text, the voices of teenagers heard off-screen while the color of the sky (in time-lapse photography) quickly changes from blue to black, creates an even greater sense of imbalance and danger. In this regard, Van Sant's use of speed ramping is not only a means of capturing character interiority, but also a way of eliciting emotions from spectators through movement and sound.

The emphasis on slowing down the image via speed ramping also underscores the importance of the body and its vulnerability within the space of the high school. As already noted, Michelle is highly self-conscious about her body. This is stressed when her gym teacher tells her that she has to wear the proper clothes for class. We see this too with Brittany, Jordan, and Nichole, where the slowing down of the image draws attention to Brittany's attraction to Nathan's body, and also later in the film when, in fear of becoming over weight, all three of the girls self-vomit in the bathroom after eating lunch. Lastly, John's encounter with Boomer brings attention to the threat of the body itself as Alex and Eric approach in the distance, ready to attack the school. Like John's drunken father at the start of the film, who unexpectedly side swipes a parked car, there is an 
element of uncertainty and foreboding in the slowing down of the image and the vulnerability of the body. The emphasis on slowness within slowness (speed ramping within the long take) generates meaning and character psychology without the need for motivated editing. These features of speed ramping are representative of database narrative not only because they create narrative drama without the emphasis on editing, but also because they invite viewers to piece together the film's heterogeneous components in combination with their knowledge of Columbine in order to unravel the film's non-chronological structure and ambiguous text.

Speed ramping reveals the possibilities of new media technologies as well as exploring the database in the digital age. In similar ways, speed ramping connects the digital aesthetic to gaming technology, where the cinematic time of the action is slowed or sped up to create a vision of virtuality. It is what Alexander Galloway (in reference to bullet time in The Matrix [1999]) calls "gamic cinema, a brief moment where the aesthetics of gaming moves in and takes over the film only to disappear seconds later" (67). In the final section, I will argue that the affective motion and sensory experience characteristic of video gaming digital technologies underlies Van Sant's use of the travelling long take and its representation of the Columbine event.

\section{Video Gaming and First Person Shooter Perspective}

In an interview, Van Sant discussed how the long following-shots in Gerry connect to the first person perspective in certain video games. Van Sant states:

The way the camera works in [the video game] Tomb Raider, if you want to call it a camera, is that it sort of swings and swims around, always keeping the central figure somewhere in the middle of the frame.... [I]t 
would be really great if our camera could do exactly what this camera does.... In some ways, Gerry is Béla Tarr fused with Tomb Raider! (qtd. in Macaulay, "Sands of Time”).

Van Sant's comment demonstrates how the ability to navigate through 3-D computer space is creating new aesthetic possibilities for cinematic expression.

Writers have often noted that the long takes in Elephant have a poetic aesthetic as well as a documentary style where life simply unfolds in front of the camera. There is no denying that the long takes evoke a meditative and quiet quality. But it also has a strong association with the subjective perspective of video gaming. Manovich describes how video games such as Doom and Myst rely on the player's ability to traverse and explore the game’s landscape. He notes, "new media spaces are always spaces of navigation” (252). The building of sets and use of exterior locations in cinematic filmmaking cannot provide a total landscape of the sort found in the virtual world of video games. Of course, there are many factors filmmakers have to consider when building the spatial environment of a film's narrative world. For example, shooting a film on-location requires a state or city permit. There is also the desire to control the elements within the space itself. This is why films rely primarily on continuity editing to create the illusion of cinematic time and space as a virtual whole. But gaming technologies require a totally rendered actionable space that does not rely on techniques of editing and montage. This is because the designers of video games have already built a complete and total space that is navigable for the gamer.

The spatial environment of video gaming appealed to Van Sant because of its ability to complexly track the central figure. Although Van Sant could not replicate the 
intricate movements of a "Tomb Raider point of view," video gaming clearly informs the cinematography of Elephant, which is evident in the use of the long following-shot that lurks behind the actors as they travel the environs and corridors of the high school (Figures 4-6).
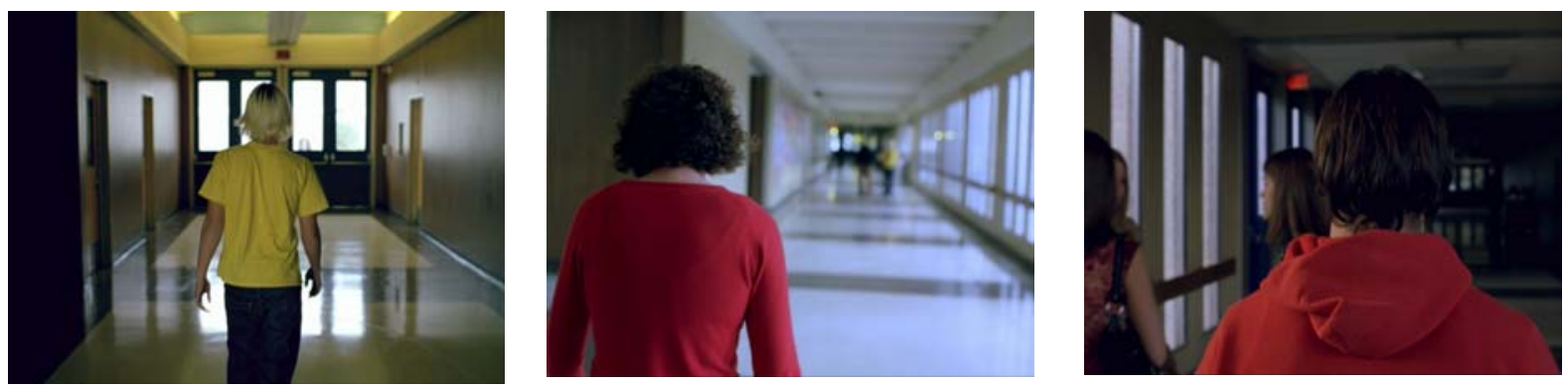

(Figures 4-6. Elephant's use of long-following shot offers a video gaming-like and lurking perspective)

The camera's movement in following the actors from behind is similar to the video gaming perspective of exploring and navigating. Here, the tracking long take in Elephant captures the logic of gaming in what Janet Murray describes as "the pleasure of moving around the unfolding of the maze” (129). Whereas the long take has often been associated with distancing and calling attention to the mediation of time and space, in Elephant, by contrast, the long take attempts to immerse viewers into the story by creating an interactive environment through the pleasure of movement.

Of course, the viewer is not like a video game player who controls a character's movement through space. It is more relevant to regard viewers as occupying the position of the "lurker," an Internet term that describes, for example, someone who watches online gaming, but does not play, or one who reads chat room postings, but does not post messages. ${ }^{30}$ Here, we are reminded of Van Sant’s comment noted above, “It’s not that I

\footnotetext{
${ }^{30}$ Both Dana Polan and Jan Simons offer unique accounts of lurking in television and cinema. See Dana Polan's The Sopranos. Durham: Duke University Press, 2009, chapter 6, and Jan Simons' Playing the Waves: Lars Von Triers' Gaming Cinema. Amsterdam: Amsterdam University Press, 2007, 147-52.
} 
don't want you involved in the characters, but I want you involved by watching them....”

In the content of this remark, we can see the long takes in Elephant as a means of engaging viewers' curiosity through their real time-like effect. That is, audiences experience the unfolding of events in tandem with the characters. The long take creates a viewership that reflects a game-like perspective as well as the affective dimension characteristic of the non-playing watcher. Furthermore, when considering that the film assumes viewers have prior knowledge of the Columbine shootings, the long following shot evokes a greater sense of suspense and anxiety. As the camera follows the characters, there is not only a sense of curiosity to navigate and explore the social space of the high school, but also a feeling of anticipation in the perspective of lurking, knowing that there is a future danger that lies ahead within these corridors. ${ }^{31}$

Additionally, we can see how the long following-shot in Elephant share similarities with the videogame's use of the subjective camera shot known as first-person shooter perspective (FPS). Galloway notes that the designers of the (FPS) video games have appropriated the cinematic technique of the subjective shot "to achieve an intuitive sense of affective motion” (69). In cinema, the subjective shot shows the inner psychological workings of a character—a kind of mind's eye perspective. For example, a spinning image may capture the drunken state a character. The point of view shot can, by contrast, show what the character sees in the physical sense. As Galloway points out, the Lady In The Lake (1947) is typically cited as a fully formed example of the subjective shot, because the viewers see through the eyes of private detective Philip Marlowe (Robert Montgomery) tracking his movements in real space and time. But Galloway

\footnotetext{
${ }^{31}$ As noted in chapter one, the lurking perspective in Stanley Kubrick’s The Shining (1980) is also noteworthy, specifically the scenes where the camera follows behind Danny (Danny Lloyd) as he rides his big wheel through the hallways of the Overlook hotel.
} 
notes the subjective shot is infrequently used in cinema ("materially marginalized" as he puts it): "they happen relatively infrequently within the apparatuses of filmmaking, and they are aesthetically marginalized in that they represent only specific moods and situations” (43). The subjective shot in cinema captures a brief moment of a character's interiority—a way of creating character identification. In video gaming, by contrast, it becomes, as Galloway notes, “[an] active subjective position that enables and facilitates the gamic apparatus” (69). In this regards, the marginalization of the subjective shot is similar to Hollywood's avoidance of the long take, in that both potentially reveal that construction of a film's virtual reality, making viewers conscious of their looking.

The subjective shot is central in the design of (FPS) video games. That is, a subjective camera perspective combined with a gun in the foreground constitutes the heart of the image in the FPS genre. Galloway recognizes that these gaming aesthetics are influencing forms of filmmaking. He specifically cites Van Sant's real time use of over-the-shoulder tracking shots in Elephant which "evoke a third person shooter genre... and then shifts to FPS proper perspective at a few crucial moments to depict actual gun violence” (60). The proper FPS images Galloway refers to occur during the shooting in the corridor of the school when the image positions a gun within the frame to mimic a video game aesthetic. Van Sant explains, "In Elephant, one of the killers in briefly playing a video game (Figures 7-8). We couldn’t get rights to [the video game] Doom so we designed one ourselves that resembles [his earlier film] Gerry, with two guys walking in a desert” (qtd. in Galloway, 60). 

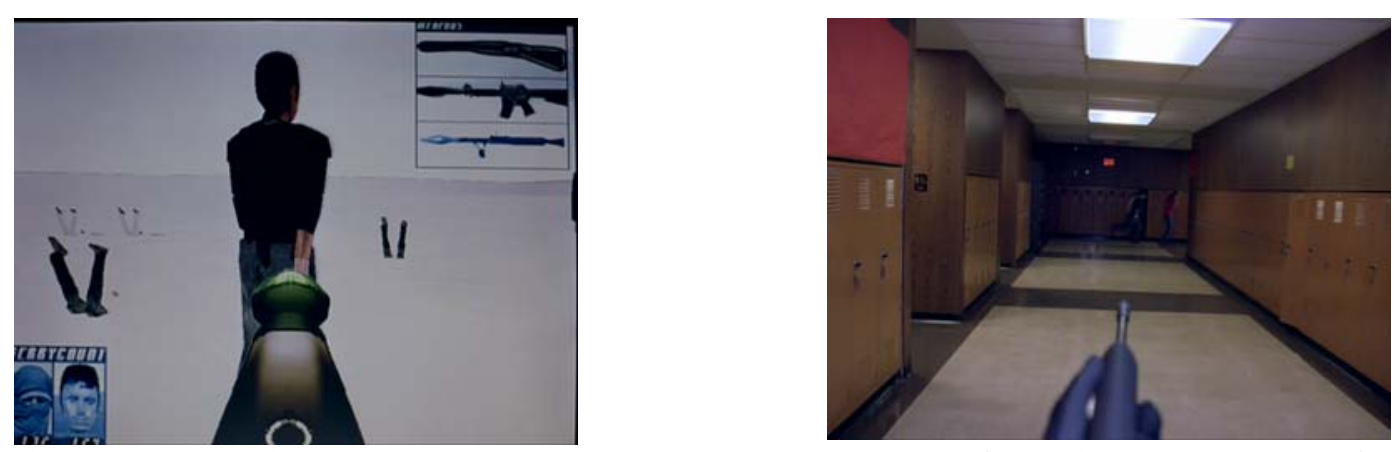

(Figures 7-8. Left: Eric playing Gerrycount, a reference to Van Sant's film Gerry. Right: Simulation of first shooter perspective while Eric and Alex plan the attack on the school)

Elephant's navigable space and video gaming aesthetic via the long take is another way of producing narrative paths and trajectories out of its catalogue of excess information. The following-shots through the corridors of the high school evoke the pleasure of spatial navigation. But, at the same time, they also create a sense of uncertainty and tension through their unfolding of space and time. Again, in order to create this effect, the film relies on the audience to bring previous knowledge and memories of the Columbine shootings to their viewership, including the anticipation of the final event when the shooting occurs.

The video game aesthetic captured in the following-shot adds another complex layer to the film's political reading of the Columbine event. It not only evokes a psychological tension connected to (FPS) video gaming and the lurking perspective, but it also culturally engages with the national conversation after the Columbine shootings around youth marketing of violent entertainment. Since video gaming was a key component in the debate in the marketing of violent entertainment, Elephant's database and video game aesthetic takes on a greater significance in the political decoding of its text.

Marsha Kinder notes that the fusion of games and film, for instance, was a direct response to changes from structuralism to post-structuralism as well as the political 
events in Paris in May of 1968. Cinema, as Kinder notes, had a privileged relationship to the events because of the firing of Henri Langlois, director of the Cinematheque Francaise who helped to spark the uprisings against de Gaulle’s government. Alternative cinema sought to de-naturalize realism of Hollywood cinema, which Kinder states, was "perceived as powerful transmitters of a political hegemony that was culturally colonising the world" ("Equivocations" 128). The hybrid of game and cinema "exposed" the realist illusion through its deconstruction of grand narratives.

Elephant's gaming aesthetic of a self-enclosed environment where the camera can move freely would seem to have the opposite effect of politically undermining the hegemonic mode of filmmaking, including the so called "progressive text." This technique of de-centering the master narrative through disturbing the self-governing worlds of classical cinema and revealing its structure, has strong ties to Barbara Klinger's critique of the progressive text traced to the work of Louis Althusser. Klinger points out that the progressive text seeks "to compose a knowledge of art" and to install "a sense of the reflexive, formal geography of the text, which, by critical extension, can be viewed as internally empowered to engineer an 'auto-critique' of the ideology in which it is held" (76). By departing from the dominant mode of narration, the text produces a rupture or lack in order to generate critical contemplation, providing viewers a pathway into the workings of ideology. Klinger notes the progressive text is "antirealist, as it rattles the perfect illusionism transmitted by a major sector of classic cinema” (78). Realism, from this standpoint, reproduces and values the dominant ideology by disguising the components that build the film's story world. Klinger’s essay critiques the progressive text because it fails to account for the flexibility of genres to incorporate differences into 
their system. In other words, genres cannot expand without a "combination of disequilibrium (excess, differences) and equilibrium (containment, repetition)” (88).

In this same way, the video-gaming aesthetic of Elephant not only attempts to create a virtual world with tendencies to narrative fantasy and realism, but it also within this self-contained world, allows for variation, permutation, and difference. Elephant's achronological and repeating narrative lines are characteristic of database and gamic narratives, which invite viewers to explore and build narrative trajectories out of its disparate pieces. These competing narratives situated within a video gaming aesthetic suggest the difficulty in representing a traumatic event through one point of view or one grand narrative. Yet, the film does not seek to distance viewers in order to achieve political effects. In other words, the film does not expose its structure as a "progressive text," nor does it reveal a hidden truth. Nevertheless, Elephant's treatment is political in the same sense that it undermines Hollywood's hegemony (as Kinder notes in gamic cinema associated with the politics of May of '68 does). To be specific, the film's use of video gaming aesthetic negotiates with modes of conventional cinema and database narratives, offering new ways of seeing, while at the same time sustaining the mystery of the unknowable causes that led to the massacre.

\section{Conclusion:}

Weeks after the Columbine shootings, the U.S. Senate committee held hearings on youth marketing of violent entertainment, adding to an atmosphere of paranoia and moral panic. At the opening of the Senate hearings, Republican Senator Sam Brownback stated, "We are not here to point fingers but to identify the causes of cultural pollution and seek solutions” (qtd. in Jenkins, “Littleton”). Brownback referenced metal and Goth 
bands such as Cannibal Corpse and Marilyn Manson as possible factors and causes into the Columbine shootings. This is primarily because Eric Harris and Dylan Klebold were considered goth teens, calling themselves: "The Trench Coat Mafia." The goal of this thesis is not to investigate the psychological and sociological causes behind the Columbine shooting. But it is important to point out that not only did these Senate hearings fail to recognize how culture produces meanings from popular forms of entertainment, but more importantly, they revealed how the ruling party attempted to manufacture consent by creating fear and moral panic in its discussion of popular culture. As Henry Jenkins points out, Congress was not out to create federal policies to regulate media content; instead, "They counted on public pressure to intimidate the entertainment industry into voluntarily withdrawing controversial works from circulation” (“Littleton”).

The Senate hearings on the marketing of violent entertainment illustrates Gramsci's concept of hegemony—not through force and coercion, but by shaping and winning consent. Jenkins notes that because of these hearings, "Many schools took away web and net access. Many kids were placed into therapy based on their subcultural identifications or interests in computer games or certain kinds of music" ("Littleton”). The impact of Columbine was felt in the entertainment industry. The episode "Earshot" of Buffy the Vampire Slayer (scheduled a week after Columbine) was cancelled because a scene involved a suicidal student with a loaded rifle in the school's bell tower. The episode "Lines of Fire" of Homicide: Life on the Streets, which involves a father/gunman who takes his daughter and son hostage after losing his job and custody battle, was moved ahead one week in order to distance it from Columbine. Many movie theatres 
enforced a policy that required teenagers to show photo identification to see R-rated movies as a way to limit their exposure to violent entertainment. ${ }^{32}$

Elephant's opposition to the manufacturing of consent around the causes of Columbine event constitutes its counter-hegemonic political moment. It does this through its employment of the long take and database aesthetics, which intermingle with the anxiety and moral panic surrounding to the Columbine tragedy. The film's narrative gaps invite viewers to reflect upon how mass media representations and the rhetoric of the ruling party attempt to shapes political subjectivity through consent. Yet the film preserves the indeterminate zone between artist and spectator through its refusing to offer viewers solutions for why this terrible tragedy occurred. In particular, the film does not try to overtly mobilize viewers by making them aware of a hidden truth. As Van Sant states, "You just watch and make the associations for yourself, as opposed to having the film-makers impose ideas on you. Here the causes have already happened and I don’t think there's a clear answer as to why. So we're not showing the causes, just the crisscrossing network of the last two days” (qtd. in Said, "Shock Corridor” 17). This, I argue, is what situates the politics of Elephant in the terrain of an undeterminable zonewhere the film’s long takes and database aesthetics not only break with the traditional mode of Hollywood production, but it invites viewers to develop competing narratives in making sense of its narrative gaps.

\footnotetext{
${ }^{32}$ Miller et al. note that this led President "Bill Clinton to charge the Federal Trade Commission with the task of producing a study of the culture industries that target children with violet texts. Over a period of several months, the Commission undertook this charge, inter alia, by spying on teenagers across the country as the entered movie theatres, in what it described as an 'undercover shopper survey'” (32-33).
} 


\section{Chapter Three}

"Made In America:"

\section{The Television of Delay in Twin Peaks and The Sopranos}

I...started thinking about it [The Sopranos] as Twin Peaks in the Jersey meadowlands.

---David Chase, (qtd. in Heath, “Sopranos”)

I think there were shows that came along afterwards that owed a debt to what we'd done. The one that meant the most to me was David Chase saying that The Sopranos had been influenced by the show [Twin Peaks].

---Mark Frost, (qtd. in Andrew, “Rebirth”)

The past two chapters explored how digital media are informing variant articulations of the long take in cinema. I would like to turn now to the medium of television in order to understand how the dynamic of speed and slowness are creating new ways of seeing the televisual text in the digital age. Laura Mulvey's Death 24x a Second argues that digital technologies are changing the perception of cinema both stylistically and consumptively. Mulvey describes this phenomenon as the "cinema of delay." She notes, "There is narrative cinema in which delay is essential to the desire for the end, elongating the road down which the story travels, postponing the structurally inevitable conclusion. There is narrative cinema in which delay opens up alternative narratives opportunities, displacing the desire for the end” (144). For Mulvey, delaying cinema has two functions. One refers to aesthetically slowing down the flow of the moving image. The other refers to digital technologies allowing viewers to halt the flow of the film, to repeat and return to sequences, isolate moments for textual analysis, and to find "the film behind the film" (145). I argue that television is also representative of this 
shifting perspective of time that Mulvey identifies in the production and consumption of cinematic texts. It is what I shall refer to it as the television of delay.

Twin Peaks (1990-1991) and The Sopranos (1999-2007) are exemplary case studies of the television of delay in their unconventional approaches to the television format. In 1990, Twin Peaks had a significant impact on broadcast television in terms of both its style and content. Director David Lynch and Hill Street Blues writer Mark Frost's detective melodrama brought elements of the uncanny, the surreal, and the absurd to primetime television, while at the same time reflecting on themes of Americana. Aesthetically, they stressed slow temporal progression, such as the languid opening credits, unusual emphasis on objects, and ethereal dream sequences. Moreover, in investigating Laura Palmer's murder, they defied a strict rule of the detective narrative by using the supernatural alongside the genre's traditional use of deduction and reasoning (Olson 281).

Unlike Twin Peaks, David Chase’s mafia melodrama The Sopranos' aired on HBO, a cable and satellite commercial free network that allowed for explicit violence, language, and nudity. Chase, who often cited Twin Peaks as a source of influence, deviated from the traditions and "tightness" of the mafia narrative by using meandering plotlines, temporal interludes, dream sequences, and narrative ambiguities (Polan, Sopranos 7-9). A most notable example occurs in the now infamous final scene in the last episode of the series that ended with no narrative closure, leaving viewers to ponder the fate of Tony Soprano, a topic which will be explored furthered in chapter four. Like Twin Peaks, Chase explored issues of American culture through its references to popular movies and music, as well as discussions of immigration and the American dream. 
Both of these shows continue to gain audiences through syndication on cable, DVD purchases, rentals, and on-video-demand sites, demonstrating that the processes of delay and repetition in the uses of speed technologies are able to spawn "ancillary afterlife.” As John Caldwell notes, "cable television taught television that programs never die; they just keep resurfacing in the niche afterlife” (229). ${ }^{33}$ For our purposes of discussing accelerated culture, the significance and popularity of Twin Peaks and The Sopranos is that they provide insights into changes in television's economic mode of production, and the new technological conditions of time-shifting. In addition, the production and reception of these shows illustrate that the conditions of speeding up society have contributed to multiple and contingent changes in meaning.

Three points are covered in this chapter. First, I provide a very brief tracing of new economic processes of television in order to understand how both shows are situated within their respective networks. These conditions of existence, I claim, are a result of flexible accumulation and the compression of time and space impacting the mode of production in television. I argue that these new economic conditions created an opening for new expressions of the televisual text: for example, ABC looking for fresh and edgy shows to rebuild its network in the 1980s, or HBO’s new programming of “Original Series” at the end of the 1990s. Lynch, Frost, and Chase seized these opportunities, bringing art-house and European styles of cinema to the television format. Secondly, I provide examples from both shows in order to demonstrate how delay and movement are aesthetically represented. I argue that narrative digression and the intrusion of delay halts the narrative flow in order to evoke the uncanny, the absurd, the surreal, and the

\footnotetext{
${ }^{33}$ Here, we should also note television and video's impact on now popular and classic films, such as It's a Wonderful Life (1946) or A Christmas Story (1983) —both films that did little business at the box office in their intial release.
} 
transcendental. Lastly, I argue that these digressions, in certain instances, advance the narrative action through a character’s magical-like or supernatural deduction.

\section{Flexible Accumulation and the Impact of Cable, VCR and Satellite}

The art film styles and embellishments that inform the story worlds of Twin Peaks and The Sopranos, in part, emerged out of the conditions caused by flexible accumulation upon the entertainment industry. According to David Harvey, flexible accumulation is characterized both by new patterns in the labor section, and the compression of time and space though the speeding up of culture. The emergence of flexible accumulation is due to a number of factors, including a reaction against the rigidities of Fordism, competition from foreign companies, and saturation of standardized goods. In short, Harvey writes that flexible accumulation is "a series of novel experiments in the realms of industrial organization as well as in political and social life” (145). For Harvey, this "new regime” in capitalism, which is marked by decentralization, does not mean “disorganization.” Capitalism, in the post-Fordist era, on the contrary, becomes even more organized through its "flexible response” towards the labor and consumer sectors. "Imploding” capitalism, from this perspective, intensifies its organization.

Specifically, there are three interrelated technological developments I want to highlight in regards to flexible accumulation and changing spatial-temporal relations in television: satellite communication, cable technology, and the VCR. The overlapping and converging of these three technological shifts combined with new economic conditions resulted in unexpected developments in television's mode of production.

The birth of HBO occurs during the new "flexible regimes" of capitalism in the

1970s. HBO was the first subscription television service (STV) to utilize the technology 
of satellite and cable signals. CATV (Cable TV) was initially used only to service rural and mountainous populations. However, in 1972, the FCC removed its restriction to allow for cable to reach urban and metropolitan areas as well. In October of 1975, HBO “inaugurated its satellite cable service” with its live feed of Muhammed Ali and Joe Fraiser’s heavy weight fight “Thrilla in Manila” (Edgerton, “Introduction” 2). After the broadcasting of this legendary event, HBO became a national network, setting the groundwork for other (STV) networks, such as ESPN and Showtime. This little history reveals that the compression of time and space through flexible accumulation involved both the FCC's deregulation of CATV, and the diffusion of TV satellite communication.

The emergence of satellite and cable networks had a significant effect on the three major broadcast networks CBS, NBC, and especially ABC, resulting in a dramatic decline in market share. In the 1980s, network television reconstructed its mode of production in order to stay competitive. One of these structural changes was to transform television into a self-conscious and highly visual medium that markets, (to use John Caldwell term) “televisuality.” NBC’s Hill Street Blues, for example, broke new ground in the 1980s, adding a distinctive gritty and realistic punch to the traditional police narrative. Another example is the highly expressionistic and postmodern look of Michael Mann’s television police drama Miami Vice. The signature looks in these shows is a way for networks to market a new brand or style of television to its viewers.

$\mathrm{ABC}$ was hit the hardest during these new industrial conditions and fell to the level of basement ratings. ABC had to re-make its image in order to stay competitive. One of the philosophies put forth by ABC’s new President of Entertainment, Brandon Stoddard, was innovative programming. Bill Carter writes in the New York Times, "He 
[Stoddard] declared an end to the old style at ABC and said the network would strive for shows that 'stood for something”" (“Twin Peaks”). ABC began a five year plan to make the network competitive with the other networks and to respond to the growing need for “quality television.” A part of ABC’s plan was to invest in riskier shows that would push the boundaries of conventional television both narratively and aesthetically. Twin Peaks clearly fitted with what $\mathrm{ABC}$ was searching for. They even promoted the show as "the series that will change TV" (qtd. in "Television," Collins 344). In a recent interview with The Guardian, Twin Peaks creator Mark Frost reinforced this, stating: "We decided that we had a break to daylight here; a chance from the network [ABC] to go mad, to do whatever we felt like doing...we were able to secure from them unprecedented artistic controls on the show" (Andrew, "Rebirth”). Although the eccentric world of Twin Peaks was short lived, it became one of the highest rated shows of 1990, and would later earn cult status through syndication and video rentals.

In the mid-1990s, HBO sought to diversify its network by changing its programming strategies and introducing original series to its schedule. A factor that distinguished HBO from the broadcast networks was commercial free movies. But with the widespread popularity of the VCR and home video renting, HBO needed a new programming strategy in order to evolve as a network channel, and create a "more intense” relationship with its subscribers (Anderson, “Aristocracy” 32). HBO’s new plan was to produce original series programming alongside its regular schedule of commercial free movies and sporting events. Marketing the slogan, “It's not TV. It's HBO,” the introduction of original series not only significantly transformed HBO, but also enabled it to directly compete with the major broadcast networks. In the summer of 2001, "NBC 
chairman Robert Wright challenged his colleagues to consider what they might learn from HBO’s extraordinary success” (qtd. in “Introduction,” Edgerton 16). David Chase’s The Sopranos was at the center of HBO's shift in their programming strategy. According to David Thorburn, The Sopranos, during its third and fourth seasons, was watched by an estimate of 14 million viewers in 7.3 million TV Homes, a staggering amount for pay subscription television (61). The phenomena of The Sopranos helped to promote and elevate HBO's signature brand of television, as well as influencing broadcast and other cable networks.

This brief examination of the economic, technological and social conditions raises a number of points. For our purposes of examining the television of delay it is important to stress that in producing these shows, $\mathrm{ABC}$ and $\mathrm{HBO}$ illustrate that television is not a medium for a homogenized mass audience. The popular reception of both shows demonstrates that individualized networks are able to gear their programming to the specific tastes of specific "niche” audiences.

The acceleration of culture through the new technologies of satellite communication, cable, and the VCR produced openings for new stylistic approaches to the television format. ABC, who had to re-make its image in order to stay competitive, took advantage of this. $\mathrm{HBO}$ too was forced to change its offerings because of the impact of the VCR and home video renting. At the same time, the VCR, DVD, and DVR devices that allowed for repetitive viewings created new audiences for the shows' afterlives. In short, the economic conditions of flexible accumulation and the compression of time and space by the new technologies dramatically changed the face of television. In the next section, I examine the impact of these changes by looking at how 
Twin Peaks and The Sopranos' used art house styles of cinema in their representations of narrative time and space.

\section{Delaying Television: Twin Peaks}

In episode four, “The One-Armed Man” in Season One of Twin Peaks, Agent Dale Cooper (Kyle MacLachlan) says to Sheriff Harry Truman (Michael Ontkean): "Harry, in the heat of the investigative pursuit, the shortest distance between two points is not necessarily a straight line.” Cooper's statement may be seen as a meta-textual remark about the complexity of Twin Peaks' narrative mode as well as the show's unusual treatment of time. Referencing Peter Brooks' work on plot and narration, Mulvey notes, "the line of narrative cannot follow the straightest path from point to point without deviating from its course" (124). For Mulvey, the departure from the flow of narrative progression can "vary significantly, built around... an aesthetic of suspense, or at a further extreme, the intrusion of digression...” (124). According to Mulvey, delay has two central functions in regards to the narrative's causal chain. In traditional storytelling, the progression of the narrative confronts obstacles and problems that characters must solve in order to advance the action. As David Bordwell puts it: "The premise of Hollywood story construction [is]: causality, consequence, psychological motivations, the drive toward overcoming obstacles and achieving goals” (Classical 13).

But there is also a delay that transgresses and impedes the narrative flow, where causality is not overtly motivated and ambivalence frustrates the linear. For Mulvey, this type of delay is a vehicle for “the film's uncertainty, unstable materiality torn between stillness of the celluloid strip and its illusion of its movement, leading to further reflection on the representation of time...” (26). The film image, according to Mulvey, has an 
uncertain status towards the passing of time. Cinema's secret (its "ghostly presence") is the still frame, which is concealed by both the mechanical image moved at 24 frames per second, and the illusion of movement through the continuous ordering of narrative time and space. For Mulvey, when the moving image is halted or slowed down, its "moment of registration" of time and space rises to the surface, thereby uncannily bringing forth its materiality.

Traditionally, television does not want to obstruct or call attention to the forms that build the fantasy of the story world. Like Hollywood, the television narrative coordinates and closes up narrative gaps in order to present the illusion of a continuous and smooth ordering of fictional time and space. Narrative motivation, as Bordwell puts it, "unifies" and "justifies its story materials and the plot's presentation of that story material” (Classical 19). Linear ordering of narration and invisible styles of editing is how fantasy sustains itself. Speed, in this sense, has an intimate connection to fantasy and the unification of the narrative, because its materials must be ordered and paced in order to present a smooth and transparent unfolding of events in time and space. Another way to put it is that immediacy is a way to manage narrative contingencies both formally and narratively. But as I will argue below, in their formal expressions, Twin Peaks and The Sopranos foreground contingency and uncertainty in the televisual text, by mediating between delay, in the traditional sense of characters overcoming obstacles, and the aesthetic of delay that intentionally disturbs linear durational order.

Certainly there are elements that distinguish television from cinema, such as commercial breaks and cliff hanger endings that keep viewers enticed and returning to the show. Delay, in this respect, is not a transgression of television viewership, but a part 
of its mode of production. Television writing builds into its narrative structured commercial breaks in terms of its temporal flows within the episode. ${ }^{34}$ Although The Sopranos was commercial free in its initial airing on HBO, it still contained a built-in element of delay, which reflects that the show was broadcast in a series of episodes. It must also be noted that The Sopranos was not locked into a yearly seasonal schedule, and thus had more time for development. For example, viewers waited more than a year and a half for the start of the fifth season in March of 2004. I will refer to this feature as the television of delay in order to distinguish it from cinema that offers a self-enclosed narrative constructed for viewing in a single sitting. ${ }^{35}$

The first season of Twin Peaks was a huge hit for ABC in the spring of 1990, drawing in many viewers who were intrigued by the plot as well as Lynch and Frost's untraditional approach to the detective narrative. Lynch and Frost's depiction of the sawmill town of Twin Peaks and its panoply of characters not only offers a heightened emotional experience, as if one has been transported to another world, but also invites viewers to unscramble and decode its narrative puzzles. The journey to uncover these clues is interrupted by the show's campy dwelling upon singular objects, as well as strange and unexplained disjunctions in the storyline, which are typical of the surreal, the absurd, and the aesthetics of delay. This is not to suggest that Lynch and Frost do not

\footnotetext{
${ }^{34}$ It is important to stress that I am not using the term "flow" traditionally defined in television studies as: "the scheduling of programs and advertising breaks within and between them as a continuum" (qtd. in Thompson, Storytelling 6). I am following Kristin Thompson's argument that: "Rather than perceiving the narrative as flowing into and incorporating the commercials, they [viewers] most likely think of it as being suspended for the duration and resuming after the break" (16). Of course, this break or suspension in television watching is also the wait time between entire episodes and seasons. It is also interesting to note that DVR devices, DVD rentals, and online-streaming now allow viewers to watch an entire season of a television show without the wait time of live television.

${ }^{35}$ It should be mentioned that there are films, especially trilogies such as Lord of the Rings and Star Wars that allude to its franchise's next installment. But again, these films are constructed around one sitting.
} 
want viewers' emotional involvement. On the contrary, Twin Peaks seeks emotional response through its "poetic" orchestration of sounds and images. As Kenneth C. Kaleta notes, "It [Twin Peaks] is a world of the senses, operating with an immediacy and an intensity not of narrative development, but of the poetic concentration of its images and sounds” (137). This lush world of visual and audio expressions of Twin Peaks is achieved by Lynch and Frost simultaneously deviating from and working within the conventions of television.

Twin Peaks is full of secrets—clues to be uncovered and decoded in order to solve its mystery. Exaggerated attention on singular objects begs for further interpretation and investigation in deciphering the show's puzzle. Here, Frost and Lynch play with film's ambivalence between stillness and movement by introducing the surreal and absurd. These moments often impede and disrupt the narrative flow. For example, in the pilot episode, a traffic light is shown swinging back and forth in an empty street, helping to create an uncanny atmosphere. But when the traffic light is show again at the conclusion of the pilot, right before Sarah Palmer’s (Grace Zabriskie) shocking vision of evil entity BOB (Frank Silva), its meaning is called into question. The familiar image of the traffic light, a literal signal of halting, temporally delays narrative progression, creating a sense of uncertainty. But it is not made clear if the traffic light has any significance in the Palmer murder case. Why do Frost and Lynch keeping returning to it? Through a brief intrusion of delay, the traffic light embodies the show's element of mystery as well as its "ghostly presence." But the meaning assigned to the traffic light in terms of forwarding the story remains elusive. 
Delay not only registers film's uncertainty towards the passing of time, but can manifest in the comedic and the absurd. In the pilot episode of the show, Cooper and Sherriff Truman travel to the town's bank to investigate Laura's safety deposit box for possible clues. As the bank assistant leads them into a room, the trophy of a mounted deer head is strangely seen resting on the table. The assistant says to them in an affectless manner, “Oh, it fell down.” Cooper and Truman stare blankly at the head of the deer and then continue with their investigation. A deer is certainly representative of the rural area of Twin Peaks. But the manner in which the head of the deer is staged within the narrative (and strangely placed within the conservative setting of a bank) is off-beat and interrupts the flow of the story. The deer is positioned front and center, overwhelming the space within the shot, thwarting narrative progression as it constantly draws attention to itself (Figure 9). Again, an object situated within the everyday is defamiliarized and made uncanny and surreal through extended duration.

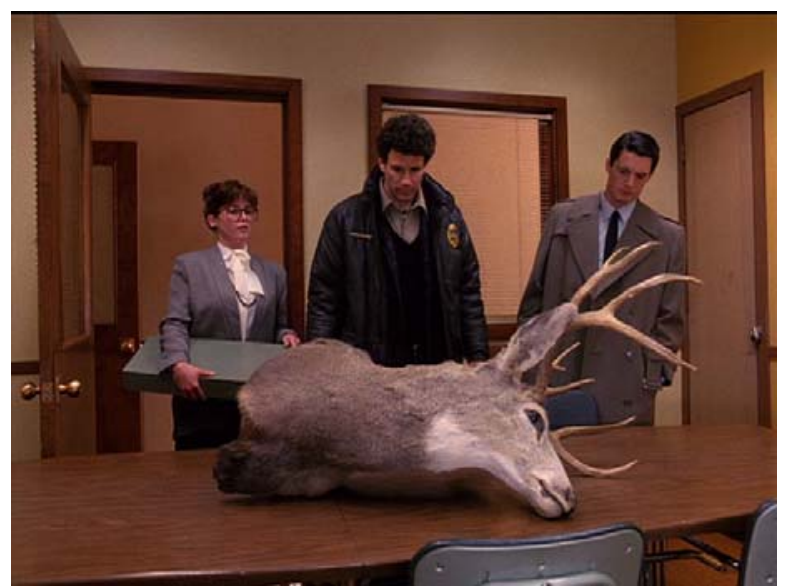

(Figure 9. Cooper and Truman oddly encounter the trophy of a mounted deer head at Twin Peak's local bank)

Another example is the strange emphasis on donuts (Figure 10). Of course, the depiction of donuts in the context of television and law enforcement is a stereotype. 
Lynch and Frost, however, play with this association by shifting it into the realm of the comedic and the absurd.

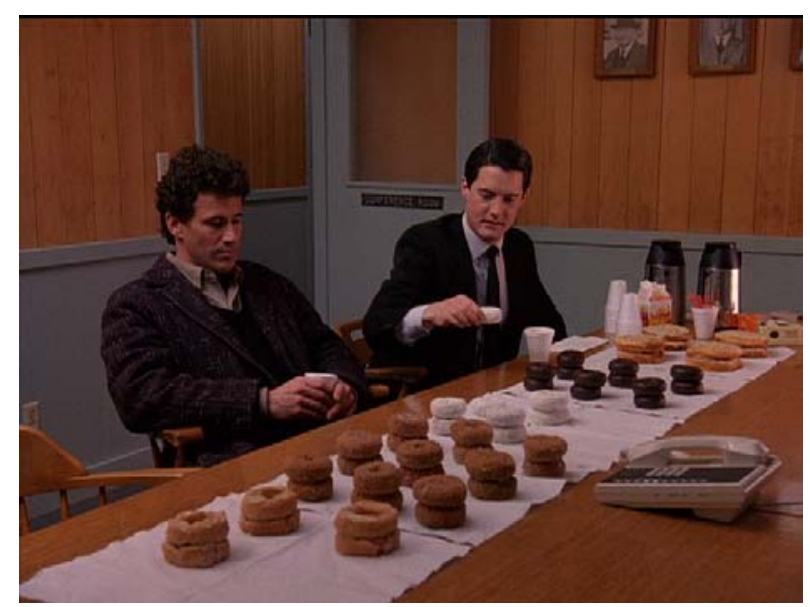

(Figure 10. Lynch's unusual emphasis on donuts)

It is obvious in the image above that the ratio of donuts to Twin Peaks' very small police department is excessive. Such unusual emphasis on food and beverages is, of course, not new territory for Lynch. (The infamous and frightening outburst by Frank Booth [Dennis Hopper] on the virtues of drinking Pabst Blue Ribbon rather than Heineken beer, in Blue Velvet [1986] comes to mind.) Throughout Twin Peaks, Lynch and Frost are constantly stopping the narrative in order to do justice to the pleasures of sugar foods, particularly breakfast and desserts ranging from coffee, pancakes, and huckleberry and cherry pies. These shots of sucrose often subordinate the narrative flow: for example, Cooper's expression of ecstasy while eating cherry pie: "This must be where pies go when they die,” or, Gordon Cole’s (David Lynch) exaggerated response, “I plan on writing an epic poem about this pie.” Whereas the swinging traffic light evokes a sense of uncertainty, the head of the deer and the unusual emphasis on food derails the linear temporal flow of the narrative and create surreal and quirky moments.

Temporal digressions can call attention to the mediation of time within an episode itself. This is often manifested in Lynch and Frost's use of dance and music. Early in the 
pilot episode, Donna Hayward (Lara Flynn Boyle) and Aubry (Sherilyn Fenn) are talking in the hallway in the high school as one of Angelo Badalmenti’s signature cool jazz themes is heard. The school bell rings as everyone scurries off to class. The image cuts to two teen girls walking forward in the hallway. Suddenly, a student in the background snaps his fingers, mimes strumming a guitar chord, shuts his locker, does a spin, and dances down the hallway (Figure 11).

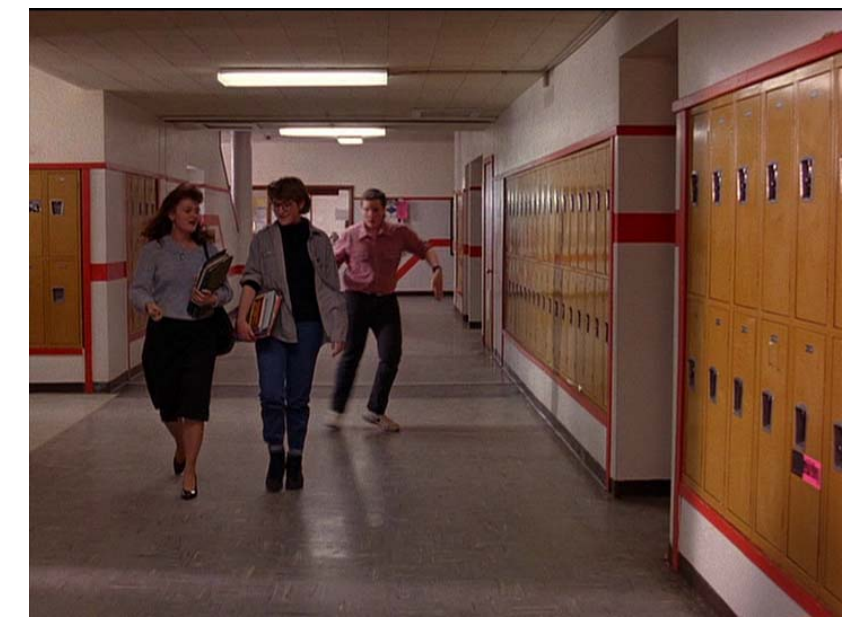

(Figure 11. A background character dances to the show's soundtrack)

Like Cooper and Truman greeted by the mounted deer head at the bank, the dancing teenager temporally (and hilariously) impedes the narrative flow. Yet at the same time, his dance calls attention to the show's soundtrack, bringing its mediation to the surface. Indeed, unplanned dance is a motif that runs throughout the show. Other examples, such as the dancing dwarf in Cooper's dream, Aubry's dance in the diner, and Leland Palmer's (Ray Wise) dance to the song "Mairzy Doats" are representative of digressions that slow down the show's temporal flow as the narrative shifts to the background. ${ }^{36}$ In this regard,

\footnotetext{
${ }^{36}$ However, later in the series, dancing becomes an important role in understanding BOB's ritual of dancing compulsively after he kills his victim, which Cooper uncovers in the episode "Arbitrary Law" in Season Two.
} 
the television of delay is taken out of the domain of the visual and inserted into the audio realm.

Musical numbers in Twin Peaks are enthralling: for example, the slow and hypnotic performance of “Just You,” performed by James (James Marshall), Donna (Lara Flynn Boyle), and Madeline in the episode “Coma,” which starts the second season. Such use of musical numbers is a theme that runs throughout Lynch's body of work. He often uses slowly paced older pop songs, for example, Bobby Vinton’s “Blue Velvet” in Blue Velvet, or Roy Orbison’s “Crying” in Mulholland Drive (2001). Music in Lynch’s work evokes a sense of mystery, creating a surrealistic atmosphere within familiar places, for example, Audrey's spontaneous dance in the diner. We find the same expression in the performance of “Just You." The song is a digression, but it also advances the James and Donna storyline (more on this later in the chapter). These musical sequences of delay do not depend on the elements that typically construct fantasy. Lynch and Frost expand the boundaries of television by introducing fantasy through heightened and poetic emphasis on objects, spontaneous moments of delay, and musical digressions, situating viewers between the realm of the normal and the surreal.

\section{Delaying Television: The Sopranos}

David Chase's The Sopranos follows many of the traditions of the mafia/gangster narrative. Themes of family, loyalty, and betrayal, for example, are representative of The Sopranos' story world. Yet, the show breaks with the traditional narrative structure of television through digressions, slow pacing, and long dream-sequences. Chase frequently acknowledged the influence of Twin Peaks, specifically its poetic use of the dreamscape 
and surrealism in the television format. ${ }^{37}$ And like Twin Peaks, many of the episodes of The Sopranos are filled with in-jokes, pop cultural references, and unexplained occurrences that have no closure or clear exposition. As Dana Polan notes, The Sopranos exhibits a narrative structure that is a "sprawling work which flirts with narrative logic," rather than the "tightness" of traditional mobster fiction (21).

As in Twin Peaks, digressive moments and sequences in The Sopranos touch upon the surreal and even transcendental. These otherworldly digressions allow for character reflection as well as for viewer speculation. The fact that The Sopranos was televised in a commercial free network permitted greater emphasis on delays and narrative departures. For instance, at the end of the first episode in Season Six, "Members Only,” Tony is shot in the stomach by his Uncle Junior (Dominic Chianese) who is suffering from dementia. The shooting of Tony is a classic example of a cliff hanger ending in television. One would think the follow up episode should start with speed and immediacy: Tony being rushed to the hospital or doctors trying to save his life. On the contrary, the next episode, “Join The Club” begins quietly as Tony lies on a bed in a hotel room. ${ }^{38}$ He leans up and looks off screen. The image cuts to the hotel window that looks out onto the cityscape. In the horizon, a strange glowing light spins in the distance. Later, it is revealed that Tony is at a convention in Costa Mesa, California, and is in possession of someone else's briefcase, which belongs to a man named Kevin Finnerty. Viewers learn that Tony is in a coma and that the space of the hotel is a standin for his unconscious, or he is possibly stuck in purgatory. But it takes time before this

\footnotetext{
${ }^{37}$ See also Chase's response to Lynch's use of dreams in the 2011 PBS series America In Primetime.

${ }^{38}$ Similarly, in Twin Peaks, after Cooper has been shot in his hotel room, the second season starts off very slow as Lynch deliberately creates a scene of stillness or frozenness while Cooper lay hurt on the floor, which was the cliff hanger ending for the first season.
} 
information is revealed, thus illustrating Chase's penchant for slow duration and images that evoke contemplation and reflection. As Polan notes, "[The Sopranos often] slow things down, impart minimal information, and set up a situation in which the spectator waits at leisure for something to happen” (30).

The "Join The Club" episode ends with Tony returning back to his room. He looks at the window again and sees the glowing light in the horizon. But this time the image is framed closer to underscore its presence (Figure 12).

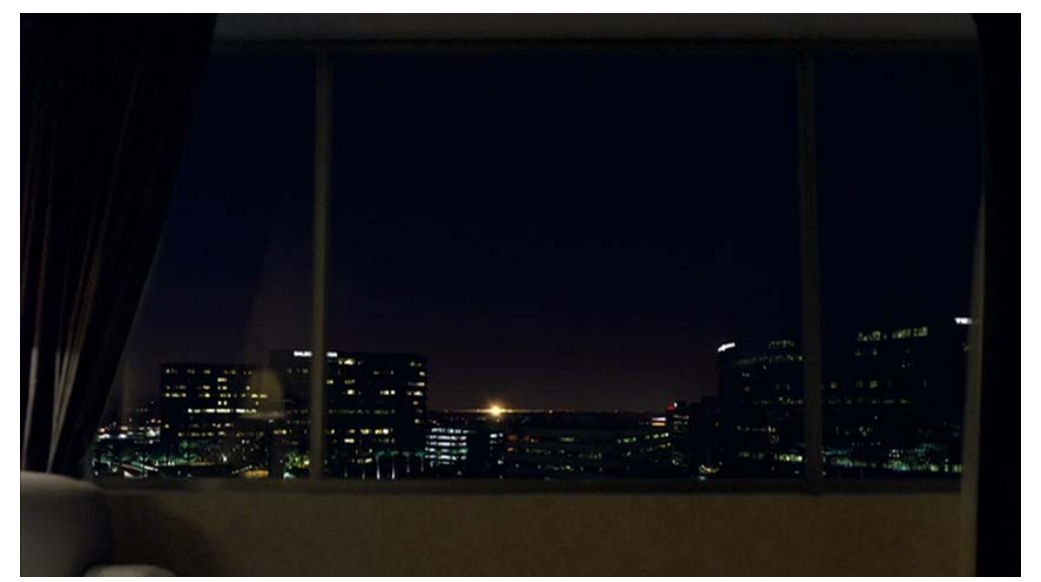

(Figure 12. Tony's point of view of the elusive beacon light spinning on the horizon through the hotel window in Costa Mesa)

The glowing light, a navigational beacon for airplanes, evokes a sense of uncertainty. Yet its significance and why it is emphasized remains elusive. Like the swinging traffic light that blinks for an empty street in Twin Peaks, the glowing light in the horizon invites inquiry into its presence. But the light's meaning in relation to Tony's coma is left unexplained. That is, its symbolism is intentionally ambivalent. From this perspective, the "alternate world” that fills in for Tony's mind not only illustrates Chase's emphasis on dreamscape and surrealistic imagery, but also connects to Tony's fossilized state, caught between life and death—a moment of twilight embodied by the space of the hotel, which, after all, is a place of transition. To capture this state of entrapment 
between two worlds, the representation of time is distorted. While in real narrative time, in the space of the hospital, spectators anticipate Tony's recovery from his coma so he can get back to "business."

The strange glowing light in Tony's “alternate world” triggers more speculation during Carmella (Edie Falco) and Rosalie’s (Sharon Angela) trip to Paris during the eleventh episode, “Cold Stones” of the same season. Carmella has fallen in love with Paris. Like Tony, she finds herself in a world outside of her own. But instead of entrapment or loss of identity, Carmella's emotional journey through Paris is (to use Mulvey's reference to D.N. Rodowick's work on Gilles Deleuze's concept of the timeimage), an "aleatory stroll," a loosening of the linear narrative, and an opening of spaces for contemplation (111). Chase has stated numerous times his love of European cinema. Here, one is reminded of Michelangelo Antonioni's La Notte (1961), where early in the film Lidia (Jeanne Moreau) takes a long “aleatory stroll” through various spaces of Milan. The connection to Carmella is that Lidia has become estranged from her husband and popular writer, Giovanni (Marcello Mastroianni). Lidia’s stroll through the city spaces embodies their disintegrating marriage. At the end of season four in The Sopranos, Carmella and Tony separate because of his affair with his "goomar," (his girlfriend on the side). But at the end of the fifth season, Tony and Carmella reconcile, because she asks him to front $\$ 600,000$ for her to build a spec house with her father.

During Carmella and Rosalie’s visit to the Gallo-Roman baths, Carmella contemplates time and existence, recalling Tony's brief awaking during his comatose state, when he said to her, “Who am I? Where I am going?” Distraught, Carmella confides in Rosalie, “At the time, I did not know what he meant. Coming here, I feel the 
same way.... In the end, it all gets washed away.” Here, Carmella speaks to the elusiveness of time and memory in her reflection upon both Paris's history and her relationship to Tony. Thus, the trip to Paris captures Carmella’s distant emotional estrangement from Tony, which is materialized through her solitary strolls, her philosophical musings, and unusual emphasis on objects, which, in turn, opens a space for reflection and contemplation.

At the end of the episode, Carmella waits on the city street as Rosalie returns back to the hotel room. Carmella looks up at an arch window, as a sculptured face in the wall of the archway gazes back at her. She turns to look at the top of the Eiffel Tower in the distance, as its blue spinning light cuts across the nighttime sky (Figure 13).

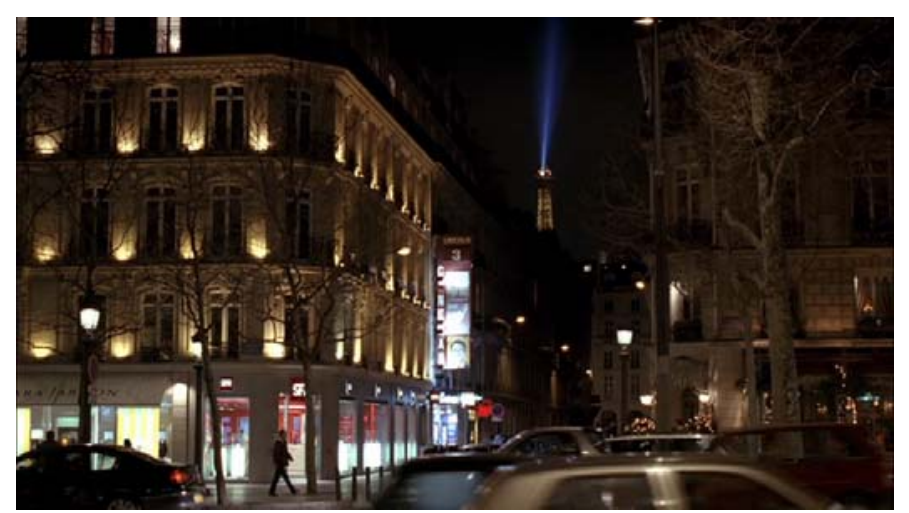

(Figure 13. Carmella's point of view of the spinning light of the Eiffel Tower, which possibly connects back to Tony's unconscious state in Costa Mesa)

The spinning light and sculpted/mummified head in the building of the wall has a sort of “otherworldly” connection to the glowing light Tony encounters at the hotel during his fossilized state. Of course, Carmella could not have access to Tony’s vision/dream-this is something only viewers are privy to. The significance of the lights in both episodes resides in the divergence between paths that Tony and Carmella take in response to their estrangement. Tony, for a moment, lives in another world, becoming what he desires the least—an average family man trapped in transit. Whereas Carmella, for a brief moment 
of time, obtains what she desires through her emotional and "aleatory" journey into the sites of Paris, a place completely different from northern New Jersey. ${ }^{39}$

Yet, it may be misleading to offer a symbolic reading of the glowing light. Often in The Sopranos and Twin Peaks a random event occurs, but has little or no meaning in terms of forwarding the narrative. As Polan points out, Chase's love of art cinema of the 1950s and 1960s (which often encourages close readings of dreamlike sequences), "is perhaps revealing that his reference for dreams is to television and that he seems most indebted to experimental efforts in that medium, such as Lynch's show [Twin Peaks], that replace the extended interpretation with a mysterious uncanniness that remains on the surface and has no depth behind it” (127). This uncanniness in both shows is triggered by the moving image's ambivalent relationship to movement and stillness. The slowing down of the narrative temporal flows by unusual emphasis on objects and character digression brings to the surface the mediation of time and space. These instances of delay evoke the surreal, the comedic, and the absurd as well as provide an open space for character and viewer reflexivity within the televisual text.

\section{Forwards through Delay: Dreams and Secrets}

The intrusion of delay is a way in which Twin Peaks and The Sopranos

destabilizes the narrative's temporal flow in the television format. As we have seen, both shows foreground delay through unusual emphasis on objects and ambivalently driven narrative digressions. However, in certain instances, digressions also help characters to

\footnotetext{
${ }^{39}$ We can even add Vito Spatafore's (Joseph R. Gannascoli) storyline in the sixth season as a journey into an alternate world. When it is revealed that Vito is a homosexual, he flees from New Jersey, leaving behind his family. Vito ends up in a small town in New Hampshire where he meets Jim (John Costelloe), a cook/volunteer fireman who is also gay. Vito temporally begins a new and quiet life with Jim. But once Vito settles in, he cannot live an ordinary life. He returns to New Jersey, where he is brutally murdered by his brother-in-law and New York mob leader, Phil Leotardo (Frank Vincent).
} 
problem solve and overcome obstacles within the everyday, thus, pushing the narrative forward. This is most notable in both shows' use of dreams. From this perspective, digressions in the shows oscillate between slowing down the unfolding of time and space and enabling unspoken or magical-like deductions that advance narrative action.

Dreams in Twin Peaks have a double function in relation to digression and narrative causality. Firstly, dreams are a passageway to uncovering clues and suspects. This is illustrated in Cooper's method of “Tibetan rock-throwing.” In episode two in Season One, “Zen, or the Skill to Catch a Killer,” Cooper assembles Sheriff Truman, Lucy Moran (Kimmy Robertson), and Deputy Andy Brennan (Harry Goaz) to demonstrate the rock throwing technique, a procedure he discovered while analyzing his dreams. While he thinks of a suspect's name, he throws a rock at a bottle. If the bottle breaks, the suspect is involved with the murder. When Lucy says Leo Johnson's (Eric Da Re) name, Cooper throws the rock and breaks the bottle. Viewers learned earlier that Leo may be associated with the murder of Laura Palmer when his wife Shelly (Mädchen Amick) finds his bloody shirt. But at this point in the narrative, his connection to the case remains unknown. Cooper's dream/Tibetan rock-throwing method compresses and moves the narrative forward as they pursue Leo.

That same night, Cooper has the infamous red room dream where he learns of the entity BOB and sees his former partner Mike the Seer (Al Strobel). After a long day of investigating the murder of Laura Palmer, Cooper retires for the evening at the Great Northern. A close shot shows him asleep to the sounds of thunder, as viewers enter his dream of a mysterious room enclosed by red drapes. In the dream, a much older Cooper sits on a chair and meets who he thinks is Laura Palmer, but it is actually her cousin. 
Next to Laura's cousin is an enigmatic dwarf known as the "The Man from Another Place” (Michael J. Anderson), who strangely tells Cooper that his favorite bubble gum is coming back in style. Laura's cousin whispers something into Cooper's ear. Suddenly, cool jazz is heard as the dwarf breaks into a dance. Strobe lights flash as the dream ends. The next morning Cooper tells Sheriff Truman about the dream. He states that Laura's cousin whispered into his ear the name of the murderer. But he cannot remember what she said. Cooper states, however, that finding Laura's murderer is simple: "break the code, solve the crime.”

Here, the red room dream takes on a second function: it not only digresses and temporally slows down (or even halts) the narrative flow, but it enables Cooper to penetrate the extraterrestrial world of the Black Lodge, which uncovers vital clues to Palmer's murder. The Tibetan rock-throwing technique and the red room dream help Cooper to overcome obstacles within the everyday. At the same time, the temporal digression of the dream advances the narrative, leading to new clues and codes into the investigation of Palmer's death.

The Black Lodge in Twin Peaks is an extra-dimension where secrets are revealed. These secrets have a certain resemblance to the film's secret, which Mulvey identifies as film's materiality—-the photo image. She notes:

Stillness may evoke a 'before' for the moving image as filmstrip, as a reference back to photography or to its own original moment of registration. Although the projector reconciles the opposition and the still frame comes to life, this underlying stillness provides cinema with a 
secret, with a hidden past that might or might not find its way to the surface (67).

Linear ordering of narrative events submerges the film's secret, preventing viewers from experiencing its constructedness. Stillness or the freezing of the narrative flow, however, allows for film’s secrets to surface.

An example of this phenomenon is provided by Margaret, the log lady (Catherine E. Coulson) and her mysterious log (Figure 14). In episode five of Season One, “Cooper’s Dreams,” Cooper learns that Margaret’s log harbors important knowledge in regards to Palmer’s death. While Cooper, Truman, Deputy Hawk (Michael Horse), and Doctor Hayward (Warren Frost) search the woods for a log cabin with red drapes, they stumble upon Margaret who invites them into her home for tea and cookies. Here, Margaret informs them that her log has vital information about Laura's death. Hawk confirms this by responding: “The wood holds many spirits.” Dale asks the log what it saw the night Laura's was killed. The log, channeled through Margaret, reveals that there were three men during the night of Laura's death, and the presence of the owls, which are connected to BOB and the Black Lodge.

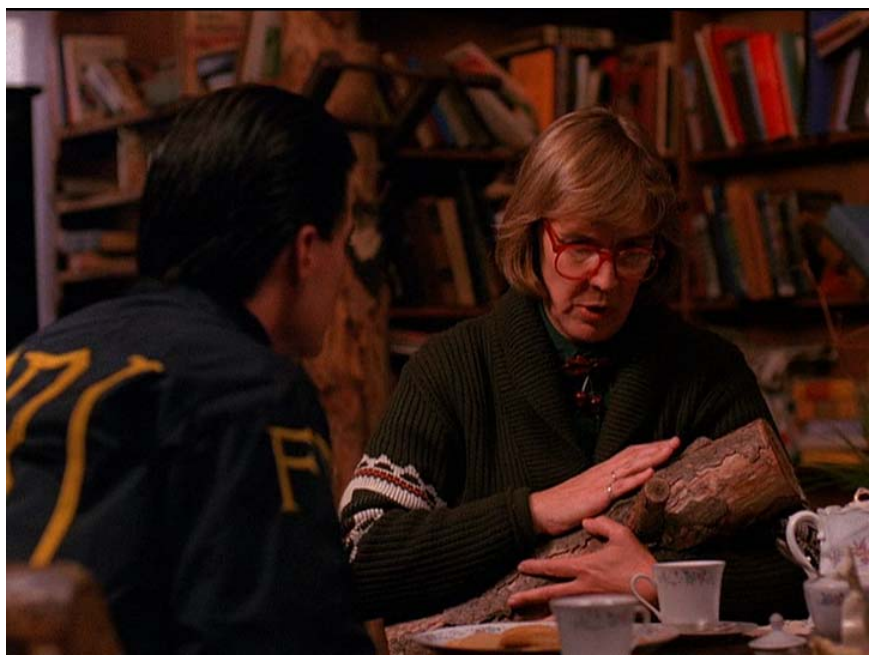

(Figure 14. Cooper and Margaret the Log Lady: a séance over tea and cookies) 
The episode of Margaret's conjuring of the log's secret resembles episodes that Mulvey points out in her reading of Roberto Rossellini’s Voyage to Italy (1954), where "material traces of the past" are brought to life through movement out of stillness (105). Specifically, Mulvey highlights the mobile and fluid camerawork in the filming of the statues during Katherine’s (Ingrid Bergman) visit to the Archeological Museum of Naples as a "magical means of bringing to life those blocks of stone" (116). The moving camera acts as a magic wand, conjuring life out of stillness, registering the statues' past to present life. In the séance scene with Margaret, by contrast, except for the dramatic use of score, the camera work is static as she become a medium between two worlds. Margaret’s strange and uncomfortable disposition materializes and “conjures” the spirit world out of the log, "excavating” the knowledge it harbors. The secrets of the log are manifested through Margaret's exaggerated body language and gestures. A familiar object, such as a log, is de-familiarized into an uncanny presence. As we saw in chapter one, the force of the contingent is what resists meaning and rationalization. Here, Margaret's body language is characteristic of the contingent and the indeterminate, underscoring her superpowers as the log's medium. Adding to the uncanniness of the scene is the fact that the séance occurs over the pleasantries of tea and cookies, not the traditional setting for communicating with the spirit world. Frost and Lynch bypass the traditional methods of the detective narrative by using the log as a supernatural element to forward the story. The log's secret, channeled through Margaret's body language, connects viewers to an extraterrestrial dimension, demonstrating Twin Peaks' reliance upon clues and tips from a place hidden from the everyday. 
Dreams in The Sopranos also oscillate between halting and forwarding the narrative. In the final episode of Season Two, "Funhouse," Sal aka "Big Pussy” (Vincent Pastore) is revealed as an informant for the FBI, which leads to his execution and body being dumped into the ocean. Sal's death remind us of Pete Clemenzia’s (Richard Castellano) famous line in The Godfather (1972): "Luca Brasi sleeps with the fishes.” But Chase gives an interesting twist on this iconic mafia image by blowing Sal's cover through a dream Tony has. Early in the episode, Tony gets food poisoning and has fever dreams all night. During one of his sick dreams, Sal is embodied as a talking fish. He tells Tony that he has "flipped" and is now an informant or "rat" for the FBI. Tony has had suspicions about Sal since the end of season one when Vin (John Heard), a police detective who supplies Tony inside information, tells him that Sal is an informant. Tony asks for proof before taking action. But Vin kills himself, leaving Tony to speculate about Sal's status. The dream, however, confirms this. The following morning, Tony and Silvio (Steven Van Zandt) visit Sal's home and find the wire. Instead of Sal blowing his cover or being exposed through the act of informing, he is caught by Tony's dream. In this regard, Tony's dream acts as a sort of magical-like deduction, leading him to uncover Sal's secret.

Although Tony's dreams are not a portal into an extraterrestrial dimension, they do function as a pathway into his emotions. The narrative hook of The Sopranos is that Tony, a mobster, turns to therapy because of panic attacks and depression. In therapy, Tony discusses personal secrets and emotional baggage. Of course, Tony cannot say anything specific that will incriminate him as a mobster. Nevertheless, Dr. Jennifer Melfi's (Lorraine Bracco) office is a secret space where viewers learn of Tony's 
feelings. ${ }^{40}$ There are many sessions with Dr. Melfi where Tony truly expresses his pain and frustration, specifically in the pilot episode, where Tony cries about a family of ducks leaving his pool, and their symbolic connection to his concern about losing his own family. But there are also many instances where Tony deflects his true emotions, quickly switching topics, yelling at Dr. Melfi that therapy is "bullshit."

In Tony’s dreams, however, viewers have direct access to his real feelings. This is illustrated in "the test dream" that occurs in the late part of Season Five. Recently separated from Carmella, Tony checks into New York’s landmark The Plaza Hotel for rest and relaxation. Tony has learned that his cousin, Tony Blundetto (Steve Buscemi) had taken part in the unauthorized murder of a New York gang member. Tony has come under extreme pressure to find and surrender his cousin in order to prevent a war with New York. That night, Tony has a series of dreams within a dream, lasting over twenty minutes of screen time. Tony's dream is filled with bizarre scenarios, such as having dinner with Annette Bening, being run down by an angry mob, and riding in the backseat of his deceased father's car with dead members of his crew. The dream ends with Tony being hectored by his high school football Coach Molinaro (Charley Scalies) for not being prepared. Waking from the dream, Tony calls Carmella and tells her that he had “one of his Coach Molinaro dreams” again.

Tony's reluctance to give up his cousin is tangled with a secret, which has caused him guilt and shame. At the start of Season Five, Tony B. is released from jail for

\footnotetext{
${ }^{40}$ It is interesting to note that Chase stated in an interview with Virginia Heffernan from the New York Times that he requested the camera not move during the filming of Tony's therapy scenes. In Chases' words: "There's one rule on the show: the camera in the therapy office does not move-forward, backward or sideways. I've been in a lot of therapy, and I never saw a camera move in to my face” (qtd. in Heffernan, "Real Boss"). But we can suggest that, similar to Twin Peaks and the séance scene with Margaret the log lady, the stillness of the camera in the therapy scenes has a connection to secrets. That is, the confines of Dr. Melfi's office and static camera work positions Tony to confront his past secrets.
} 
serving time for hijacking a truck 17 years ago, a job that Tony did not show up for because he was supposedly attacked by black men. But in episode five, "Unidentified Black Males,” Tony’s recent panic attacks are traced to his cousin. Tony tells Dr. Melfi that he missed the hijacking job because he had a panic attack after fighting with his mother. Tony lied to his cousin in order to conceal his secret. Here, the "the test dream" takes on additional significance. Tony’s dream helps him to overcome his apprehension about killing his cousin. At the same time, the dream provides viewers direct access to Tony's true feelings towards his cousin, as his secret manifests through abstract imagery and bizarre scenarios. The dream prepares Tony to kill his cousin, and it also provides viewers with a pipeline into the "real" Tony and his secrets. As in Twin Peaks, the use of dreams in The Sopranos derails the narrative flow and, at the same time, acts as a link within the narrative's chain of cause and effect. ${ }^{41}$

Both shows' use of dream logic as a form of digression raises the question of narrative fantasy and temporality. In traditional cinema and television, fantasy creates the "seamless" world of the narrative, where time and space are ordered in a linear fashion, and gaps are sutured in order to provide viewers with an illusion of virtual wholeness. Todd McGowan notes, “The classical Hollywood film hides fantasy’s role in producing temporality by not depicting any moments bereft of fantasy...” (202). Speed, in this sense, has an intimate relationship to fantasy. The forward movement and linear unfolding of time and space through precisely paced editing and camera movements

\footnotetext{
${ }^{41}$ This phenomenon of deduction through dreams is not solely tied to Tony. During the "Cold Stones" episode, Carmella's confirmation that Adriana (Drea de Matteo) is dead manifests through a dream. Adriana, who was the fiancée of Tony's nephew and mob member Christopher (Michael Imperioli), is killed at the end of Season Five when she is discovered to be working with the FBI. To cover up her death, Tony lies that Adrianna left Christopher and moved away. But Carmella has had suspicions about Adriana's random disappearance. Her feelings are confirmed during a dream where she sees Adriana walking along a park in Paris with her dog. In the dream, a police officer tells Carmella that Adriana is dead.
} 
“erases” the text’s mediation, providing the illusion of narrative time and space as

continuous and coherent. During the dream sequences in both shows, however, time and space become distorted and fragmented through slowness and digressions, bringing forth its mediation. In the dreams described above, there is no clear sense of progression or sense of chronology that conforms with traditional narrative causality. Yet, at the same time, I have argued, these dreams forward the narrative, becoming a magical-like link in the narrative's causal chain of events.

\section{Conclusion:}

Twin Peaks and The Sopranos follow a "principle of delay" that suspends the temporal flow of the televisual text. These techniques often delay and derail the narrative, exhibiting the structure of what I have referred to as the "television of delay." These disturbances and points of punctuation in the narrative flow vary from brief moments to long digressions, eliciting a range of expressions such as the surreal, the absurd, and the transcendental. I also argued that delaying television in both shows not only halts the temporal flow of the episode, but also advances the narrative through magical-like deductions. Delay in both shows reveal secrets such as Laura Palmer's illicit past, and Tony's secret about why he did not show up to the hijacking job that led to his cousin's imprisonment.

Both shows' stylistic experimentations with audio and visual helped to expand the landscape of television in terms of form and content. These styles were, I argued, in part, responses to the convergence of new technological developments and new economic conditions of flexible accumulation, as evident in HBO taking advantage of the FCC permitting cable signals into metropolitan areas. The broadcast networks were also 
impacted by the increasing popularity of cable and satellite television, specifically ABC, who in the 1980s had basement ratings. In order to compete with cable, the networks had to change their mode of production, which would lead them to take risks with unusual shows such as Twin Peaks. But we also saw that the VCR and movie renting economically impacted HBO. In order to continue their unique relationship with their customers, HBO developed new programming, centered upon the production of original series, such as The Sopranos. In this respect, new economic practices (flexible accumulation) in combination with new technologies such as satellite communication, cable, and the VCR created conditions for new forms of expression in television. Frost, Lynch and Chase seized upon these openings, using the manipulation of time and space enabled by time-shifting technologies, to bring art house and European cinema styles to the television format.

One question I have not explored is narrative closure. This is of particular importance in the examination of delaying television and speed for both shows. As we have seen, to delay the causal action of the fiction is to postpone narrative movement towards closure. Obstacles are the normal drive of the traditional narrative. Television scenes often end with what Bordwell terms a "dangling clause—a new line of action, a step toward a goal, a character's reaction to a new piece of information” (Classical 66), which sustains the serialized series, enticing viewers to continue watching. But what happens if the series never resolves its narrative? What happens if dangling clauses stay suspended? How is closure connected to speed? It is to these questions I shall now turn. 


\section{Chapter Four}

\section{"An Uncertain Future:"}

The Instant, Narrative Closure, and The Pensive and Possessive Spectator

\section{in Twin Peaks and The Sopranos}

In chapter one, we saw how the forces of the contingent and the irreversibility of time were both a "lure" and "threat" in the long take. Drawing upon Mary Ann Doane’s work on the emergence of cinematic time, I argued that digital video retains its bonding to the index, because of its intimate connection to the instantaneous and the contingent. In this chapter, I would like to explain how the instant is aligned with climactic narrative closure and the transparency of the text. Both Laura Mulvey and Doane stress that the still frame, or "image as point," is hidden in the moving image via the mechanical reproduction of the projector. However, in the cut or at the end of a film, Doane notes, "one can claim there is a suspension of time or an incomplete performance of action" (217). For Doane, the cut or end of the film demonstrates that cinematic temporality can "be held or possessed in a metaphorical sense" (217-218). The importance of narrative closure, in this regard, specifically the climactic ending or moment of catharsis, lies in its structuring of time and space.

Consider the climax of Die Hard (1988) when John McClane (Bruce Willis) lets go of villain Hans Gruber's (Alan Rickman) hand as he falls to his death from the Nakatomi Plaza building. Climactic scenes like these provide viewers with a feeling of completeness and satisfaction. But these narrative moments are, in a certain sense, also failures to obtain the instantaneous, because, as Doane argues, they are "riven by delay" and memory work. It is interesting to note that Gruber's death is filmed in slow motion, 
so viewers can fully take in this climactic moment. For this reason, as Mulvey points out, the significance of time-shifting technology is that it allows for repetition and replaying of the text. In this sense, the text is not completely closed; instead the illusion of unification or "marriage” is achieved, which can be subsequently archived, owned, and (as we will see in this chapter) “possessed” by viewers. Speed, time-shifting, and climactic narrative closure, in this respect, have an intimate connection to each other.

But they also raise questions pertaining to the conventions of genres and their relation to the archive. Having access or owning an archive of film and television permits one to become even more familiar with the popular film and television genre. Of course, this is not something new to the history of cinema and television. But accelerated culture, specifically digital media, improve this feature, permitting greater scrutiny of text by halting and delaying the moving image for textual "excavating.”

For example, consider Tony Montana’s (Al Pacino) now famous movie quote in the cathartic ending of Scarface, "Say hello to my little friend" as he makes his last stand, holding a M16 gun. What is unique to the digital age is that dramatic scenes like these can now be owned, replayed, and scrutinized, enabling them to enter into the lexicon of popular culture and thus, demonstrating the importance of speed's relationship to the popular archive. Furthermore, popular films like Scarface and The Godfather have become commodities, inscribed onto shirts, books, and pinball machines. The Sopranos and Twin Peaks similarly generated lucrative ancillary items ranging from merchandise, such as “The Secret Dairy of Laura Palmer” to “The Sopranos Family Cookbook” to VHS and DVD sales. This raises a question: What is at stake when a show deviates from the conventions of its genre, as in the now infamous non-violent and "pensive" diner 
scene in the finale of The Sopranos? How does this connect to the acceleration of culture and the television of delay?

This chapter continues exploring the television of delay, focusing on the creative tensions between narrative closure and the wait time for narrative exposition that both shows encountered in their reception. Specifically, I spotlight the controversial ending of the final episode of The Sopranos in June of 2007, and the pressure that ABC and eager viewers put on Lynch and Frost to reveal Laura Palmer’s murderer sooner than later in Twin Peaks. In addressing narrative closure, I draw upon Mulvey’s concept of the pensive and possessive spectator. The "pensive" spectator, for Mulvey, is characteristic of a contemplated and a reflective viewership. The "possessive" spectator, on the other hand, is the site of a fetishistic spectatorship that colonizes the moving image. New media technologies heighten both of these modes of spectatorship, “adding something new,” because they allow for the halting and replaying of the text. I add that both of these modes of viewership have a privileged relationship to the speed of time-shifting technologies in the decoding of the text.

In both Twin Peaks and The Sopranos, to defer or delay narrative closure invites contemplation and slowness- the pensive spectator. But it can also ignite tensions within possessive spectators who seek immediate resolution. As Mulvey points out, “A tension begins to emerge... between a cinephilia that is more on the side of the fetishistic investment in the extraction of a fragment of cinema from its context and a cinephilia that extracts and then replaces a fragment with extra understanding back into its context” (144). Hence, the pensive and possessive modes of spectatorship can be in tension with each other in the encoding and decoding of the text. I will argue that, in both Twin Peaks 
and The Sopranos, this tension is entangled with the management of the opposition between speed and the wait time required by narrative exposition. I will also show how time-shifting technologies, which offer accessibility to film and television archives intensify this creative tension.

\section{The Pensive and Possessive Spectatorship}

Agent Cooper's infamous red room dream in Twin Peaks had a significant impact upon its reception. Critically, the sequence was praised as a highlight of the series, introducing art film and avant-garde styles of cinema to primetime television. After its airing, Cooper's dream generated conversation, stimulating audiences to contemplate and decipher its bizarre meaning in connection to Palmer's murder. Tony Soprano's “test dream,” like the red room dream, was also singled out as a highlight of the series. But because the episode came late in the season, it was expected that the narrative would be compressed and forward the narrative more quickly towards its conclusion. In fact, the dream, oddly, turned out to be more of a digression, slowing down the story's temporal flow rather than building anticipation and suspense. As Alan Sepinwall puts it: "The only complaint more persistent among 'Sopranos' fans...is those loud and long protests whenever Tony checks into a hotel and the viewers check into his unconscious mind" (“Dreams”).

The long digression into Tony's dream is part of the landscape of The Sopranos where unplanned events randomly appear and go nowhere, providing no closure. Dana Polan identifies the logic of The Sopranos as "a sort of narrative forgetfulness. Plot lines may simply disappear and characters may not always seem to learn the lessons of the moment and carry them on into their narrative future” (57). In certain way, it can be 
suggested that The Sopranos exhibits the tendencies of what Allan Cameron identifies as the memory problem film. ${ }^{42}$ A notable example is the fan favorite "Pine Barrens" episode in Season Three, where Tony delegates Christopher (Michael Imperioli) and Paulie (Tony Sirico) to pick up his collection from Valery (Vitali Baganov), a large Russian man and associate of the Russian mob. During the pick up, Paulie gets into an unprompted fight with Valery, resulting in his death. Christopher and Paulie decide to bury him in the Pine Barrens, a heavy forested area in southern New Jersey. But a shocking twist occurs. When they open the trunk of Paulie's car at the Barrens, Valery is still alive. Christopher and Paulie chase Valery through the woods. Paulie fires his gun, and it appears to have hit Valery in the head. They check for Valery's body, following his trail of blood. But Valery's body is nowhere to be found, leaving Paulie and Christopher lost in the woods. The "Pine Barrens" episode has prompted fans to speculate whether Valery is still alive, or whether Chase will return to the narrative of this episode. Valery never shows up again in the series, leaving viewers with a suspended "clause" to decipher. ${ }^{43}$

Tony’s "test dream" and the "narrative forgetfulness" of the "Pine Barrens" episode exhibit the elusive nature of filmic time and human recollection, as if echoing that fact that the "ephemeral" experience of cinema has always made it hard for viewers to hold onto their favorite moments and images. But time-shifting technologies have

\footnotetext{
${ }^{42}$ See chapter four in Allan Cameron's Modular Narrative in Contemporary Cinema. New York: Palgrave macmillan, 2008.

${ }^{43}$ David Chase, aware of the fans' desire to know what happened to the Russian, toyed with viewers by occasionally bringing up the episode throughout the series as a joke. For example, Steve Buscemi, who directed "Pine Barrens," playing the role of Tony B., makes a reference to the episode when he is swimming with his two sons. He yells at his kids by telling them to stopping putting pine cones in the filter. Another example occurs when Christopher re-tells the story about the incident at Pine Barrens to his crew at the Bada Bing Bar, and jokingly blames the botch killing on Paulie. Paulie takes offense at Christopher's joke and a fight almost ensues.
} 
changed this, allowing access to a large database of film archives for textual analysis and repeated viewings for scrutiny. Emerging out of delaying cinema is a new relationship to cinematic time, and the formation of what Mulvey refers to as the hybrid possessive and pensive spectator.

Mulvey identifies the pensive spectator as curious and committed to decipherment, thereby opening “a space for consciousness” (186). She notes, “To delay a fiction in full flow allows the changed mechanism of spectatorship to come into play and, with it, shifts of consciousness between temporalities. By halting the image or repeating sequences, the spectator can dissolve the fiction so that time of registration can come to the fore” (184). The pensive spectator exhibits a double logic in regards to narrative temporality and speed. First, the film itself can elicit a pensive spectatorship through the style and aesthetic of delay in its presentation of the text by, for example, using the long take or temporal digressions. Second, the immediacy of time-shifting technologies intensifies the pensive spectator, because it permits viewers to scrutinize the text for meanings that may have been missed in live viewing, allowing for something extra to be uncovered. $^{44}$

Twin Peaks' digression into the red room dream, for instance, is characteristic of the aesthetics of delay and what I have referred to as the television of delay. The pacing of the dream slows down the narrative flow in order for viewers to take in this very unusual and strange scene. The protracted rhythm of the scene produces a sense of

\footnotetext{
${ }^{44}$ Recent examples of the pensive spectator projects worthy to note are Robert Ray's The ABC's of Classic Hollywood. New York: Oxford University Press, 2008. Through a classification system he terms the "ABC method," Ray isolates and fragments objects within the film in order to generate knowledge and meaning of the movie. Another is Nicholas Rombes year long journey of "The Blue Velvet Project," which halts the film every 47 seconds for textual analysis. The project can be viewed at http://www.filmmakermagazine.com/news/2011/08/the-blue-velvet-project-1/. Of course, there is a fetishistics aspect tied to this methodology because both writers highlight parts of the text for detailed investigation, demonstrating that the pensive and possessive modes overlap with each other.
} 
reflection and contemplation. Even the strange shaking of the dwarf's body, seen in the corner of the room, with his back facing the camera, elongates and stretches the passing of time within the dream. This desire to analyze the scene for "semiotic value" is further heightened through time shifting devices that enabled viewers to scrutinize the mise en scene for "deferred meanings." Robert J. Thompson, for instance, notes that Twin Peaks inspired many fans to comb through its texts, "searching the intricately dense episodes for clues to Laura's murder...inspir[ing] thousands of fans to subject the show to deep scholarly analysis” (156). According to David Lavery, Twin Peaks, in its living airing, "was reported to be the most videotaped on all of television" (11). The growing popularity of the VCR in the 1990s fitted well with the airing of Twin Peaks, a show that fills the filmic space with an abundance of details, which can be "excavated" and reviewed for deeper textual investigation.

The pleasure of decoding Twin Peaks resulted in an online community where fans formed a "collective intelligence" to unravel its clues. Twin Peaks premiered roughly a year and a half before the birth of the Internet in August of 1991. After the airing of the pilot episode, fans formed an online community through a Usenet site called alt.tv.twinpeaks in order to discuss and pull from each others' resources to decode and decipher the show's odd happenings and narrative puzzles. ${ }^{45}$ The Twin Peaks Usenet, according to Henry Jenkins, is one of the first media platforms that enabled an online community to quickly circulate information on recently aired episodes, which “[attracted] by some

\footnotetext{
${ }^{45}$ Conceived in 1979 by Duke University graduate students Tom Truscott and Jim Ellis, Usenet is a worldwide shared electronic bulletin board system that allows users to discuss information on subjects or categories known as newsgroups. Usenet was created for technological and scholarly purposes and were housed in Universities and technology and research companies. In Dec of 2001, Google expanded its Usenet archive, which is available to view on the web. For more information, see: http://www.salon.com/technology/feature/2002/01/07/saving_usenet/index.html
} 
estimates 25,000 readers" (Convergence 32). Here, the coming-together of a fan community is enabled by delaying the moving image. The combination of different perspectives becomes a collective force dedicated to combing a scene for textual meaning. As we will see in the final chapter, online communities can also develop into artistic publics, building a sense of community and connectedness through speeds of communication technologies. In this respect, Twin Peaks and the fandom it spawned is not only an example of accelerated culture that does not relinquish the distance needed for critical reflection, but also points to a new emerging culture using new media technology in unpredictable ways.

In The Sopranos, the uncertainty of Tony's “test dream” and the whereabouts of the Russian in the "Pine Barrens" episode both invite reflection upon and contemplation of its meaning, thus setting in place a "pensive spectatorship." As indicated above, Chase never sutures the narrative of the missing Russian, leaving viewers to tarry with missing information. But the long digression into Tony’s “test dream” intrusively delays the temporal flow of the episode arriving unexpectedly at a crucial point in the season when the narrative should (typically) be moving faster (the dream was roughly over twenty minutes in length). Alan Sepinwall adds, “'The Test Dream’ seemed to especially anger the whacking crowd because it took place late in the season, just as the New York mob civil war storyline was threatening to satisfy their bloodlust” (“Dreams”). Writer and producer of The Sopranos’ Terence Winter echoes this tension, stating: “People complained to me about it ['the test dream'].... Unfortunately, some people, all they're interested in is [sic] the mob (stuff). Everyone has their own thing. You can’t please everybody" (qtd. in Sepinwall, "Dreams”). In short, the foregrounding of Tony’s "test 
dream” angered fans who desired to see the mafia war storyline. Winter's comment about viewers' complaint of the show's dream sequences exhibit features of what Mulvey describes as a possessive spectatorship.

Possessive spectatorship involves a twofold logic. First, as Mulvey notes, "With electronic or digital viewing, the nature of cinematic repetition compulsion changes. As the film is delayed and thus fragmented from linear narrative into favorite moments or scenes, the spectator is able to hold on to, to possess, the previously elusive image” (161). According to Mulvey, the possessive spectator is "more fetishistically absorbed by the image of the human body” (11). Specifically, her example is the body of the movie star. The possessive spectator is not a new phenomenon for cinema. Collecting stills of the movie star, as she points out, has a long tradition in film fandom as a way to hold onto the "elusive image.” Today, however, digital technologies allow for greater access to film and television content that viewers can control and possess. For example, viewers can replay favorite scenes, make homemade trailers of movies, and even parody or create "mashed-up videos" that circulate on the Internet. Speed has a special connection to the possessive spectator, because digitalization allows immediate access to the film's content and thus intensifies the colonization of the moving image.

Secondly, unlike the pensive spectator, the possessive spectator requires immediacy in order to occupy the desired image. In other words, the flow of the moving images (its continuous unfolding of time and space and creation of narrative fantasy through its "erasure" of the medium), brings the spectator closer to the text in order to enable the possession and halting of the image. By contrast, the de-emphasis on transparency and the aesthetic of delay in pensive spectatorship opens up a "space of 
consciousness,” which can then be halted for textual analysis through time-shifting devices.

The two-fold logic of the pensive and possessive spectator is closely related to Jay David Bolter and Richard Grusin’s premise of the double logic of remediation. They note, “Our culture wants to both multiply its media and to erase all traces of mediation: ideally, it wants to erase its media in the very act of multiplying them” (5). They distinguish remediation by the logic of immediacy and hypermediacy. Immediacy involves the removal or erasure of the presence of mediation in the act of using new media technologies. Whereas hypermediacy is the acquiring of those technologies that “mutually” depend on immediacy to remove its presence. From this perspective, hypermediacy is more aligned with the pensive spectatorship, inviting inspection of the image's mediation through slowing down the temporal flow, which can then be intensified by halting the image through time-shifting technologies. The possessive spectator, by contrast, requires immediacy: looking through and arresting the image, an effect which is also heightened by time-shifting technologies that enable repeat viewings and stopping of the moving image.

For Mulvey, then, visual pleasure and fetishism are associated with the possessive spectator and the colonization of the image. Drawing upon her famous essay, "Visual Pleasure and Narrative Cinema,” she argues the “'fetishistic spectator’ becomes more fascinated by image than plot, returning compulsively to privilege moments, investing emotion and ‘visual pleasure’ in any sight gesture, a particular look or exchange taking place on the screen” (165-166). Mulvey identifies the male’s gaze and women to-belooked-at with three looks in relation to cinematic time and space: the camera's 
perspective of recording the event, the actor's point of view, and the audience's look.

She notes, "The conventions of narrative film deny the first two and subordinate them to the third, the conscious aim being always to eliminate intrusive camera presence and prevent a distancing awareness in the audience" ("Visual" 26). According to Mulvey, the subordination of the first two looks (which both define classical Hollywood cinema), is typically associated with the male spectator who positions the woman as the object-to-belooked-at. Mulvey ends her essay arguing for a disruption of the male gaze and "to free the look of the camera into its materiality in time and space and the look of the audience into dialectics of passionate detachment” (27). ${ }^{46}$

Although Mulvey's theory of rupturing visual pleasure has been well-contested, it does offer some valuable insights into the textual analysis of narrative closure. For my reading of The Sopranos and Twin Peaks, I want to focus on Mulvey's argument that the pleasure of looking is suppressed by bringing the mediation of the moving image to the film’s surface (its materiality). Bolter and Grusin note that Mulvey’s notion of the male’s desire to possess the female body is a "desire for immediacy" (80). In this respect, to suppress the desire to look resembles a spectatorship of "hypermediacy" where "looking at” comes into tension with "looking through.” But I add that climactic narrative closure is also a desire for the instant, the privileged moment satisfaction as the moment of catharsis. Closure, in this sense, has an intimate connection to speed through both erasure of mediation and narrative resolution. This, as we shall see, will become a point of tension in the deferral of narrative closure in both Twin Peaks and The Sopranos.

\footnotetext{
${ }^{46}$ Mulvey acknowledges there have been many critiques of her essay since its publication in 1975. Specifically, she highlights Miriam Hansen’s essay on the erotic appeal of silent movie star Rudolph Valentino as "an object of spectacle for female audiences" (Death 169).
} 
Before we move on, it is important to stress again that these two modes of spectatorship are not mutually exclusive. Mulvey draws upon Christian Metz to explain that "the intellectual spectator cannot be detached from fetishism" (Death 11). Images such as a bizarre dream sequence may overwhelm viewers, or they may temporally defer the narrative flow of the episode, morphing into the surreal or the absurd. But in either case there is still a desire to understand its meaning, even if it goes against the intended effect of the artist. As Metz puts it: "I know nothing at all, but I desire to know" (qtd. in Mulvey, Death 12).

\section{The Path to Narrative Closure}

According to Marc Dolan, Twin Peaks' uniqueness lies in its expansion of the detective genre in relation to the serialized format of television. Dolan notes that Twin Peaks distinct approach to the detective narrative form lies in its novel use of the "open ended medium of televised serial narrative” (32). Television shows are often episodic (stand alone episodes), or serialized (continuous narrative line). For Dolan, Twin Peaks was neither of these, "but consisted instead of one of these narrative forms (the episodic serial) layered on top of another (the continuous serial)” (35). Lynch and Frost used this hybrid form in order keep viewers retuning and guessing each week who killed Laura Palmer, as well as exploring the daily and quirky happenings in the town of Twin Peaks. This is most notable in the second season, when Frost and Lynch developed new plotlines while still keeping focus on the investigation of Laura Palmer's death. In this sense, this open-ended approach permits regulated improvisation as well as new possibilities and experimentation within the framework of the detective genre. 
The same approach is evident in The Sopranos through its incorporation of classical elements of the mafia narrative in the modern day suburbs of New Jersey. Chase stated in an interview with Peter Bogdanovich that he thought of The Sopranos as mini movies contained within a "vague" seasonal arc. Episodes such as "College," "Pine Barrens,” and "Remember When,” are examples of stand alone stories that still had a function within the overall narrative arc of the season. ${ }^{47}$ This open-ended approach permitted Chase to not only explore Tony Soprano's private and family life, but also to examine the daily doings of mobster life in suburban New Jersey. For both Twin Peaks and The Sopranos, the mixing of the serial and episodic approach within the connective tissue of the detective and mafia genres kept viewers interested, as well as enabled the creators of both shows freedom of narrative expansion and experimentation.

The manner in which the detective and mafia narratives satisfy closure is distinct. Movement in detective fiction, as Dolan argues, moves through two stages, operating in an "inside/out" fashion. He notes that "the actions of the detective(s), which move from beginning to end of the text, work to uncover the action of the criminal(s) up to the point where the text began. In other words, when a reader has finished a detective story, s/he knows why it started the way it did" (36). Narrative closure is accomplished when the detective(s) has assembled the pieces of the puzzle or mystery that led to the case. In other words, viewers always start a detective narrative story by arriving too late on the scene which sets the story in motion. What is unusual in Twin Peaks is that the clues and tips are housed within another time and space continuum, which demands movement between two worlds. It requires Cooper to operate psychically as well as traditionally in the "inside/out" mode of the detective narrative. For Frost and Lynch, this requirement

\footnotetext{
${ }^{47}$ Taking from Chase and Bogdanvoch's interview on The Sopranos Season One DVD set bonus feature.
} 
structured the story world of Twin Peaks. For this reason, Lynch and Frost did not want to reveal the murderer until the end of the series because they knew keeping the murderer a secret sustained the energy of the show. Laura Palmer's death, in certain respect, acts as the macguffin—a meaningless plot element or an absent structure used to sustain viewer interest. As Lynch states, "the progress towards it, [who killed Laura Palmer] but never getting there, was what made us know all the people in Twin Peaks: how they surrounded Laura and intermingled...the mystery was the magical ingredient" (qtd. in Rodley 180).

If narrative closure in the detective genre is solving the crime through the accumulation of data, closure in the mafia narrative is a matter of the death(s) of gang member(s). Many mafia narratives will end with the mob leader sticking to his code, resulting in a violent death. Sometimes a gangster will “flip," becoming an informant for the FBI, which usually results in an important member of the mafia being sent to prison, and the informant being placed in a witness protection program. ${ }^{48}$ The Sopranos' now infamous finale, “Made in America,” which aired in June of 2007, had neither of these endings. The manner in which the last scene is staged and edited suggests that audiences are about to witness the spectacle of the death of Tony in the public sphere. Or, at least it can be posited that some kind of action is about to occur that involves Tony.

The scene takes place in a diner where Tony, sitting in a booth, waits for his family to arrive, performed against the background of the rock band Journey's “Don't Stop Believing.” The suspense of the scene is emphasized through a crosscutting pattern between Tony in a position of stasis, and the activities of the various patrons within the

\footnotetext{
${ }^{48}$ Here, I am focusing on one attribute of the gangster genre. For a fuller account of the gangster narrative, see Edward Mitchell's “Apes and Essences: Some Sources of Significance in the American Gangster Film.” The Genre Reader. Ed. Barry Keith Grant. Austin: University of Texas Press, 1986.
} 
space of the diner. This shifting perspective between stillness and movement evokes a sense of doom. Adding to this heightened intensity, Tony's family members, one by one, enter the diner as they join him, except for Meadow (Jamie-Lynn Sigler), who is seen outside having trouble parking her car, which also adds to the narrative tension. The diner, an icon of Americana, is de-familiarized into a space of uncertainty, anticipating what could potentially be the end of Tony Soprano.

Death as a public spectacle is a tradition of the mafia narrative, for example, the scene in The Godfather (1972) when the Sollozzo family attempts to assassinate Don Corleone (Marlon Brando) at the fruit stand in the market street. Or, when Don Corleone son’s Michael (Al Pacino) shoots Virgil Sollozzo (Richard Newman) and Mark McClusey (Sterling Hayden) at point blank range in a restaurant. Similar styles of murder in public occur in The Sopranos. In Season Six, Part Two, in the episode "Stage 5,” just after Johnny Sacs dies of lung cancer, Gerry Torciano (John Bianco), prepped to be the next mob boss, is gunned down in a restaurant. In the following episode "Remember When,” Faustino Santoro (Daniel P. Conte) and his bodyguards are killed in the street by Phil Leotardo's (Frank Vincent) crew. In the next to last episode of the series, “The Blue Comet,” Bobby Baccalieri (Steven R. Schirripa) is violently murdered in a train shop. For the mafia, death as a public spectacle conveys a message to their rival crew as well as enforces their power and control of their territory.

In certain ways, death in the mafia narrative compares with Mulvey’s reading of climactic deaths in Hitchcock's films. Mulvey notes the death of the villain in Hitchcock’s films frequently occurs in the public sphere, for example, Sabotage (1936), Strangers on a Train (1951) and North by Northwest (1959). She notes, "these scenes 
very often constitute a visual climax to the film as a whole. Their complex staging often takes place in public so that spectacle has its own built in ready audience...” (Death 93). Tony's potential death in the diner has a certain likeness to these scenes in Hitchcock's films: the patrons of the diner as the built-in audience, witnesses to the spectacle of death. But it also suggests that the patrons in the diner are a stand-in for viewers of the show itself. Chase stated that he did not want to follow the "rise and fall of...” which often defines the gangster narrative. As he puts it: “Our show doesn't have a rise and fall—it’s like The Going Along of Tony Soprano (qtd. in Lavery and Thompson 24, their emphasis). Similar to Twin Peaks, the moment by moment travelling with Tony has a meandering and "indeterminate quality," allowing for unplanned and unexpected twists and turns in the development of the narrative. Chase did not want to get locked into the serialized narrative. Instead, as noted earlier, he turned towards telling smaller tales within the connective tissues of a seasonal arc. The "going along of Tony" is part of the show's ephemeral quality, in its de-emphasis of straightforward narrative cause and effect.

In the final scene at the diner, however, this sense of "going along of Tony" is severed. Viewers, like the patrons in the diner, stand outside of Tony in a more voyeuristic and "possessive" position, attached indeterminately to a bodiless gaze (Figures 15 and16). This effect is achieved by shooting the scene from no one's perspective. This radically externalized looking at Tony creates a sense of urgency and immediacy in viewers. More specifically, by situating Tony as the object of the viewers' gaze, the episode may be read as an invitation of how Tony lives his life day to day, never knowing when he will be unexpectedly attacked. 

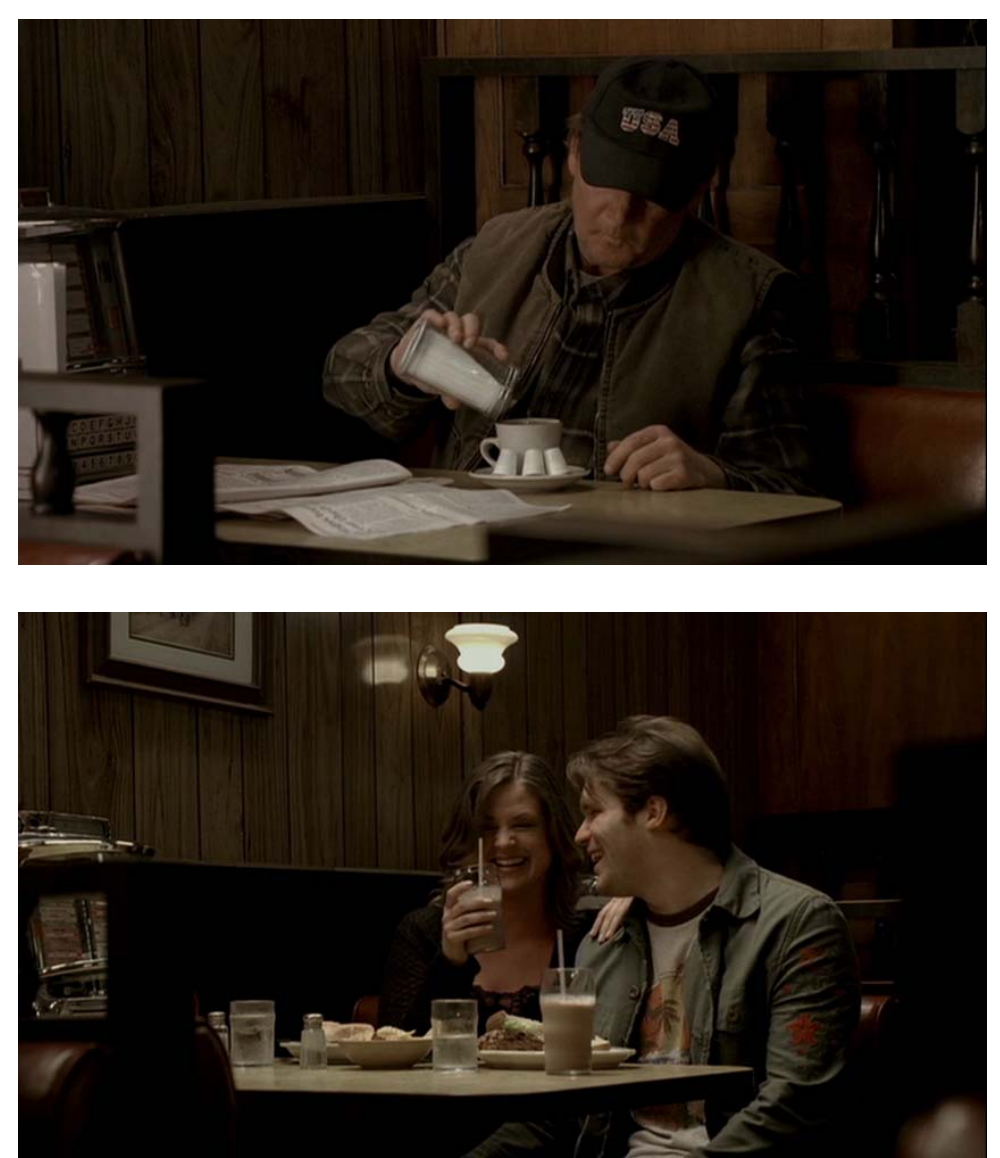

(Figures 15-16. Both images framed from no one's point of view)

Complicating the scene further, Chase intermixes these images of the de-corporal gaze with shots of Tony's perspective as he waits for his family. For example, a man wearing the "Members Only" jacket is shown entering the diner. Hearing the door's ringing bell, the image cuts to Tony looking up. The image returns to the man walking forward, but now Tony’s son, Anthony Jr. (Robert ller), is seen following behind the man. Tony smiles as he grabs a menu for Anthony. But for some reason, the image keeps returning to this mysterious man, inviting viewer speculation (Figure 17). There is even a shot where the man walks past Tony's booth, heading towards the men's room, a possible reference to The Godfather when Michael retrieves the planted gun in the bathroom before killing Sollozzo and McClusey (Figure 18). Here, the emphasis on the mysterious 
man puts durational limits on the final scene, suggesting a possible attack on Tony and the possibility of climactic closure.

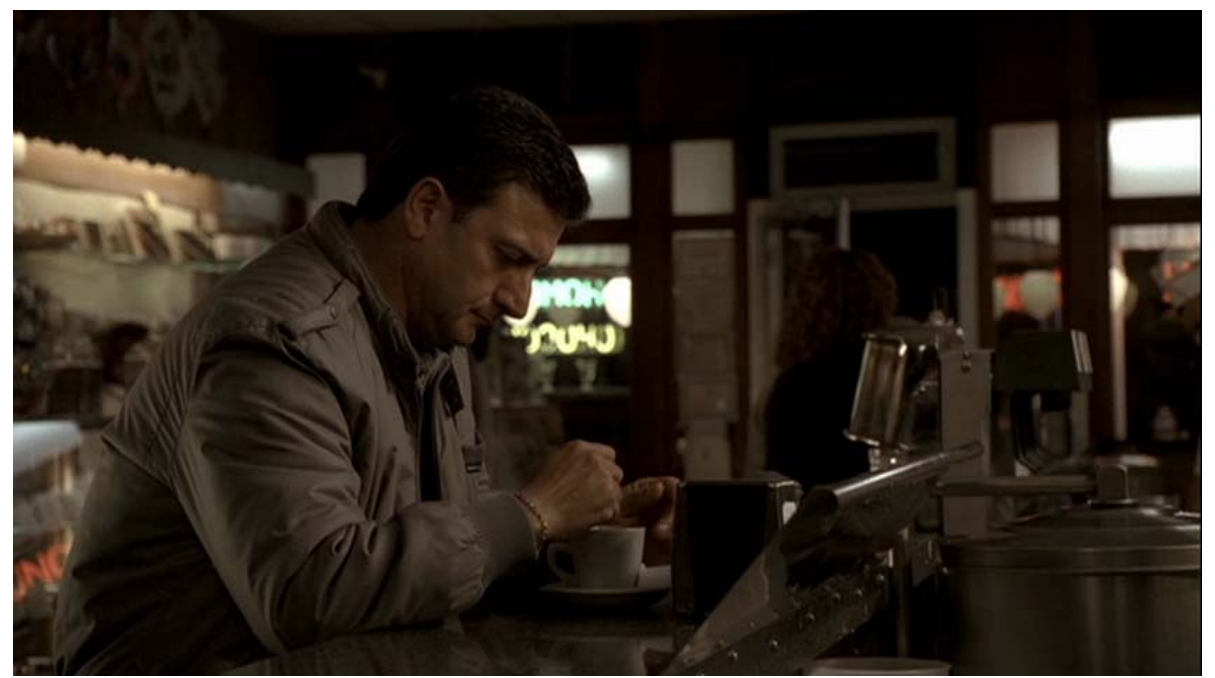

(Figure 17. The mysterious man in the Members only jacket)

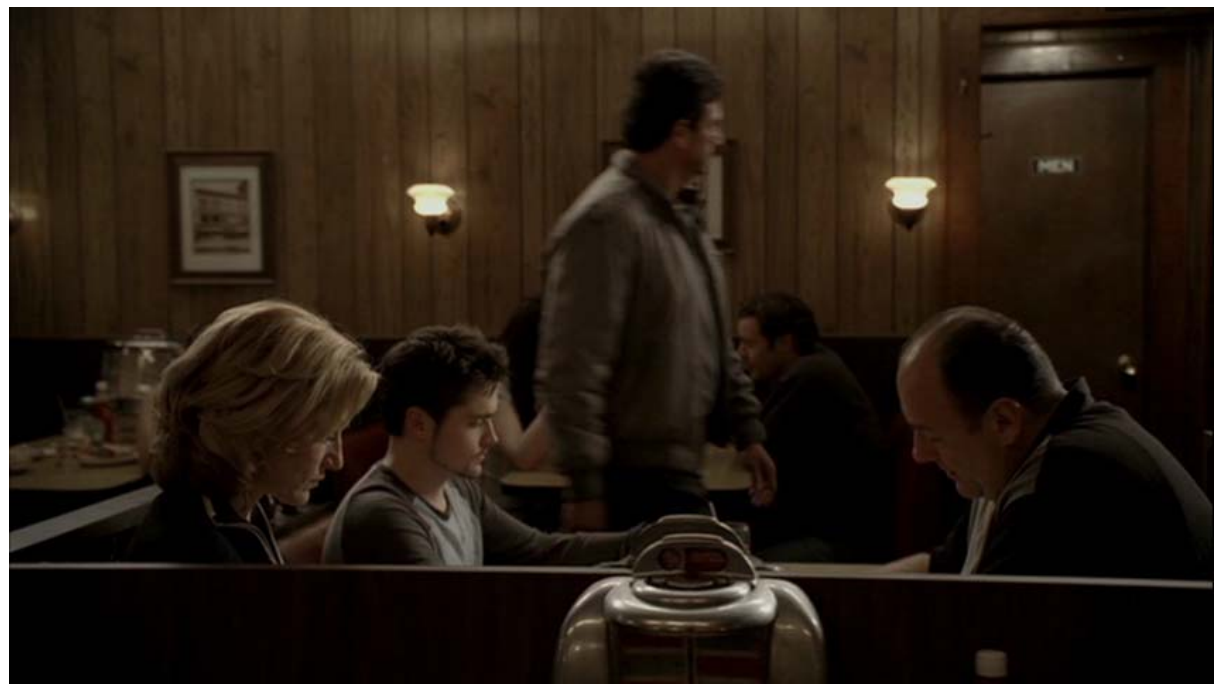

(Figure 18. A possible reference to The Godfather?)

The speeded-up compression of the narrative, heading towards closure in a climactic scene is a traditional mechanism of suspense. Immediacy pushes viewers towards the precipice of the narrative, which is then satisfied through the overcoming of the obstacle. This final scene has attributes of the deadline or appointment form of narration. The quick edits between Tony's perspective and the activities of the diner blurs spectators, but also builds anticipation and a sense of uncertainty, potentially setting 
the stage for Tony's death—-the fall of the gangster. This is what we traditionally think of as narrative finality. David Bordwell adds:

The deadline proper is the strongest way in which story duration cooperates with narrative causality. In effect, the characters set a limit to the time span necessary to the chain of cause and effect.... [A]ppointment and deadline stress the forward flow of story action: the arrows of the time spectator's expectations are turned towards the encounter to come, the race to the goal (Classical 45).

According to Bordwell, the deadline narrative often appears in classical Hollywood cinema. The scenes speed up narrative time in order to compress the action and create suspense, keeping viewers focused on the situation at hand (such as "just in time" rescues or the countdown of a bomb that must be defused). The ending of Die Hard is a great example of finality, where Gruber literally hangs and then is dropped from the precipice.

Alternate styles of cinema, however, often de-emphasize causality by elongated time and relying upon "chance encounters." This is often the case in The Sopranos where events occur with no warning: the unexpected death of Tony B. in upstate New York; Tony’s unplanned and gruesome killing of Ralph Cifaretto (Joe Pantoliano) over the death of their horse Pie-O-My; and Tony's sister, Janice (Aida Turtutto), in a fit of rage, shoots and kills her fiancée, Richie Aprile (David Proval). Probably one of the most shocking and unexpected deaths is Tony killing Christopher in the final season. A few minutes into the episode, Christopher and Tony are returning in a SUV vehicle from a meeting with Phil Leotardo. Christopher, upset with his vehicle’s CD player, plays with the sound adjustments, veering off the road, almost crashing into two teenage girls 
driving in the opposite direction. The truck rolls down a hill and lands upright, and both survive the accident. Tony is able to get out of the truck. But Christopher remains in the driver's seat, coughing up blood. He asks Tony to call for help. Tony looks in the back seat of the truck and sees the infant carrier seat has been impacted by the limb of a tree. Just as Tony begins to call 911, he stops himself and pinches Christopher's nostrils, suffocating him to death. Christopher, one of the central characters of show, is randomly killed with no dramatic warning. Furthermore, his death occurs strikingly early in the episode instead of following tradition and occurring at the end. These examples demonstrate that The Sopranos does not follow the classical form of building suspense and compressing narrative duration. Instead, events randomly occur often with little warning. The show's reliance upon "chance encounters," refuses to set "explicit limits" on narrative temporality. This creates a point of tension in the final episode, when the crosscutting style of editing suggest that something big is about to happen, as in the traditional deadline or appointment narrative. And the final episode too breaks with the tradition of mafia narrative, ending with no closure or violent death for Tony. No answer to the question of the mysterious man in the "Members Only" jacket. Chase, thus, denies the visual pleasure that would be afforded by the spectacle of the death of Tony, leaving the narrative ending open and contingent—and frustrating.

This effect is reinforced by the final cut to black in the episode which resembles freeze frame endings in cinema. Mulvey argues that the moment of narrative ending can be a metaphor for "death," as the ending of the causal chain of cause and effect. She states, "the metonymic structure of narrative, its causal link, changes to the register of metaphor. Death marks the end but also the point of 'beyond narratability'” (Death 79). 
Drawing upon the work of Garrett Stewart, Mulvey notes two metaphors of death and narrative ending at the site of the freeze frame. First, there is the metaphor which subordinates film's secret, its material presence. Death, from this perspective, "stands in" for the end, giving the film added meaning, as in the ending of Butch Cassidy and the Sundance Kid (1969). The freeze frame stands in for both the characters' death, and the death of the narrative itself. The second metaphor is that the freeze frame represents the film's mediation: the single frame flickered over and over, leading into "infinity" and "an uncertain future” (Death 81). For example, the famous ending of François Truffaut's The 400 Blows which freezes on Antoine at the lip of the ocean, inviting viewers to contemplate its meaning. In sum, the first metaphor refers to the narrative, and the second to film's materiality, which the photogram repeats endlessly.

This second metaphor provides the tension at the ending of The Sopranos. Speed, in this final scene, which is representative of the deadline and appointment form, is refused its traditional satisfactory ending, leaving the narrative in disequilibrium with an unforeseeable future. ${ }^{49}$ This refusal to provide viewers with the spectacle opens a gap, indeed, creates a tension between the pensive and possessive spectator. The abrupt cut to

\footnotetext{
${ }^{49}$ It is important to note that throughout the final nine episodes in the second part of season six, Chase constantly puts Tony in some sort of physical or legal dangers. For example, the opening of the episode "Sopranos Home Movies," the FBI unexpectedly arrives at Tony's home. We think this could be the end of Tony Soprano, but then discover he is arrested for a gun charge only. In the episode "Remember When," Tony flees to Florida with Paulie because the FBI unearths the body of Tony's first murder assigned by his father. But the killing is blamed on Jackie Aprile Jr, who is no longer alive. Or, in the final episode, which opens with Tony asleep in a safe house, frames him as if he is resting in a coffin. These are moments where Chase plays with spectators in regards to Tony's fate. In certain ways, Tony escaping death or prison is similar to what Edward Mitchell describes as the "pluck" and "luck" virtue of the gangster (160-161).
} 
black that ends The Sopranos' saga creates uncertainty and which, in turn, stimulates stillness, contemplation and pensiveness in its viewers. ${ }^{50}$

By contrast with Tony's possible death in The Sopranos, the death of Laura Palmer in Twin Peaks occurs within the private sphere, setting the story in motion. Here, movement emerges out of stillness in the form of death. Laura's death occurs in an abandoned train cart, literally representing stasis and derailment. Death, in this sense, is de-linked from the movement of the train, which is then put back into motion through the investigation. One of the pleasures in watching Twin Peaks is travelling along the road towards narrative closure, building a database of clues towards solving of the case. Unlike The Sopranos, which has attributes of the memory problem film, Twin Peaks invokes viewers' knowledge of past events. Twin Peaks begins with Palmer's dead body, an image of stillness that washes up on the shore of the lake. The first image after the credit sequence is of a tranquil image of ducks peacefully swimming on the lake, which then dissolves to a table lamp, which is of two ceramic/mummified greyhound dogs. The image pans from the lamp to introduce Josie Packard (Joan Chen) and Pete Martell (Jack Nance), who is on his way to go fishing. At the lake shore, Pete discovers Laura’s body wrapped in plastic. After notifying the police, the news of Palmer's death travels throughout the town as viewers are introduced to the characters and locations of Twin Peaks.

The final movement in the opening of the pilot, before its commercial break, is of particular importance for our reading of its pensive spectatorship. At the local high

\footnotetext{
${ }^{50}$ It is interesting to note that many viewers thought their DVR had technical problems or did not record the entire the episode (Polan, Sopranos 3). Chase even stated that he wanted to eliminate the episode's credit after the abrupt cut, letting the black screen to go until HBO logo popped up at the end. But the network would not allow this to happen (Martin, Sopranos 184-185).
} 
school, various characters and their emotional reactions are shown during the principal's announcement to the student body. But one image in particular is worth underscoring: the slow travelling shot in the hallway of the high school, which contains the gaze of no one. Like the images of the patrons in the diner in The Sopranos, the travelling disembodied image seems to be out of sync with the rest of the action unfolding in the sequence, thus, intensifying viewers' sense of looking. As the principal finishes his speech, the moving image finds its object—a picture of Laura embalmed in the high school trophy case located in the school hallway. The movement from the ducks swimming in the lake to the stillness of the grey hound dog lamp, to Palmer's body on shore, and finally the traveling image in the high school hallway, which ends on Laura's high school portrait in the trophy case, sets up a dynamic of stillness and movement that invites contemplation of the death of Palmer (Figures 19 - 22).

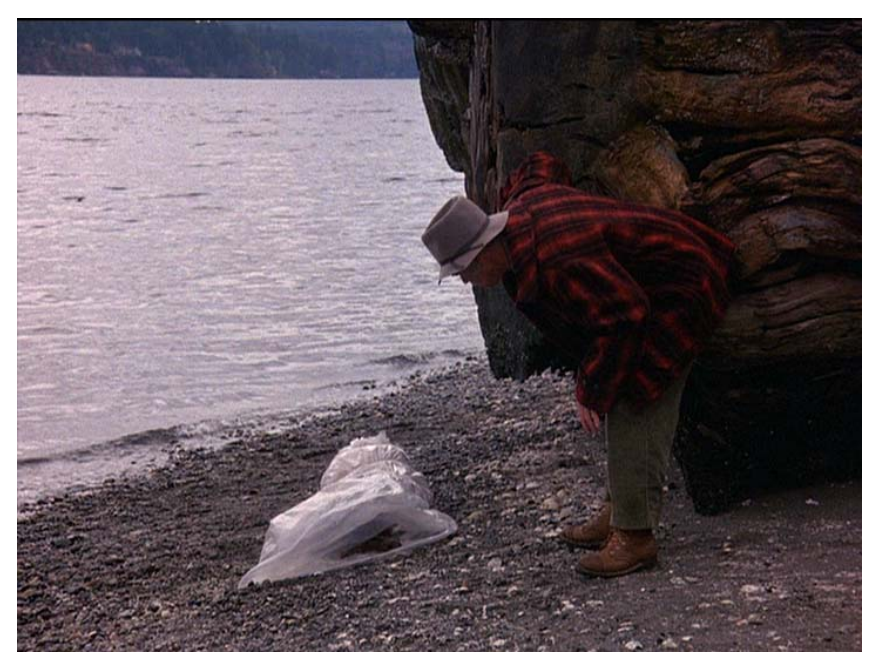

(Figure 19. Pete discovers Laura's body wrapped in plastic) 


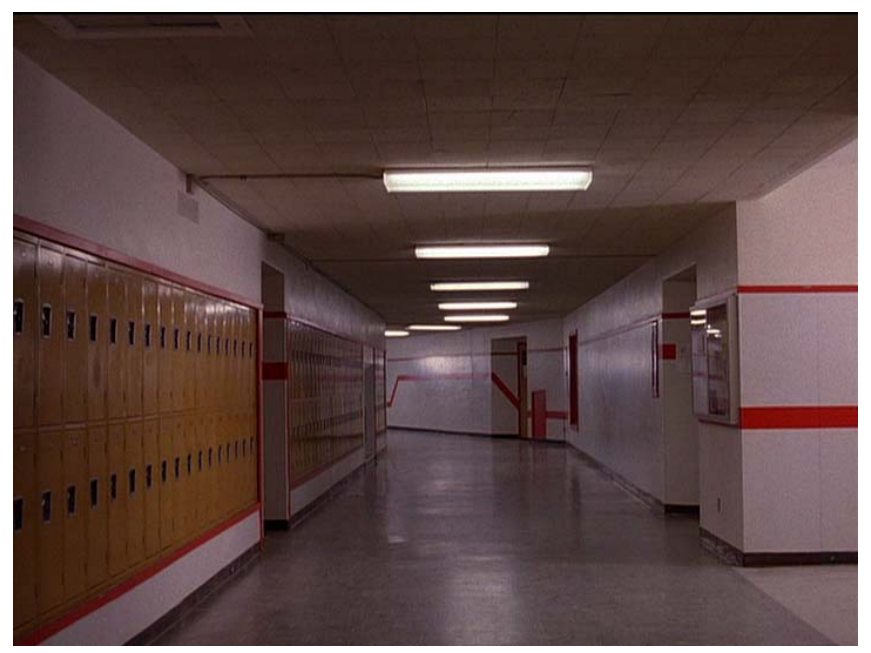

(Figure 20. A travelling shot attached to the gaze of an invisible entity?)
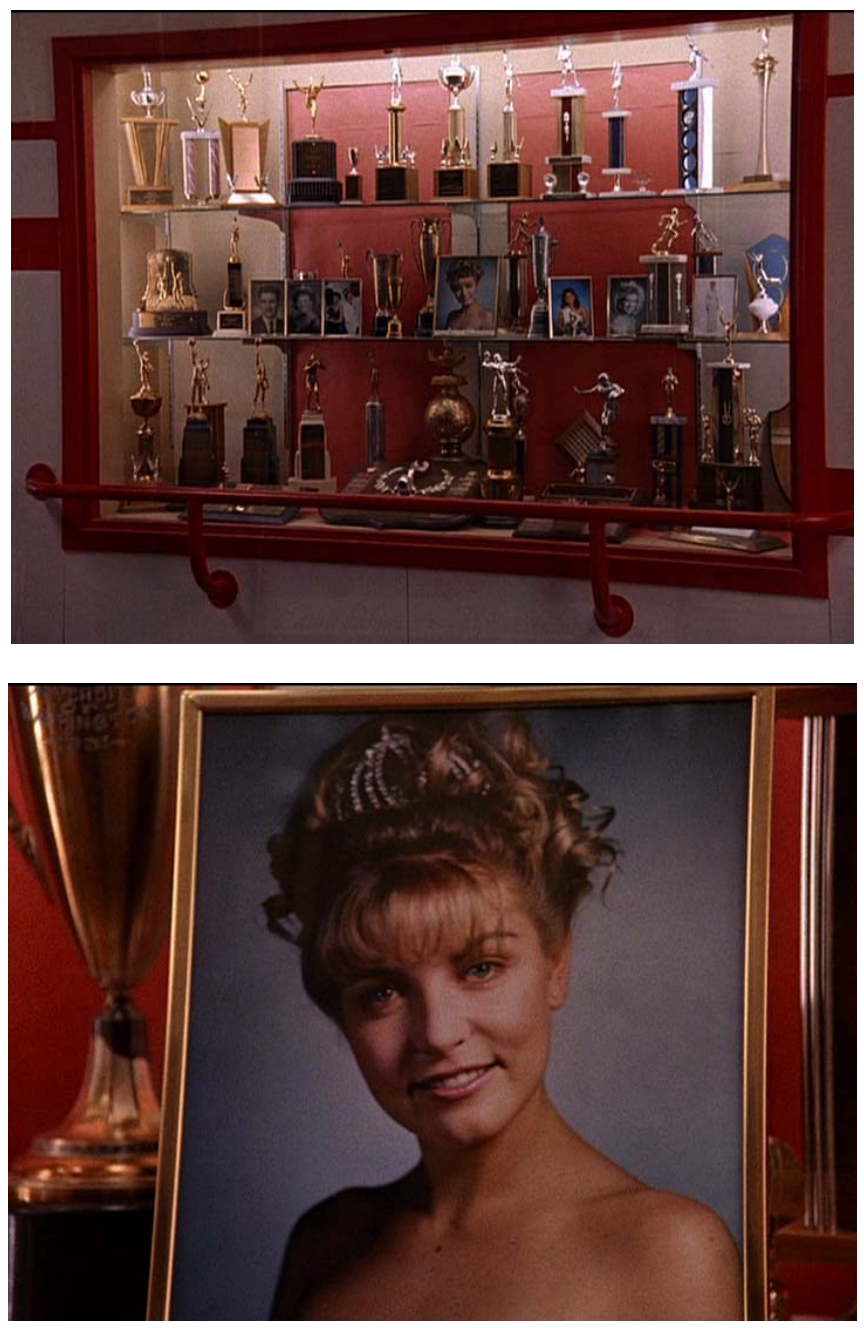

(Figures 21-22. The photo of Laura embalmed in the trophy case) 
The final shot on Palmer's photograph raises three functions relevant to delayed television and the pensive spectatorship. At one level, her photo underscores the film's “illusion of movement.” That is, the photo reveals film's secret of stillness—its "ghostly presence.” But it also suggests the presence of an unknown or invisible entity, as viewers learn later in the series, which haunts the woods of Twin Peaks. This moment of delay elicits a curious and deciphering spectatorship, adding a second level of time. As Mulvey puts it, the pensive spectator emerges through "the process of delaying cinema" which "captur[es] the moment of mutation in the act and reflecting on the representation of time” (Death 189). Referencing Raymond Bellour, she argues that stillness (such as a photograph within the mise en scene) evinces contemplation of its "frozeness." Bellour notes: "In the frozen film (or photogram), the presence of the photograph burst forth, while other means exploited by the mise en scene to work against time tend to vanish” (qtd. in Mulvey, Death 186). The materiality of Palmer's photograph breaks through the temporal flow of the narrative, asking to be unraveled. In short, the emphasis on the photograph opens a "space for consciousness" (Death 186). Laura’s body, wrapped in plastic, and the travelling shot that ends on her photograph, invites a pensive spectatorship which considers these two levels of time as a part of the narrative's mystery.

In addition, viewers can add a third level of time: to delay or halt the moving image through digital media technologies. As Mulvey notes, "the pensive spectator who pauses the image with new technologies may bring the cinema the resonance of the still photograph...” (186). As an example of this phenomenon, consider the scene in the Pilot episode where Cooper reviews the video of Laura and Donna's picnic in the mountains. 
Cooper is unsure who is operating the video camera. However, in analyzing the footage, Cooper pauses on an extreme close up of Laura and discovers a motorcycle reflected in the pupil of her eye (Figure 23). The motorcycle is later traced to James Hurley, who was Laura's secret lover. Cooper's halting of the video resembles a pensive spectatorship that Bellour identifies with experiencing the still photograph within the mise en scene. It illustrates the third level of time within which viewers can delay the televisual image, and potentially uncover new meanings.

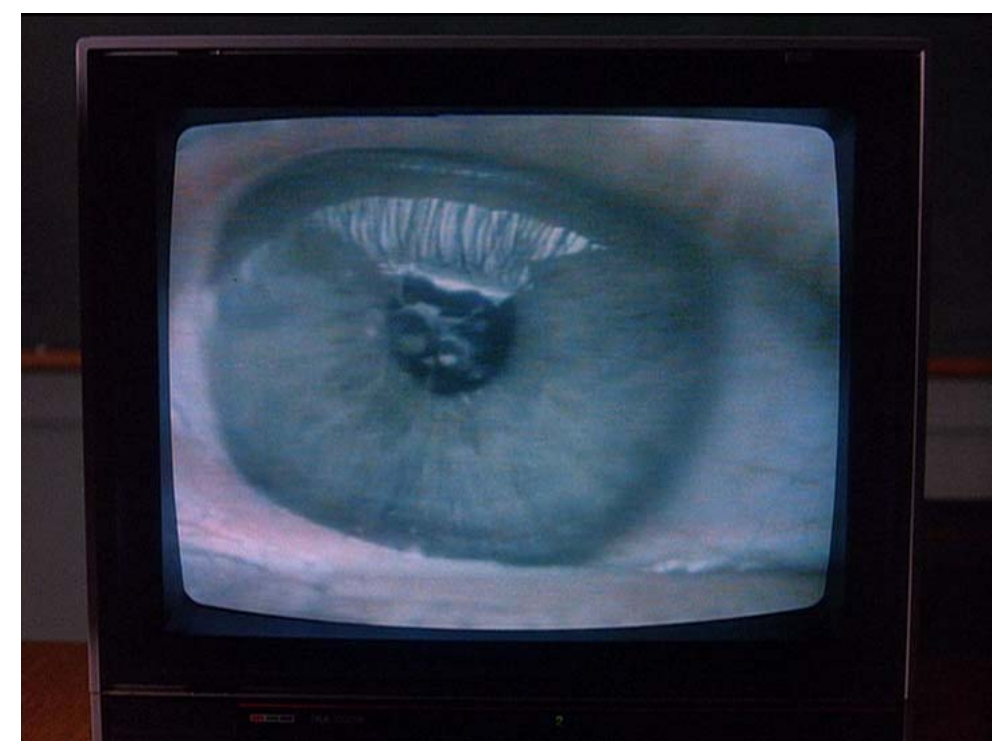

(Figure 23. James' motorcycle reflected in the pupil of Laura's eye)

During Twin Peaks' second season, ABC moved the show's prime slot of Thursday night to Saturday evening when viewer ratings began to wane. They also requested that Palmer's killer be revealed as part of the second season's story arc. Although Lynch was uncertain about ABC's request to solve the mystery, Frost felt he had an obligation to $\mathrm{ABC}$ as well as to eager viewers to resolve it sooner rather than later (Patterson and Jenson, “Our Town”). ${ }^{51}$ In a recent interview with the TimesOnline,

\footnotetext{
${ }^{51}$ Lynch interestingly added: "I was in an airport one time, going through the baggage claim area, and a woman was talking to her friends. And I just heard as I went by, 'I just hope they solve that murder soon. I'm getting sick of waiting.' And it was TWIN PEAKS. I think a lot of people put pressure on ABC to get it
} 
Lynch states that “A big catastrophe was the solving of the murder of Laura Palmer [midway through season two]. That wasn’t supposed to happen for a long, long time. So when it was solved, the thing was killed. The goose laid a little golden egg, solid gold, and then you're asked to kill that little goose” (qtd. in Potton, “Twenty Years”). Withholding the identity of the murderer offered viewers the possibility of endless (gratifying) interpretations of the text. As New Yorker film critic Terrence Rafferty noted in his review of Twin Peaks:

The early Surrealists loved the nonsensical, interminable inventiveness of pulp serials....Works like [Louis] Bunuel's and Lynch’s derive their force — even their narrative force—-from the swift movement of the artist's mind, a strong current of ideas and imaginative energy.... Lynch sets us drifting through a vivid dream of American life, and wakes us, two hours later, with the message that all dreams (and all soap operas) imply: 'To Be Continued' (“One Thing”).

But, we have seen, the pleasure tied to the pensive spectatorship of Twin Peaks' ran up against the possessiveness of $\mathrm{ABC}$ and its viewers who were anxious to solve the mystery sooner than later. The revealing of the murderer prematurely coupled with decline ratings and the shifting of its time slot, resulted in even more viewer loss of interest and eventually led to the cancelling of the show.

Chase was faced with a similar situation after the airing of the finale episode of The Sopranos. The feedback came not from HBO, but from viewers and fans who demanded closure. The ambivalent ending drew so much traffic to HBO.com that the 
website crashed shortly after the airing of the episode. As Chase stated in response to angry and unsatisfied fans of the show, "They had gleefully watched him [Tony] rob, kill, pillage, lie, and cheat. They had cheered him on. And then, all of a sudden, they wanted to see him punished for all that. They wanted 'justice.' They wanted to see his brains splattered on the wall” (qtd. in Martin, Sopranos 184). Chase's comment reminds us of Robert Warshow’s essay, “The Gangster as Tragic Hero,” which suggests that audiences' reaction to the gangster film involves a doubled sadism: "we gain the double satisfaction of participating vicariously in the gangster's sadism and then seeing it turned against the gangster himself” (87). Going even further, we may say that ambiguity in the ending of The Sopranos enables a third act of sadism on the part of the audience. To quote Mulvey: "The possessive spectator commits an act of violence against the cohesion of a story, the aesthetic integrity that holds it together, and the vision of its creator” (Death 171).

Both Warshow's and Mulvey's readings of sadism returns us to the double logic of speed and the pensive and possessive spectator. Firstly, the death of the gangster provides immediate resolution: releasing viewers from partaking in the sins of watching the gangster rob and kill. Secondly, extending Warshow's premise, the death of the gangster provides "satisfaction" through closure, by allowing the image to be possessed and repeated, indeed intensified through the "hypermediacy" of time-shifting technologies. But, in the finale of The Sopranos, no act of violence is committed on Tony; no cathartic ending. No image is provided that allows viewers to perform an "act of violence" on the flow of the narrative. Instead, viewers are left to contemplate the abrupt cut to black, which, in turn, lead to various readings of its elusive meaning. 


\section{Conclusion:}

The complexity of narrative closure in both Twin Peaks and The Sopranos illustrates both shows' uncertain relation to time. Most films and television shows register time and space through the smooth unfolding of action in a linear fashion. That is, fictional narrative time and the illusion of movement conceal the show's constructed reality, thereby preventing viewers from noticing the moving image’s "ghostly presence" (the "still image”). This process, as I have shown, is marked by speed and immediacy. Immediacy in the text creates its transparency. At the same time, speed of technologies allows possession of the image for repetitive viewings. Narrative closure has a close relationship to possessive spectatorship in terms of fetishism, because viewers are provided instant resolution of the narrative's chain of causality. Withholding closure or freeze framing the last image, suspends the show's temporal flow, inviting speculation in its moment of delay.

The deferral of narrative closure and visual pleasure in The Sopranos' final episode and ABC's cancelling of Twin Peaks indicates a tension between the possessive and pensive spectator. The mysterious death of Laura Palmer invites contemplation, to decode it objects and to make sense of its narrative ambiguities. Withholding Palmer's killer allowed Lynch and Frost to undertake character development and experiment with the detective genre, by introducing elements of the supernatural. These features, I argued, opened it to a pensive spectatorship which was then heightened through timeshifting technologies that allowed deeper, more extended textual analysis. Time-shifting media permit viewers to replay and hold onto the moments, and discover "deferred meanings" that might not be caught in 24 frames per second. From the uses of VCR to 
DVR players, to the small group of fans using a Usenet news board to share information on Twin Peaks in 1990, to the crashing of HBO’s website in 2007 after the last episode of The Sopranos—all of these incidents provide insights into cultural effects of the changes in technologies.

The editing of The Sopranos' final episode created an expectation of narrative closure in the specific form of the public assassination of Tony. As I have explained, there is a tradition of such violent spectacular endings to the mobster narrative. Chase's refusal to supply this ending to viewers illustrates a complex relationship between the producers' intended effect and the reception by viewers. Here, it is interesting to add that The Sopranos is one of HBO's signature brands of “Original Series” programming, which markets to a specific demographic. As Polan notes, "Clearly HBO...tries to distinguish a 'quality audience' and claim it is serving that demographic particularly well. HBO's frequent self-representation as a quality service gives the channel cultural capital in the market place” (176). Chase produced The Sopranos under the auspice of quality programming, noting "I think The Sopranos is the only show that actually gave the audience credit for having some intelligence and attention span. We always operated as though people don't need to be spoon-fed every single thing — that their instincts and feelings and humanity will tell them what's going on” (qtd. in Martin, Sopranos 185). But the hostile reception of the ending of The Sopranos highlights that even of networks which produces programs with "upscale appeal” for specific imagined elite audiences, are unable to predict their viewers' reception. Mulvey’s concept of a tension between possessive and pensive spectatorship goes some way to explain this phenomenon of upset 
and angry fans who were looking for narrative closure, even as they adopted a pensive form of spectatorship.

Lastly, Chase's denial of narrative closure and ABC's cancelling of Twin Peaks raises the question of the ownership of participatory culture. In an interview, Chase was asked by director Peter Bogdanovich whether in virtue of the success of the show, if he felt obligated to the fans (in terms of artistic decisions). Chase's response was that he “fights the thought." Owning and ownership, from this perspective, are two different processes in relation to Chase’s artistic choices, and the fans' expectation of the show. As we have seen, Chase constantly challenges viewer expectations through demythifying the mafia narrative, as is evident in the non-closure of the series. These artistic decisions presuppose the artist/network as the owner of the text. Hence, too, the importance of withholding the identification of Palmer's murderer (the MacGuffin) in Twin Peaks which allowed Lynch and Frost to control the unfolding of events in the series. But, because of the pressure from $\mathrm{ABC}$ and eager fans who wanted the mystery solved sooner rather than later, ownership of the text became compromised. In short, a tension arose between, on the one hand, a desire for closure (ABC and the fans) and on the other hand, the deferral and delay of the narrative (Frost and Lynch).

Yet at the same time, the popularity of the show was celebrated through fan participation, such as weekly viewing parties, or fans forming online communities such as the Twin Peaks Usenet group. Ownership, in this respect, is a matter of fetishism of the text, which Mulvey classifies in terms of the possessive spectatorship. This fetishism manifest itself in fans filling in the show's narrative gaps such as the unexplained disappearance of the Russian in the "Pine Barrens" episode of The Sopranos, or the 
appearance of the man wearing the "Members Only" jacket at the end of the series. As we have seen, conflict between an artist and fans can emerge when certain expectations are not met. ${ }^{52}$ In such instances, both artists and fans become involved in encoding and decoding the text, and the question of ownership is blurred to the point of being contested.

\footnotetext{
${ }^{52}$ A notable example is George Lucas' Star Wars prequel trilogy and his changing of narrative events and images in the original films. This has caused much strife amongst hardcore fans of the films, which is captured in the recent documentary, The People vs. George Lucas (2010).
} 


\section{Chapter Five:}

\section{Exploring Mumblecore:}

$\underline{\text { Speed, Digital Cinema, Media Convergence, Publics and Counterpublics }}$

Throughout this study, I have shown how the acceleration of culture is informing new ways of seeing the moving image in the production as well as reception of both film and television. In this final chapter, I would like to examine the role of speed in relation to the formation of publics. Specifically, I seek to understand how the immediacy of media communication technology is benefiting filmmakers working outside the Hollywood mode of production. My object of study focuses on a group of DIY (Do-ityourself) filmmakers called "mumblecore” that emerged out of the 2005 South by Southwest Film Festival (SXSW). During the festival, director Andrew Bujalski’s sound mixer Eric Masunaga was asked to describe a new mini movement of low budget films screening at the event—films that included Bujalski’s Mutual Appreciation, Joe Swanberg's Kissing on the Mouth, The Duplass' brothers The Puffy Chair and Susan Buice and Arin Crumley’s Four Eyed Monsters. As the story goes, Masunaga jokingly coined the term "mumblecore" as a way to describe the naturalistic dialogue that sounded like characters "mumbling" to each other. The term began to gain currency in August of 2005, when during an interview with IndiWIRE, Bujalski referred to mumblecore as a potential cinematic movement. When these filmmakers were featured in the magazine Filmmaker in the spring of 2007, the New York Times in August of 2007, and recently in a New Yorker article in 2009, the term began taking the national cinematic spotlight. ${ }^{53}$

\footnotetext{
${ }^{53}$ Although not an exclusive list, some of the films that have been identified as mumblecore are: Funny Ha Ha (2002), Four Eyed Monsters (2005), Kissing on the Mouth (2005), Mutual Appreciation (2005), The
} 
It should be stressed that mumblecore is a term that lacks fixity. It is a contested term for both its filmmakers who are uneasy about being categorized, as well as critics who have debated whether or not these filmmakers constitute a film movement. This chapter does not seek to establish a set definition for the term, or to determine if mumblecore is an authentic cinematic movement. Rather my goal is to understand the shared sensibilities and "structure of feeling” amongst "mumblecore” DIY filmmakers, while acknowledging the instability of the term itself. In particular, I will address the question of what distinguishes mumblecore from other past DIY and Independent filmmaking. How does this group of filmmakers relate to postmodernity and the acceleration of culture?

I argue that the collaborative and networking aspect of mumblecore that emerged out of film festivals and online social media demonstrates how these filmmakers collectively exhibit the features of what Michael Warner describes as the social imaginary and "world making" function of a counterpublic_-"a public...understood to contravene the rules obtaining in the world at large, being structured by the alternative dispositions or protocols, making different assumptions about what can be said or what goes without saying” (56). In particular, I argue that through their collective vision and desire to make highly personal and self-portrait films, mumblecore filmmakers can be seen as an artistic counterpublic formed against the "background" of Hollywood and Indiewood. Although I will be focusing on the filmmakers, the development of mumblecore is not independent from the development of its audiences or "addressees." As Warner notes, "[publics] fail if they have no reception in the world.... A public is

Puffy Chair (2005), Dance Party, USA (2006), Hannah Takes The Stairs (2007), Quiet City (2007), Baghead (2008), Momma's Man (2008), My Effortless Brilliance (2008), Nights and Weekends (2008), Humpday (2009), Beeswax (2009), and Alexander The Last (2009). 
always in excess of its known social basis. It must be more than a list of one's friends. It must include strangers” (74). Warner immediately adds that, of course, this openness of a public renders it vulnerable to appropriation, but this appropriation is countered by the reflexivity of its participants in constituting themselves as a public.

Mumblecore is an interesting instance of a counterpublic due, in part, to the role it assigns to the phenomenon of digital media. Here, I use this feature to address a question that Warner poses about the Internet in relation to public sphere discourse and "texts through time.” For Warner, publics are sustained through constant circulation of texts, as in the weekly or monthly press of magazine, or seasonal run of television shows that exhibits a punctuated rhythm through time. The Internet, however, decentralizes time to the point that viewers have to build narrative paths out of a database of content. This raises a question: If online texts do not have a punctuated temporal flow, will this diminish the possibility of a counterpublic? I argue that mumblecore provides a negative answer to this question, by showing that a counterpublic can develop out of digital media that do not exhibit a "punctual (temporal) rhythm.”

In order to understand this process, I distinguish traditional “material” publics organized by around "texts through time," such as newspapers and magazines, which exhibit a punctual rhythm and continuing material identity, from what I call “on-line” or “virtual publics,” which are also formed around “texts through time,” but differ in so far as their texts are de-centralized and available instantaneously, for example, video content on YouTube, or 24/7 online news websites. The key to understanding these concepts is to not see them as distinct mutually exclusive realms. An online public can manifest in a 
material public, and vice versa. A cult movie, for instance, generates online discussion and fandom, which later manifests in a public screening of the film. ${ }^{54}$

\section{The Transition into the Digital Feature and the Emergence of Mumblecore}

In order to begin tracing the emergence of mumblecore in relation to speed, technology and culture, it is important to briefly identify some of the developments occurring in independent cinema towards the end of the twentieth century. The increasing exposure of American Independent cinema at the end of the 1990s signaled a structural and industrial shift towards Hollywood. Award-winning and financially successful films such as sex, lies, and videotape (1989), The Crying Game (1992), and Pulp Fiction (1994), proved that revenue can be generated in the independent film market. Beginning with Disney purchasing Miramax in 1993, Hollywood began to form smaller art-house divisions such as Fox Searchlight, Paramount Vantage (formerly Paramount Classics), Focus Features, and Warner Independent. As Emmanuel Levy notes, “The concept that best describes independents in the 1990s is that of institutionalization. Indies now form an industry that runs not so much against Hollywood, but parallel to Hollywood” (501). The films of 1999 such as American Beauty, Boys Don't Cry, Election, Magnolia, The Straight Story, Three Kings, and Girl, Interrupted exemplify a bridging between Hollywood and independent cinema or what is often negatively or positively referred to as “Indiewood." 55

\footnotetext{
54 A notable example of this phenomenon is the cult following of the horror film Troll 2 (1990), which was the subject of the documentary Best Worst Movie (2009).

${ }^{55}$ For a full account of Indiewood, see Geoff King's. Indiewood, USA. Where Hollywood Meets Independent Cinema. New York: I.B. Tauris, 2009.
} 
In the mid to late 1990s, another current of filmmaking developed: the indie digital feature. Starting with Lars Von Trier and Thomas Vinterberg’s Dogme 95 manifesto, followed by the worldwide success of Daniel Myrick and Eduardo Sanchez's horror film and fake documentary, The Blair Witch Project (1999), the end of the 1990s and the beginning of the millennium saw a surge in digital features. The inexpensive production costs of digital filmmaking spawned small film production companies such as Blow Up Pictures, Next Wave Films, and InDigEnt (Independent Digital Entertainment). Films such as Julien Donkey-Boy (1999), Bamboozled (2000), Chuck \& Buck (2000), Time Code (2000), Tape (2001), Russian Ark (2002), Personal Velocity (2002), The Chateau (2002), 24 Hour Party People (2002), Pieces of April (2003), and 28 Days Later (2003), all were shot and edited using digital tools of technology. The combination of the inexpensive production costs and the raw, grassroots style of Dogme 95 and The Blair Witch Project not only helped to create new avenues for independent cinema, but opened the doors to digital cinema as a legitimate force of filmmaking.

What then, separates mumblecore from the films mentioned above? Like many of the films noted above, mumbelcore films have a grassroots or DIY quality, are highly personal narratives, and have a desire to capture raw and intimate moments. The mercurial and spontaneous nature of mumblecore is typically embodied in both its form and acting. These films range between zigzagging portraits of "natural" human emotions to the deadening and flattening of affect, often displayed through hand held photography and jumpy editing.

Certainly this is not a new phenomenon in the history of American independent filmmaking. Independent filmmaker, John Cassavetes is often brought up in discussions 
of mumblecore for this very reason. Cassavetes was known for his personalized and raw style of filmmaking. He self-financed and self-distributed many of his films. More significantly, for the purpose of mumblecore, Cassavetes worked with roughly the same troupe of actors, casting Ben Gazzara, Peter Falk, Seymour Cassel, and his wife Gena Rowlands in different roles. Even his friends and family members became part of the process in the production of his films. As Ray Carney notes, "these components are, in many ways, part of Cassavetes’ personal exploration of himself as well as the lives of people around him” (ix).

But here I would like to frame mumblecore not so much in terms of its styles or aesthetics, but rather by exploring the relations between its filmmakers who share a certain sensibility about filmmaking, and examining how the Internet and digital media are helping to foster those relations.

Let's, then, look more closely at the differences and similarities between mumblecore and Cassavetes. Rather than sticking to a strict hierarchical mode of production, Cassavetes involved almost everyone in the filmmaking process. The social interaction and intimacy of Cassavetes' film set is paramount in terms of excavating deep desires and emotions out of his actors. Carney notes:

For him [Cassavetes,] direction was not about control, but responsiveness. It was an invitation to shared exploration.... To be an actor for Cassavetes was to be a member of cooperative, mutually supportive group.... Cassavetes' view of direction was not a relation of superior and inferior, 
of boss and worker, but of equals working together in surprisingly intimate public way" (Films of Cassavetes 155). ${ }^{56}$

Cassavetes’ pursuit of emotional realism in his films often led to many takes, shooting almost a million feet of film per picture (Films of Cassavetes 156). But more importantly, the intimacy and collaborative style of filmmaking in Cassavetes’ films worked against the standardized mode of filmmaking, which, as Carney notes, is more difficult to unearth emotions out of performers. As Carney points out, “[Cassavetes'] films underwent weeks of rehearsals” (Films of Cassavetes 159). This, in turn, allowed him to build an intimate relationship on the set with his actors for "expressive possibilities." This is evident in the on-screen characters who are often unpredictable, spontaneous, and, ultimately, bursting with emotions. Critics and writers have noted similar features in mumblecore cinema. In this regard, Cassavetes' intimate and collaborative methodology of filmmaking can serve as a model for mumblecore.

But there are also important differences: in particular, mumblecore's intimate relationship to the technological conditions of production. The speed of digital technologies plays a major role in the development of mumblecore enabling immediate communication and sharing of content via the Internet and video streaming for consumers and producers. Although digital technologies proved to be powerful tools for independent and DIY filmmakers, the limited use of the Internet as a method of delivery for digital streaming and distribution remained a barrier at the turn of the millennium. But the increase in broadband services and the development of video streaming sites such

\footnotetext{
${ }^{56}$ It should also be noted that Cassavetes had a "short fuse," and was not hesitant to fire someone if he felt that particular person was jeopardizing his vision or disrupting the atmosphere of the set. More specifically, as Carney points, Cassavetes had fired many cinematographers over the years. In Cassavetes words: "I've often fired cameramen. Not for any reason, except that I couldn't work in an atmosphere that was less than friendly" (Cassavetes on Cassavetes, 240).
} 
as YouTube, Netflix, and Amazon-on-demand now allows for quick streaming of a video rather than manually downloading video content. And as more of the population gains access to faster Internet service, there is a significant increase in mobile and portable screens such as iPads, smartphones, and laptops where one can instantly watch video content on the go. When greater access to film and television titles is factored in, particularly the phenomena of online video streaming, we begin to see a connection to the emergence of mumblecore cinema. Such advances in digitalization not only enable an intensification in the decentralization of time and space associated with postmodernity, but also the building of a network of underground filmmakers. Aymar Jean Christian adds, "Mumblecore must be read as a product of a specific cultural moment; its efforts to depict the real in a digital age potentially reimagine how the cinematic experience is received" (121).

Although the narratives about many mumblecore films, as Christian points out, explore what cinematic connection and intimacy looks like in the digital age, my goal, instead will be to understand the role technology played in the formation of mumblecore as an artistic public. How are digital media, mediated spaces, and mobile screens changing public sphere discourse for DIY artists?

First we must digress and provide a brief historical tracing of the emergence of mumblecore culminating in its recognition in the South by Southwest (SXSW) film festival in 2005. I have chosen to focus specifically on the directors of the four films that premiered at the film festival: Mutual Appreciation, Kissing on the Mouth, Four Eyed Monsters and The Puffy Chair. It is this grouping of films at the festival that caused writers and journalists to discuss their similarities, and posit that they reflected a new 
practice of alternative cinema operating via new media technologies. And, ultimately, it was through the film festival circuit that these filmmakers began to network with each other.

Andrew Bujalski’s second film, Mutual Appreciation made its premiere at SXSW in 2005. He had already made a name for himself in the independent film market. His first feature film Funny $\mathrm{Ha} \mathrm{Ha} \mathrm{(2002)} \mathrm{is} \mathrm{considered} \mathrm{to} \mathrm{be} \mathrm{the} \mathrm{origins} \mathrm{of} \mathrm{mumblecore.}$ Shot on 16mm in Massachusetts, Funny Ha Ha tells the story of Marnie (Kate Dollenmayer), a shy and vulnerable twenty-something college grad who is looking to find love and employment. The film’s ambiguously nuanced meanings, minimalist style, de-emphasis of plot, and "natural” performances by non-professional actors (including Bujalski himself playing the role of Alex) gives it a realist documentary like quality.

Although the release date of Funny $\mathrm{Ha} \mathrm{Ha}$ is 2005, the film was completed in 2002 but had no distribution. This all changed when Boston University film scholar Ray Carney received a VHS copy of the film, which subsequently led to the film being screened at the Museum of Fine Arts in Boston. Carney is known widely for his work and research on independent filmmaker John Cassavettes. Carney's website and support for DIY filmmaking has been an important resource and channel of communication for social networking by underground film artists. In an interview with Film Comment in 2004, Bujalski recounted that, “on a whim, I sent him [Carney] a VHS of the film...on the day he received it, he just happened to be talking to the programmer of the Museum of Fine Arts in Boston who had just seen it [Funny $\mathrm{Ha} \mathrm{Ha}$ ] and said, 'I don't know how I feel about this movie I just saw, but I think it’s right up your alley’” (qtd. in Taubin, “Art \& Industry”). The Carney connection proved to be very important for Bujalski and the 
development of mumblecore. In 2004, Bujalski’s Funny Ha Ha received the "Someone to Watch Award" at the Independent Spirit Awards, exposing his work to a larger independent film world. In 2005, Funny Ha Ha had a very small release in the theaters, earning \$82,620 world wide. Funny Ha Ha was then picked up by Well Spring video where was it readily available for purchase. In 2005, New York Times film critic A.O. Scott listed Funny Ha Ha on his top ten list of movies for that year. That same year, Bujalski's second film, Mutual Appreciation made its premiere at SXSW.

In 2003, brothers Jay and Mark Duplass made a short called This is John, an eight minute film featuring a person trying to perfect his answering machine. This is John was selected for the Sundance film festival in 2004. That same year, the Duplass brothers began working on an idea for a feature film to be shot on digital video. The story, which would become The Puffy Chair, is about two brothers who are on their way to see their father for his birthday in Atlanta. On their way to Atlanta, they pick up a chair they won on eBay and deliver it to their father as a birthday present. Although the film was being praised and winning awards at film festivals, no company would distribute the film. This all changed when Ted Sarandos, chief content officer of Netflix (Red Envelope Entertainment) acquired The Puffy Chair for distribution on their web rental site. Netflix not only made the film available to its subscribers, but it also helped the Duplass Brothers get a nonexclusive DVD distribution deal so that the film could be offered at other rental stores. ${ }^{57}$ In the New York Times, Manohla Dargis reported that when the film became available on DVD, Netflix sent an email notification to its subscribers, which resulted in 100,000 of their customers adding The Puffy Chair to their "Queue.” The film garnered

\footnotetext{
${ }^{57}$ As of 2008, Netflix shut down Red Envelope Entertainment. See Jeremy Kay. "Netflix closes down Red Envelope Entertainment.” July 23, 2008. Screen Daily. < http://www.screendaily.com/netflix-closes-downred-envelope-entertainment/4039994.article>. Web. 3 Sept. 2011.
} 
further viewer exposure by being rated on Netflix’s "suggestion for you.” (As we shall see later, Netflix is one instance of a new model of digital distribution that has helped mumblecore and other DIY filmmakers to traverse geographical boundaries of time and space).

In 2003, Susan Buice and Arin Crumley began working on project called Four Eyed Monsters. Set in New York City, the story follows a couple played by Buice and Crumley who meet on an online dating site. The couple utilizes artistic means to communicate events about their past life such as video recreations and drawings. Like the other filmmakers mentioned above, Buice and Crumley had a hard time trying to find a distributor. Crumley notes in an interview with IndieWIRE, "There was a big difference between the way audiences responded and the way distributors responded. Audiences were super enthusiastic, especially people close to our age. If distributors did return calls, they usually said they didn’t know how to 'market’ it. We felt that it was lame that people liking a film wasn’t enough” (qtd. in “Four Eyed Monster”). They decided to create a video podcast of the film and invite viewers to share their dating narratives on their website. This resulted in the film gaining a cult following on the Internet. In fact, their film would become the first feature film on YouTube that could be watched for free. (Tryon 116-121).

In 2005, Chicago DIY filmmaker Joe Swanberg released his first feature film Kissing on the Mouth, which was made as a response to Bujalski's Funny Ha Ha. In an interview with Chinashop, Swanberg reported that the film was made for $\$ 1200$ with cast and crew of roughly four people. Like Bujalski, Swanberg employs a documentary aesthetic to his films. In an interview with GreenCINE, he states, "Though my work is 
primarily narrative, I'm heavily influenced by documentary film. I like the idea of characters that actively create things, rather than sitting around on couches complaining about life. It adds a level of energy to the film” (qtd. in "Young Americans”). Because of the explicit sex and nudity in the film, Swanberg did not think the film would be picked up by a distributor. Swanberg decided to post ten minutes of the film on the message board of director Roger Avary's website, where it was discovered by Matt Dentler, the director of the SXSW film festival (Gore, “Soft Spoken Saint”). Here, we begin to see the significance of new media technologies and social networking as a channel for indie filmmakers to screen their work outside the normal exhibition avenues. Dentler emailed Swanberg and invited him to show Kissing on the Mouth at that year's festival, where the film would have its premier alongside Mutual Appreciation, The Puffy Chair, and Four Eyed Monsters.

In 1997, at the age of eighteen, Matt Dentler was a film student at the University of Texas at Austin who joined SXSW as an office intern. In 2003, he took the reigns as the festival director, which involved traveling and connecting with producers, agents and studios to promote the festival. One of Dentler's goals as the director was to "find films that bigger festivals wouldn’t be able to take a chance on” (qtd. in Lim, “Generation”). His programming of the four films listed above began to create a buzz because of their experimental style, theme and content. Dentler states, "In 2005, something was different, but we didn't know it at the time. People have asked why SXSW brought all these films together that year, as if the programmers did it on purpose. We simply programmed what we liked and the rest happened on its own” (IndiWIRE, “First Person”). Since the SXSW festival in March of 2005, mumblecore's following has increased. After the festival, the 
filmmakers kept in touch and supported each other and a community of artists began to form. In August of 2007, the IFC center created a series called "The New Talkies: Generation D.I.Y.” to promote the films of these artists. Again, although many of these filmmakers have stated that they are uncomfortable with being labeled and classified as mumblecore, the term continues to be cited in examining and making sense of their films.

This brief tracing of the formation of mumblecore brings up a number of points in regard to speed, culture, and technology. Though we can conclude that these filmmakers all seemed to have difficulty in finding distributors, all of them have benefited through new media technology. Even Bujalski, who so far has opted to shoot his movies only on celluloid, generated buzz about his work through social networking sites and managed his own website to promote and sell DVDs of Funny Ha Ha. Furthermore, the tools of digital technology, such as desktop editing software and high resolution video cameras are more easily accessed and more affordable for DIY filmmakers. As mumblecore filmmaker Aaron Katz puts it, "This is the first time, mostly because of technology, that someone like me can go out and make a film with no money and no connections" (qtd. in Lim, “Generation”). The success of these filmmakers lies in their ability to use digital streaming across multiple platforms and delivery systems to promote, circulate, and distribute their films. Of course, sheer numbers of such films creates a new difficulty: how to stand out in such a crowded market place. Nevertheless, because of new technological conditions created by digital media, the means to publicly show a film, whether it is a short, feature, or even 'mash-up" parody video, is more readily accessible than ever before. 


\section{The Internet and Convergence Culture}

As we have seen throughout this study, digital media offer new ways of seeing the moving image in both the production and reception of cinema as well as television. In this context, it is important to stress the effects of available bandwidths and faster Internet access. In 2001, asked whether or not the Internet could be a digital delivery system for filmmakers, director Thomas Vinterberg stated that the Internet is "too slow, and sitting down for hours and hours actually bores me a little bit” (qtd. in Roman 85). Around that same time, New Wave Film President Peter Broderick stated that he was not convinced that the Internet could be a usable distribution system stating, “The quality is crappy. If you want to watch three minutes of a high concept short, maybe, but we've really got to come up with a whole new level of delivery” (qtd. in Roman 27). At the time, sites for short films were becoming very popular on the web. As Barbara Klinger notes, "In 2000, observers estimated that more than three hundred thousand film shorts were made each year, and almost one hundred short film Web sites already existed...” (Multiplex 195).

But what is often not emphasized is that downloading video content was not easy because a majority of the American population did not have broadband service, especially in rural areas. Slower access to the Internet can be frustrating in terms of downloading content when the web may freeze the image, or the audio may be ahead of the picture because of the slow delivery speed of the video content. According to Internet World Stats, in 2003 less than 30 percent of the American population had access to Broadband Internet access (Cable or Digital Subscriber Line [DSL]), which suggest a majority of Internet users were still using dial up access. In 2008, however, 61.5 percent of the American population had access to Broadband service (Enrique, "Broadband”). 
Today, video streaming platforms such as YouTube, Hulu, Amazon-on-demand, and Netflix provide more access to broadband service as well as faster delivery methods of video content to the private spaces for watching. Of course, the multiplex and traditional methods of renting films are still popular cultural practices, so that we cannot say that one medium has replaced another. It is important to stress, however, that the speed of technologies of online streaming and video-on-demand sites not only provides more immediate access to archives of movies, but also breaks down spatio-temporal geographical and decentralizes the distribution process. For example, the mail video rental service Netflix offers a wide and diverse selection of films and television shows, so that whether one resides in a rural or urban location, it is simple to access a wide selection of movies, including mumblecore films.

The emergence of mumblecore intersects with this transformation from film's material projection to digitalization, mobile screens, and web based movie renting. Most mumblecore filmmakers initially encountered difficulty in finding a distributor. These filmmakers, in one way or another, utilized the Internet and video sharing sites as a way to bypass the rigors of tradition film marketing and exhibition: whether it was Joe Swanberg posting ten minutes of his first film Kissing on the Mouth on the message board of director Roger Avary's website, or Susan Buice and Arin Crumley utilizing the Internet to promote their film Four Eyed Monster, by inviting viewers to share and post their own narratives on their site.

As I argued earlier, however (and as Chuck Tyron points out in Reinventing Cinema), DIY and independent filmmakers face a new challenge in standing out among the deluge of videos circulating on the web-especially those reaching for commercial 
recognition (96). In this regard, the critic and blogger plays an important role in terms of generating "buzz" and word of mouth in marketing and promoting. In short, mumblecore cinema may not need the theater venue to reach viewers, but there is still an important role for the critic writing reviews in newspapers, entertainment magazine, for film festivals, and for "top ten lists." ${ }^{58}$

New media technology also plays an important role in allowing new filmmakers to circulate their content, in ways that bypasses the traditional distribution networks with which past underground or independent filmmakers had to work. ${ }^{59}$ This, in turn, raises the question of what Henry Jenkins calls “convergence culture.” Jenkins describes convergence culture as "technological, industrial, and cultural and social changes in the ways media circulates within our culture” (Convergence 282). The fusions of both old and new media technologies, according to Jenkins, can produce new forms of meaningmaking, for example, fandom and online communities. Specifically, Jenkins notes that the development of convergence culture and the home uses of digital media have seen the re-emergence of "grassroots creativity" associated with the folk art tradition, which had been "displaced" by mass media in the twentieth century, as production centers in radio,

\footnotetext{
${ }^{58}$ It should also be noted there are differences between festivals in terms of generating buzz for films. Sundance, for instance, were, at first, resistant to screening mumblecore films at their annual festival. At the time, the only film they screened was The Puffy Chair. This is one reason why Matt Dentler chose these films for the SXSW film festival. Dennis Lim notes in his piece on mumblecore in the New York Times in August of 2007 that: "While many of these movies have screened at festivals, mumblecore is the sole significant American indie film wave of the last 20 years to have emerged outside the ecosystem of the Sundance Film Festival.... For credibility purposes the perception of the mumblecorps as underdog outsiders, too indie for Sundance, is hardly a bad thing. Especially not since South by Southwest, which takes place in March, two months after Sundance, has stepped up to serve as the movement's unofficial headquarters. Matt Dentler, the producer of South by Southwest, said that a few years ago he resolved to “'find films that bigger festivals wouldn't be able to take a chance on.'”

${ }^{59}$ This was one of the barriers Cassavetes faced in distributing his films. After receiving no offers to distribute A Women Under the Influence (1974), Cassavetes formed his own distribution operation, hiring a staff of twenty-somethings, paid for 200 prints, and had his actors make media appearances. (Carney, Cassavetes on Cassavetes 356-360).
} 
film and magazines developed into what Adorno and Horkheimer termed the "culture industry.” Today, by contrast, a science fiction movie inspires viewers to create a fan magazine based on the film's story world and characters with the result, as Jenkins puts it: "mass culture gets pulled back into folk culture” (Convergence 136). In short, we are seeing more people using tools of digital media technology for creating popular culture, which reflects the forms associated with folk art rather than with mass media.

Speed has a central function in the phenomenon of convergence culture: the immediacy of digital communication technologies allows amateur filmmakers to move beyond the boundaries of the home and private sphere of circulating content. Jenkins focuses on parody or "mash-up” videos, in which fans appropriate and repurpose content from their favorite films or television shows. But we can see that mumblecore too is an instance of "convergence culture" that creatively uses digital technology. I will now extend this argument by showing that how mumblecore exhibits the collective spirit of what Michael Warner identifies as a counterpublic. But first, we need to explain in more detail what Warner means by "publics” and "counterpublics.”

\section{Publics and Counterpublics}

Warner points out that a public is not defined by its demography, "but mediated by print, theatre, diffuse networks of talk, commerce and the like” (56-57). In other words, the public is constituted by the "regular flow of discourse in and out..." (94). For example, newspapers, television, cinema, and magazines are publics organized by the circulation of time, dates, and "punctual rhythm." Certainly media sources come and go, but what binds the "on-going life" of a public is not only its self-awareness as a public 
and openness to strangers, but also its continuous circulation of texts. As Warner notes, "the temporality is not continuous or indefinite; it is punctual" (95).

Warner then indicates he is unsure how "web discourse" will affect the "temporal framework" of the public sphere. He notes, "one way the Internet and other new media may be profoundly changing the public sphere is through the change they imply in temporality” (97). One concept, in particular, that stumps Warner is how the requirement of punctuality relates to the Internet. He notes that the "24/7 access" of the Internet is not structured temporally (that is, it is not always unfolding through time), and it is not "centrally indexed" as in newspapers or magazines; nor does the Internet have the "punctual rhythm" of broadcast media as in television or radio. As Mark Poster puts it: "the temporal instantaneity of digital texts undermines their spatial stability" (92). Here, we are reminded of Lev Manovich’s conception of database logic and new media technology. Manovich notes, "Many new media objects do not tell stories; they do not have a beginning or end; in fact, they do not have any development, thematically, formally, or otherwise that would organize their elements into a sequence” (218). In this regard, the user must formulate and structure the data in order to generate a narrative paths or "trajectory" out of its catalogue of information through clicking hyperlinks or scrolling through web pages. For these reasons Warner is unsure if the Internet possesses the punctuality and unfolding of time found in publics.

If we are to resolve Warner's inquiry, we need to distinguish between older type publics organized exclusively by traditional dated forms of text, from virtual publics that are exclusively organized by decentralized participation in "instantaneous" texts of the Internet. Let's refer to the former as material publics and the latter as online publics. 
Material publics are publics organized and linked by a text's regulated temporality, such as the weekly release of a film, the monthly printing of a magazine, and the seasonal run of a television show. Warner argues that the constant circulation of such texts is required to sustain a public and what he calls its "social imaginary." Without the constant dissemination of such texts, there is no interaction and "reflexivity" to generate and maintain the binding of a public. More importantly, such texts are sites, where the public maintains its openness—what Warner calls "stranger relationality," i.e. a public's capacity to reach strangers through interacting with its text. Warner notes that, of course, the practices shared by material publics are not restricted to dialogue. To claim this would be to ignore its essential world-making attribute of publics. As Warner puts it, "public discourse as conversation obscures the importance of the poetic [world-making] functions of both language and corporeal expressivity in giving a particular shape to publics” (115).

The collaborative spirit of filmmakers such as Andrew Bujalski, the Duplass Brothers, Aaron Katz, Greta Gerwig and Joe Swanberg, who share and pull from each others' resources by acting in each other's films and/or assisting with each other's productions, is characteristic of the "world making" of a public. This is especially evident in the group production Hannah Takes the Stairs (2007). Buice and Crumley's Four Eyed Monsters is another interesting example which incorporates the audience's stories of their own relationships into the film through video podcasts. Even Swanberg's Kissing on the Mouth is a response to Bujalski's Funny $\mathrm{Ha} \mathrm{Ha}$-all of these films have elements of a public though performance and the notion of publicness, and, importantly, the self-transformation of the personal lives of these filmmakers in the process of making 
these films. As Joe Swanberg states, "it's about taking aspects of yourself that you like the least and amplifying them. In making the movies, we really try to expose all our issues, whatever is hardest to deal with. I'm always playing jerks, and it still definitely comes from autobiography. It's useful to watch later and remind myself, like 'Don't be that guy”" (qtd. in Van Couvering and Swanberg, "Meant to Say”). And filmmaker Jay Duplass states, “The Puffy Chair was a complete accident, or it came out of a process of seeing that the accidents were what we had to offer. It wasn't until we tapped into the private, weird stuff that the script started to soar” (qtd. in Van Couvering and Swanberg, “Meant to Say”).

Online publics, by way of contrast, are decentralized and not regulated and organized through the linear/serial unfolding of "text through time" (90). Of course, many websites and blogs list their dates on their web page. YouTube, for example, enables one to sort through uploaded videos by time frames such as "today," "this week" or "this month." Warner acknowledges that, of course, there are websites that have successfully "migrated" their materials into serial web form, but their basic temporality is not punctual.

This returns us to Jenkins' claim that the Internet offers opportunities for "consumer participation" in grassroots creativity. Jenkins cites the phenomenon of fans creating fanzines, parody videos, and online discussion groups about specific shows or films. Furthermore, the immediacy and speed of the Internet gives it the ability to reach global populations beyond the limits of material print and media broadcast. At the same time, the Internet allows for localized forms of "grassroots expression." But, it is important not to make too sweeping or euphoric claims on behalf of the Internet. For 
example, Jenkins notes George Lucas asserts his ownership of his films by attempting to control fan fiction for Star Wars. And it is important to stress that traditional institutions, such as critics and national media sources, continue to have a vital function in promoting works of art, enabling them to "stand out" in the crowded market place.

What concerns Warner, however, is whether on-line communication, with its nonpunctual temporality can organize publics that it seems to depend upon the constant punctual circulation of text for their existence. The difficulty, he speculates, is that we may even have to "abandon 'circulation' as an analytic category” in relation to the Internet (98). I suggest instead that publics which organize through the Internet are neither purely material nor purely online, but instead are organized through the interaction and interfacing of digital and traditional forms of communication. For example, technological conditions of digitalization in conjunction with "grassroots convergence" have helped mumblecore filmmakers to create their own social space as a network of artists. But mumblecore filmmakers not only use the web to promote their films online. They also showcase their work at film festivals, such as SXSW and "The New Talkies: Generation D.I.Y.” that the IFC Center put on in 2007 to promote mumblecore. From this point of view, what has helped to organize mumblecore as an artistic public is not only new media communication technologies (the Internet, digital tools of filmmaking and mobile screens), but also traditional communication forms of technologies in traditional material forms: posters, films, books, photos, etc. circulating at film festivals, independent theatres, colleges, and cafes. ${ }^{60}$ In short, not only the Internet and digital media but also traditional forms of social communication are evident in mumblecore formation as an artistic public.

\footnotetext{
${ }^{60}$ See Rebecca M. Alvin’s “Cinemas of the Future.” Cineaste, Vol. 32 No. 3 (Summer 2007).
} 
Warner conceives of counterpublic as a special kind of public. In particular, he sees counterpublics as sites for the possibility of emancipation abandoned during the structural transformation of the public sphere (what Habermas calls its "refeudalization" [195]). Counterpublics are formed as a site of tension with, even struggle against, the "norm" and status quo. As Warner puts it, a counterpublic is "a scene where a dominated group aspires to re-create itself as a public and in doing so finds itself in conflict not only with the dominant social group but with the norms that constitute the dominant culture as public” (112). According to Warner, "counterpublics...maintain at some level, conscious or not, an awareness of its subordinate status” (56). Thus, although they may not directly attack the hegemonic public sphere, counterpublics "can have a critical relation to power" (56). From this point of view, the larger public functions as a backdrop to a counterpublic, against which it operates not necessarily in the sense of being at war with it, but rather in the sense of being in tension with it. For example, mumblecore films are not so much a direct assault on mainstream cinema, but rather operate against the "background" of Hollywood and, to a certain extent, Indiewood. The tension with Hollywood exists, then, more at the level of economic practices then the aesthetic artistic. ${ }^{61}$ As Anish Savjani (producer of Hannah Takes The Stairs) states, “They aren’t making these films for money, or to get into Hollywood. It's pure, it's honest, it's collaborative, and it's a process they're developing film by film” (qtd. in Van Couvering and Swanberg, “Meant to Say”). In short, by creating their own social space through the uses of digital technologies, Hollywood operates as a backdrop to mumblecore, rather than an entity to be resisted or politically challenged.

\footnotetext{
${ }^{61}$ I thank Henry Krips for suggesting this important distinction.
} 
Importantly, Warner stresses that a counterpublic involves a "social imaginary" that aims to transform lives. In other words, if, as Habermas argues, the public sphere has lost its potential for transformation, counterpublics capture that emancipatory spirit, becoming a site of "poesis" albeit on a micro and local level. As his main example, Warner draws upon gender and sexuality, noting, “A public, or counterpublic...can work to elaborate new worlds of culture and social relations in which gender and sexuality can be lived...” (57). He then also adds that such practices of world-making can be seen in youth cultures and artistic publics.

Mumblecore exhibits these attributes of a counterpublic. Its filmmakers are aware of their subordinate status because of the difficulty in finding film financing and distribution. Certainly this is one of the benefits of digital media in terms of its access and affordability. As Filmmaker Magazine editor Scott Macauly states, "These [mumblecore] filmmakers seem remarkably free of the anxiety you see in indie film directors who have brought their higher-budgeted films to festivals and are praying for them to sell” (qtd. in Lim, “Generation”).

Through their shared sensibilities and practices of personal filmmaking, mumblecore has certain qualities that Warner identifies as a counterpublic. Of course, this is not something new to the history of cinema. But unique to mumblecore is their deployment of digital media and its potential of networking of a community of filmmakers and viewers who have a collective interest in these types of cinematic works. Speed plays an important role in sustaining mumblecore's network of artists and fans. The hypertext of online streaming sites, for instance, not only provides access to hard to 
find movies, but also helps mumblecore cinema promote and distribute its films to a wider audience.

\section{Conclusion:}

Mumblecore demonstrates that community and a sense of place are not lost in the acceleration of culture. On the contrary, mumblecore's "success” demonstrates that digitalization as a powerful medium in which DIY filmmakers can organize and work outside the walls of Hollywood. ${ }^{62}$ Of course, mumblecore is not constituted by the artists alone. It is also dependent upon its audience, indeed, upon making an audience for itself. Here, mumblecore must show its "public” spirit by not remaining an elite group of practitioners, but instead remaining open to strangers, what Warner terms: "stranger relationality.” Without openness to strangers, mumblecore as an artistic counterpublic would cease to exist.

\footnotetext{
${ }^{62}$ This is not to suggest that artists seeking to go beyond the "noncommercial context" continue to use bloggers, critics, and other media institutions to market their work and, in particular, stand out of from the crowd of videos circulating on the web.
} 


\section{$\underline{\text { Conclusion }}$}

The project of Accelerated Culture has attempted to understand how the forces of speed are impacting the production and consumption of the moving image in the digital age. I have argued that speed creates new ways of seeing the moving image. Drawing upon examples from cinema and television, this study argued that the interrelation of the production and reception of these texts are often contingent and unpredictable. Economic processes and technological advances are not the sole factors in terms of generating the practices of meaning-making in the production and reception of cultural objects. Rather, such practices are formed when these and other disparate factors and structures of knowledge and looking are articulated under given social conditions. The factors considered throughout this study were primarily new economic practices and new media technologies, because they are the most prevalent forces in the changing formation of modernity to postmodernity in the speeding up of everyday life.

The first section of this study began by looking at how speed is aesthetically represented in the long take. Under the classical Hollywood system, the long take was often avoided because it threatened to reveal the system of filmic time and space, thus distracting viewers, and causing them to lose investment in the narrative. Or, to turn the

point around, speed plays an important role in the construction of the cinematic narrative because, through its role in a style of invisible editing, it "erases” the mediation of the narrative. But, I have also shown speed may have the reverse effect: the long take as a form of speed may be immersive and intensify viewers' investment in the narrative. In order to examine this phenomenon, I provided a brief history of advances in camera supports, and the gradual interfacing between cinematic and computer generated images 
as factors in determining the speed of the cinematic moving image. This is not to suggest that technologies alone determine the speed. On the contrary, consumption also influences the speed of the moving image. This was specifically noted in the "YouTubeification” and personal camcorder aesthetic of the long takes in Cloverfield. Similarly, Elephant's database narrative is characteristic of consumption informing production in its gesturing towards an emerging computer culture at the turn of the millennium. But whereas Cloverfield engages with the phenomenon of YouTube in its making of a “homemade catastrophe” post 9/11, Elephant employs a database aesthetic that conjures memories of Columbine and subsequent debates on youth marketing of violent entertainment.

Digital media is not only changing the perception of the moving image in cinema, but is also impacting the medium of television. Chapters three and four investigated the shows Twin Peaks and The Sopranos in order to understand how new economic processes in the entertainment industry and time-shifting technologies are informing new ways of seeing television. Drawing upon the work of Laura Mulvey on digital media and new perceptions of time, I argued that television is representative of this changed perspective through what I called the television of delay. I chose to formally analyze Twin Peaks and The Sopranos because of their unusual representations of narrative time and space, including an emphasis on ambivalent objects, long dreams sequences, and elongated pacing. The popularity of both shows demonstrates that television is not a medium for mass homogenized audiences. Twin Peaks and The Sopranos' introduction of art-house aesthetic into primetime television had a profound impact on the television industry, demonstrating that networks can tailor a show to specific "niche" audiences. 
Film has a privileged relationship to the elusive nature of memory. Time-shifting technologies now allow one to replay, halt, or own a film, which has changed the horizons of perception of the moving image. With many ways to access video content, the question of time and memory in the digital age can inform new practices of looking. For example, many DVDs offer bonus material on the making of a film or television show. In 2001, I learned about David Chase's method of writing and filming from watching The Sopranos' first season DVD bonus material. As a personal experience, it changed the way I watched future episodes, because I knew that Chase was greatly influenced by Surrealism. Time-shifting as a speed machine has the potential to alter perception of the moving image, as well as create new film and television knowledge cultures (Tryon 22-25). I argued that examining the reception of Twin Peaks and The Sopranos' in relation to time, memory, and new media is important in terms of understanding the tensions regarding their narrative closure and the cultural currency of the detective and gangster genre.

Anne Friedberg argues that the emergence of postmodernity brought "new acts of looking” in what she describes as "the mobile and virtual gaze” (Window Shopping 3). In her study, she included not only forms of cinema, but television, the VCR, malls, and movie theatre complexes. Writing in the early 1990s, Friedberg understood that these cultural forms were becoming more intertwined as "commodified forms of looking” (Window Shopping 7). Today, these cultural forms are strongly present in the medium of television. We are seeing more television shows incorporate formal styles of cinema, such as handheld camera work, jump cuts, and database aesthetics. With increased sales of high definition LCD and Internet ready televisions, set-top-box converters that allow 
for online digital streaming to televisions, and the various platforms to access media content and video-on-demand, structures of perception in both the production and consumption of the moving image will become even more important for the field of film and media studies as a cultural object to be studied.

The speeding up of culture raises concerns about the attenuation of lived reality, the waning of critical distance, and the disappearance of slow time. In the Introduction, I specifically drew upon the work of Jean Baudrillard and Paul Virilio as writers who attempted to address these concerns. I noted that although their arguments are provocative, their works read culture and technology in a one to one relation. In the Introduction, I also drew upon Lance Larson's “Video Archives” in order to show how a community of movie geeks and cinephiles can form out of time-shifting technology. I specifically highlighted filmmakers (and once employees of Video Archives,) Quentin Tarantino and Roger Avary as developing their knowledge of cinema through having access to an archive of videos. In chapter five, we find similarities to the "Video Archives gang” in the development of mumblecore. I argued that one phenomenon that distinguishes mumblecore from past DIY filmmakers is the development of digital media communication technologies. More specifically, I argued that the Internet is crucial to mumblecore establishing a network and community of artists who share a sensibility in personal filmmaking. On this basis, I suggested that the "social imagining" in the formation of mumblecore exhibits the tendencies of Michael Warner's calls a counterpublic. But more importantly, I used the development of mumblecore as an example of how forces of speed can play a positive role in the imagined audience. 
The ability to connect with others locally and globally through online media raises new questions for public sphere discourse. Specifically, I attempted to answer a question that Warner posed about online media and the formation of publics and counterpublics. Warner argues that the existence of "texts through time" and the "daily and weekly rhythms of circulation” (98) are essential to publics and counterpublics, and that therefore there was a difficulty in seeing how publics could survive in the age of the Internet. I argued, however, that "material publics" and "online publics" are not mutually exclusive realms. Material publics are organized by "punctuality" and "text through time.” Online publics are de-centralized and feature none (or little) of the rhythms and "punctuality" of traditional publics. But I argued that the social imaginary for such public may also be located at the interface of online and the material. For example, mumblecore network through online media to circulate and promote their films, which in turn enables their productions to be screened at public forum of film festivals and special screenings. This intimate relationship between material and online publics is a new phenomenon enabled by the acceleration of culture.

Although I only focused on mumblecore as a recent example of the formation of such a public, larger questions loom regarding other mediums and online media. For example, how is online music streaming impacting the formation of alternative and DIY music? How does the phenomenon of e-book readers and e-publishing platforms (which permit unpublished writers to self-publish their work) impact underground writers? USA Today recently reported that, according to the Association of American Publishers, "Total net revenue for 2010 [e-book sales]: \$878 million with 114 million e-books sold. In adult fiction, e-books are now 13.6\% of the market” (Donahue, "Self Published”). The report 
went on to discuss the success of both self-published and published writers, and be possible a significant impact on the publishing industry. Of course, as I argued in the case study of mumblecore, a new challenge then arises: how to "stand out" in a crowded market place. Nevertheless, the increasing popularity of the e-book is another instance of how the acceleration of culture is informing public sphere discourse in the digital age.

New media technologies and new systems of communication may evoke uncertainty, but they also potentially transform the way we experience the everyday world. The media tools of email, blogs, social networking and video sharing sites have redefined the ways in which cultures communicate and interact with each other. Of course, this is not to suggest that technology is the sole cause of new creative uses of time and space in television and cinema. Nor does it deny that there are stresses and problems that emerge with the speeding up of culture. Nevertheless, I hope to have shown that the culture of acceleration can open up new frontiers, expand geographical boundaries, and articulate new relations of subjectivity and publicness in the digital age. 


\section{$\underline{\text { Works Cited }}$}

Alvin, Rebecca M. “Cinemas of the Future.” Cineaste. < http://www.cineaste.com/articles/cinemas-of-the-future.htm>. Vol. 32 No. 3 (Summer 2007). Web. 28 Aug. 2011.

Anderson, Christopher. "Producing an Aristocracy of Culture in American Television." The Essential HBO Reader. ed. Edgerton Gary, R. and Jeffery P. Jones. Lexington: The University of Kentucky Press, 2008. Print.

Andrew, Anthony. “Twin Peaks: How Laura Palmer's death marked the rebirth of TV drama.” The Guardian. March 20, 2010. < http://www.guardian.co.uk/tv-andradio/2010/mar/21/twin-peaks-twenty-years-on>. Web. 22 Sept. 2011.

Bacher, Lutz. The Mobile Mise En Scene: A Critical Analysis of the Theory and Practice of Long-Take Camera Movement in Narrative Film. New York: Arno Press, 1978. Print.

Balio, Tino. The American Film Industry. Rev. ed. Madison: University of Wisconsin Press, 1985. Print.

Barthes, Roland. Camera Lucida: Reflections on Photography. Trans. Richard Howard. Hill and Wang, 1980. Print.

---.Mythologies. Trans. Annette Lavers. New York: Hill and Wang, 1972. Print.

Baudrillard, Jean. Simulacra and Simulation. Trans. Shelia Faria Glaser. Ann Arbor: University of Michigan Press, 1994. Print.

Bazin, Andre. What is Cinema? Volume 1. Trans. Hugh Gray. Berkeley: University of California, 1967. Print. 
Bauman, Zygmunt. "Postmodernity, or Living with Ambivalence.” A Postmodern Reader. ed. Joseph Natoli and Linda Hutcheon. Albany: SUNY Press, 1993. Print.

Bernard, Jami. Quentin Tarantino: The Man and His Movies. 1st U.S. ed. New York: Harper Perennial, 1995. Print.

Bolter, Jay David and Richard Grusin. Remediation: Understanding New Media. Cambridge, MA: MIT Press, 2001. Print.

Bordwell, David. Figures Traced in Light: On Cinematic Staging. Berkeley: University of California Press, 2005. Print.

Bordwell, David, et al. The Classical Hollywood Cinema: Film Style \& Mode of Production to 1960. New York: Columbia University Press, 1985. Print.

Caldwell, John Thorton. Televisuality: style, crisis, and authority in American Television. New Brunswick: Rutgers University Press, 1995. Print.

Cameron, Allan. "Contingency, Order, and the Modular Narrative: 21 Grams and Irreversible.” The Velvet Light Trap. Number 58, Fall 2006. International Index to Performing Arts. Web. 11 Dec. 2011.

---. Modular Narrative in Contemporary Cinema. London: Palgrave macmillan, 2008. Print.

Canavese, Peter. “Gus Van Sant—Gus Van Sant’s Last Days.” Groucho Reviews. June 27, 2005. <www.grouchoreviews.com/interviews/112>. Web. 17 Apr. 2011. Carney, Ray. Cassavetes on Cassavetes. New York: Farber and Farber, 2001. Print. ---.The Films of John Cassavetes: Pragmatism, Modernism, and the movies. Cambridge: Cambridge University Press, 1994. Print. 
Carter, Bill. “'Twin Peaks’ May Provide A Ratings Edge for ABC.” New York Times. April 16, 1990. <http://www.nytimes.com/1990/04/16/business/the-mediabusiness-twin-peaks-may-provide-a-ratings-edge-for-abc.html>. Web. 22 Sept. 2011

Cavagna, Carlo. "Elephant: Interview with Gus Van Sant and Diane Keaton.” Aboutfilm.com November, 2003. <www.aboutfilm.com/features/elephant/feature.htm>. Web. 1 July 2011.

Christian, Aymar Jean. “Joe Swanberg, Intimacy, and the Digital Aesthetic.” Cinema Journal. 50, No. 4, Summer 2011. Print.

Collins, Jim. “Television and Postmodernism.” Channels of Discourse, Reassembled: Television and Contemporary Criticism. $2^{\text {nd }}$ edition. ed. Robert C. Allen. Chapel Hill: University of North Carolina Press, 1992. Print.

Comolli, Jean-Luc and Jean Narboni. “Cinema/Ideology/Criticism.” Film Theory \& Criticism. Seventh edition. ed. Leo Braudy and Marshall Cohen. New York: Oxford Press, 2009. Print.

Conant, Michael. “The Paramount Decrees Reconsidered.” The American Film Industry. ed. Tino Balio. Rev. ed. Madison: University of Wisconsin Press, 1985. Print.

Cook, David A. A History of Narrative Film. $2^{\text {nd }}$ edition. New York: W.W. Norton \& Company, Inc., 1990. Print.

Dargis, Manohla. "Hollywood Shines on Sundance; Independent Film Gets Burned.” New York Times, sec. 2; Arts and Leisure Desk; FILM: 1. January 21, 2007. <http://www.nytimes.com/2007/01/21/movies/21darg.html>. Web. 13 Aug. 2011. 
Dawson, Jeff. Quentin Tarantino: The Cinema of Cool. New York: Applause, 1995. Print.

De Argaez, Enrique. “Broadband Usage in USA.” Internetworldstats.com <http://www.internetworldstats.com/articles/art030.htm>. Web. 16 Aug. 2011.

Denby, David. "Youthquake; Mumblecore Movies.” The New Yorker. March 16, 2009 : 114. <http://www.newyorker.com/arts/critics/cinema/2009/03/16/090316crci_cinema_ denby?currentPage=1>. Web. 4 Jan. 2011.

Doane, Mary Ann. The Emergence of Cinematic Time: Modernity, Contingency, The Archive. Cambridge, MA: Harvard University Press. 2002. Print.

Dolan, Marc. "Twin Peaks and Valleys of Serial Creativity: What happens to/on Twin Peaks.” Full of Secrets: Critical Approaches to Twin Peaks. ed. David Larey. Detroit: Wayne State University Press, 1995. Print.

Donahue, Deirdre. "Self-Published author find success." USA Today. December 13, 2011. <http://www.usatoday.com/life/books/news/story/2011-12-14/selfpublished-authors-ebooks/51851058/1>. Web. 5 Feb. 2012.

Du Gay, Paul, et al. Doing Cultural Studies: The Story of the Sony Walkman. London: Sage Publications Ltd., 1997. Print.

Duhigg, Doug and Keith Bradsher. "How the U.S. Lost Out on iPhone Work.” New York Times. January 12, 2012. <http://www.nytimes.com/2012/01/22/business/appleamerica-and-a-squeezed-middle-class.html?pagewanted=all>. Web. Feb. 2012. 
Edgerton, Gary R. "Introduction: A Brief History of HBO.” The Essential HBO Reader. ed. Edgerton Gary, R. and Jeffery P. Jones. Lexington: The University of Kentucky Press, 2008. Print.

Eisner, Lotte H. Murnau. Berkeley: University of California, 1973. Print.

Friedberg, Anne. The Virtual Window: From Alberti to Microsoft. Cambridge, MA: MIT Press, 2006. Print.

---. Window Shopping: Cinema and the Postmodern. Berkeley: University of California Press, 1993. Print.

Fordham, Joe. “Children of Men: The Human Project.” Cinefex. Vol. 110. July, 2007. Odyssey. Web. 17 Feb. 2012.

Fritz, Ben and Joe Flint. “Netflix less about flix, more about TV.” Los Angeles Times. February 4, 2012. <http://articles.latimes.com/2012/feb/04/business/la-fi-ctnetflix-20120205>. Web. 6 Feb. 2012.

Galloway, Alexander R. Gaming: Essays on Algorithmic Culture, Volume 18. Minneapolis: University of Minnesota Press, 2006. Print.

Gore, Chris. “Joe Swanberg: Mumblecore’s Soft Spoken Saint.” Chinashop. April 2, 2009. < http://www.chinashopmag.com/2009/04/joe-swanberg-mumblecoressoft-spoken-saint/>. Web. 6 Jan. 2011.

Gramsci, Antonio. Selections from the Prison Notebooks of Antonio Gramsci. Ed and Trans. Quintin Hoare, and Geoffrey Nowell-Smith. New York: International Publishers, 1971. Print. 
Greencine Staff Blog. "Young Americans: Joe Swanberg LOLs.” GreenCINE. August, 28, 2007. < http://www.greencine.com/central/node/137?page=0\%2C1>. Web. 6 Jan. 2011.

Gunning, Tom. D.W. Griffith and the Origins of American Narrative Film: The Early Years at Biograph. Urbana: University of Illinois Press, 1991. Print.

Gutherie, Marisa. “HBO Exec: ‘Game of Thrones’ Will Go on as Long as George R.R. Martin Keeps Writing.” The Hollywood Reporter. July 28, 2011. < http://www.hollywoodreporter.com/news/hbo-exec-game-thrones-will216668?utm>. Web. 28 July 2011.

Habermas, Jürgen. The Structural Transformation of the Public Sphere: An Inquiry into a Category of Bourgeois Society. Cambridge, MA: MIT Press, 1989. Print.

Hall, Stuart. "Encoding/decoding.” Culture, Media, Language: Working Papers in Cultural Studies (1972-1979). ed. S. Hall, D. Hobson, A. Lowe and P. Willis. London: Hutchinson/CCCS, 1980. Print.

---. “On Postmodernism and Articulation.” Journal of Communication Inquiry. June 1986 vol. 10 no. 2, 45-60. Print.

Harvey, David. The Condition of Postmodernity: An Enquiry into the Origins of Cultural Change. Oxford England: Cambridge, MA, USA: Blackwell, 1989. Print.

Hattenstone, Simon. "Simon Hattenstone talks to Gus Van Sant.” Guardian. January 24, 2004. <www.guardian.co.uk/film/2004/jan/24/features.weekend1>. Web. 28 Apr. 2011.

Heath, Chris. “Sopranos Stars Tell All.” Rolling Stone. March 20, 2001. Issue 865, p 42, 9p. EBSCO. Web. 24 Sept. 2011. 
Hebdige, Dick. Subculture: The Meaning of Style. New York: Routledge, 1979. Print.

Heffernan, Virginia. “The Real Boss of 'The Sopranos'.” New York Times. February 29, 2004. < http://www.nytimes.com/2004/02/29/arts/television-the-real-boss-of-thesopranos.html?pagewanted=all\&src=pm>. Web. 22 Feb. 2012.

Henderson, Brian. A Critique of Film Theory. New York: Dutton Adult, 1980. Print.

IndieWIRE. "indieWIRE INTERVIEW: Arin Crumley and Susan Buice, Co-directors of “Four Eyed Monsters.” December 1, 2006. < http://www.indiewire.com/article/indiewire_interview_arin_crumley_and_susan_ buice_co-directors_of_four_eyed_/>. Web. 17 Feb. 2011.

---. "First Person: Matt Dentler on Indie Film for the MySpace/YouTube/iPod Generation.” IndieWIRE. August 19, 2007. < http://www.indiewire.com/article/first_person_matt_dentler_on_indie_film_for_t he_myspaceyoutubeipod_generati>.Web. 17 Feb. 2011.

James, Nick. “Passive Aggressive.” Sight \& Sound ns 20.4 (2010): 5. International Index to Performing Arts. Web. 3 Feb. 2011.

Jenkins, Henry. Convergence Culture: Where Old and New Media Collide. New York: New York University Press, 2006. Print.

---. “Lessons from Littleton: What Congress Doesn't Want to Hear about Youth and Media.” Winter 2000. $<$ www.nais.org/publications/ismagazinearticle.cfm?ItemNumber=144264>. Web. 19 April 2011.

Kaleta, Kenneth C. David Lynch. New York: Twayne Publisher, 1993. Print. 
Kaplan, Fred M. 1959: The Year that Changed Everything. Hoboken, N.J: J. Wiley \& Sons, 2009. Print.

Kay, Jeremy. “Netflix closes down Red Envelope Entertainment.” July 23, 2008. Screen Daily. < http://www.screendaily.com/netflix-closes-down-red-envelopeentertainment/4039994.article>. Web. 3 Sept. 2011.

Kinder, Marsha. "Hot Spots, Avatars, and Narrative Fields Forever—Bunuel’s Legacy for New Digital Media and Interactive Database Narrative.” Film Quarterly. 55.4 (2002): 2-15. Print.

---.“Narrative Equivocations between Movies and Games.” The New Media Book. ed. Dan Harries. London: British Film Institute, 2002. Print.

King, Geoff. Indiewood, USA: Where Hollywood Meets Independent Cinema. London: New York; New York: I.B. Tauris; 2009. Print.

Kitses, Jim. Gun Crazy. London: BFI Film Classics, 1996. Print.

Klinger, Barbara. Beyond The Multiplex: Cinema, New Technologies, and the Home. Berkeley: University of California Press, 2006. Print.

---. “‘Cinema/Ideology/Criticism’: Revisited.” Film Genre Reader. ed. Barry Keith Grant. Austin: University of Texas Press, 1986. Print.

Koresky, Michael. "DVD RE-RUN INTERVIEW: The Mumblecore Movement? Andrew Bujalski On His “'Funny Ha Ha’.” Indiewire.com. 22 Aug. 2005. $<$ http://www.indiewire.com/article/dvd_rerun_interview_the_mumblecore_movement_andrew_bujalski_on_his_funny_h/>. Web. 5 Jan. 2011. 
Landy, Marcia. "Culture and Politics in the Work of Antonio Gramsci.” boundary 2 14.3, The Legacy of Antonio Gramsci (1986): pp. 49-70. Print.

Lavery, David. “Introduction: The Semoitics of Cobber: Twin Peaks' Interpretive Community.” Full of Secrets: Critical Approaches to Twin Peaks. Ed. David Lavery. Detroit: Wayne State University, 1995. Print.

Lavery, David and Robert J. Thompson. "David Chase, The Sopranos, and Television Creativity.” This thing of ours: investigating The Sopranos. ed. David Lavery. New York: Columbia University Press, 2002. Print.

Levy, Emanuel. Cinema of Outsiders: The Rise of American Independent Film. New York: New York University Press, 1999. Print.

--- “Cloverfield with J.J. Abrams. Emanuel Levy Cinema 24/7 < http://www.emanuellevy.com/interview/cloverfield-with-jj-abrams-4/>. Web. 3 Feb. 2012.

Lim, Dennis. “A Generation Finds its Mumble.” New York Times, sec. AR; Arts and Leisure Desk: 1. August 19, 2007. < http://www.nytimes.com/2007/08/19/movies/19lim.html >. Web 17 Feb. 2011.

Lyotard. Jean-Francois. The Postmodern Condition: A Report on Knowledge. Trans. Geoff Bennington and Brain Massumi. Minneapolis: University of Minnesota Press, 1984. Print.

Macaulay, Scott. “Sands of Time.” Filmmaker Magazine. Winter, 2002. <www.filmmakermagazine.com/issues/winter2002/features/sands_time.php>. Web. 28 Apri1 2011.

Manovich, Lev. The Language of New Media. Cambridge, MA: MIT Press, 2001. Print. 
Martin, Brett. The Sopranos: The Complete Book. New York: Time Inc, Home Entertainment, 2007. Print.

McGowan, Todd. The Impossible David Lynch. New York: Columbia Press, 2007.

McCarthy, Todd. Variety. 26 May 2003-1 June 2003. < http://www.variety.com/review/VE1117920801?refcatid=31>. Web. 1 July 2011.

McDonald, Paul. Video and DVD Industries. London: BFI, 2007. Print.

Miller, Toby, et al. Global Hollywood 2. London: BFI Publishing, 2005. Print.

Mitchell, Edward. Apes and Essences: Some Sources of Significance in the American Gangster Film.” The Genre Reader. ed. Barry Keith Grant. Austin: University of Texas Press, 1986. Print.

Morrison, James. “The Old Masters: Kubrick, Polanski, and the Late Style in Modern Cinema.” Raritan 21 no2 Fall 2001. Wilson Web. Web. 16 Jan. 2012.

Mulvey, Laura. Death 24x a Second: Stillness and the Moving Image. London: Reaktion Books, 2006. Print.

---. Visual and other Pleasures. 2nd ed. London: Palgrave macmillan, 2009. Print.

Murray, Janet H. Hamlet on the Holodeck: The Future of Narrative in Cyberspace. Cambridge, MA: The MIT Press, 1997. Print.

Olson, Greg. David Lynch: Beautiful Dark. Lanham: The Scarecrow Press, 2008. Print. Patterson, Troy and Jeff Jenson. "Our Town.” Entertainment Weekly. 10th Anniversary: Special Collector’s Issue. \#540 - Spring 2000.

Peary, Gerald. “Gus Van Sant - Elephant.” Geraldpeary.com. November 2003, $<$ http://www.geraldpeary.com/interviews/stuv/van-sant-elephant.html>. Web. 29 June 2011. 
---.Quentin Tarantino Interviews. ed. Gerald Peary. Jackson: University Press of Mississippi, 1998. Print.

Polan, Dana. Pulp Fiction. London: BFI Modern Classics, 2000. Print.

---. The Sopranos. Durham: Duke University Press, 2009. Print.

Poster, Mark. What's the Matter with the Internet? Minneapolis: University of Minnesota Press, 2001. Print.

Potton, Ed. “David Lynch’s Twin Peaks, 20 years on.” TimesOnline. $<$ http://entertainment.timesonline.co.uk/tol/arts_and_entertainment/tv_and_radio/ article7064109.ece>. 20 Mar. 2010. Web. 2 Oct. 2011.

Prince, Stephen. A New Pot of Gold: Hollywood Under the Electronic Rainbow, 19801989. New York: C. Scribner’s, 2000. Print.

Rafferty, Terrence. “One Thing After Another.” New Yorker. 9 April 1990: 86-87.

Ray, Robert B. The ABC's of Classic Hollywood. New York: Oxford University Press, 1980. Print.

Rodley, Chris., ed. Lynch on Lynch. Boston: Faber and Faber, 1997. Print.

Rodowick, D.N. The Virtual Life of Film. Cambridge, MA: Harvard University Press, 2007. Print.

Roman, Shari. Digital Babylon. Hollywood: IFILM Publishing, 2001. Print.

Rombes, Nicholas. Cinema in the Digital Age. London: Wallflower Press, 2009. Print.

Rouch, Jean. “The Man and his Camera.” Principles of Visual Anthropology. 2nd ed. ed. Paul Hockings. Berlin; New York: Mouton de Gruyter, 1995. Print. 
Rizov, Vadim. “Slow Cinema Backlash.” IFC.com. < http://www.ifc.com/blogs/indieeye/2010/05/slow-cinema-backlash.php >. May 12, 2010. Web. 11 January. 2011.

Said. S.F. "Shock Corridor”. Sight and Sound. 14, 2, 16-18. 2004. Wilson Web. Web. 20 Apr. 2011.

Salt, Barry. Film Style \& Technology: History and Analysis. Third Edition. London: Starword, 2009. Print.

Sanders, John. Studying Disasters Movies. Bedfordshire: Auteur, 2009. Print.

Sepinwall, Alan. "The stuff that Tony's dreams are made of.” The Star Ledger. < http://www.nj.com/sopranos/ledger/index.ssf?/sopranos/stories/tonydreams_six.ht ml>. March 6, 2006. Web. 11 Sept. 2011.

Simons, Jan. Playing the Waves: Lars Von Triers' Gaming Cinema. Amsterdam: Amsterdam University Press, 2007. Print.

Sturken, Martia. "Mobilites of Time and Space." Technologies of the Modern and the Postmodern." Technological Visions: The Hopes and Fears that Shape New Technologies. ed. Marita Sturken et al. Philadelphia: Temple University Press, 2004. Print.

Taubin, Amy. “All Talk?: Supposedly the Voice of its Generation, the Indie Film Movement Known as Mumblecore has had its 15 Minutes.” Film Comment 2007: 45,45-48. < http://www.filmlinc.com/fcm/nd07/mumblecore.htm>. Web. 4 Jan. 2011. 
---. “Art \& Industry Archive: Funny Ha Ha.” Film Comment. 2004. < http://filmlinccom.siteprotect.net/fcm/artandindustry/funnyhaha.htm>. Web. 4 Jan. 2011.

---. "Part of the Problem.” Film Comment, September-October 2003, pp 26-33. ProQuest Direct. Web. 20 Apr. 2011.

Thompson, Kristin. Storytelling in Film and Television. Cambridge, MA: Harvard University Press, 2003. Print.

Thompson, Robert J. Television's Second Golden Age. From Hill Street Blues to ER. New York: Continnum, 1996. Print.

Thorburn, David. “The Sopranos.” The Essential HBO Reader. ed. Edgerton Gary, R. and Jeffery P. Jones. Lexington: The University of Kentucky Press, 2008. Print. Tryon, Chuck. Reinventing Cinema: Movies in the Age of Media Convergence. New Brunswick: Rutgers University Press, 2009. Print.

Van Couvering, Alicia, and Joe Swanberg. "What I meant to say.” Filmmaker Magazine 15.3 (2007): 40-47, 90-91, 6. $<$ http://www.filmmakermagazine.com/issues/spring2007/features/mumblecore.ph >. Web. 12 Feb. 2011.

Virilio, Paul. The Vision Machine. Bloomington: Indiana University Press, 1994. Print. Warner, Michael. Publics and Counterpublics. New York; Cambridge, Mass: Zone Books, 2002. Print.

Warshow, Robert. “The Gangster as Tragic Hero.” The Immediate Experience: Movies, Comics, Theatre and Other Aspects of Popular Culture. New York: Doubleday and co., 1962. Print. 
Wasser, Frederick. Veni, Vidi, Video: The Hollywood Empire and the VCR. 1st ed. Austin, TX: University of Texas Press, 2001. Print.

Willis, Holly. New Digital Cinema: Reinventing the Moving Image. London: Wallflower Press, 2005. Print.

Wollen, Peter. Signs and Meaning in the Cinema. $3^{\text {rd }}$ ed. Bloomington: Indiana University Press, 1972. Print. 